NBER WORKING PAPER SERIES

\title{
TECHNOLOGY, INFORMATION AND THE DECENTRALIZATION OF THE FIRM
}

\author{
Daron Acemoglu \\ Philippe Aghion \\ Claire Lelarge \\ John Van Reenen \\ Fabrizio Zilibotti \\ Working Paper 12206 \\ http://www.nber.org/papers/w12206
NATIONAL BUREAU OF ECONOMIC RESEARCH 1050 Massachusetts Avenue
Cambridge, MA 02138 \\ April 2006
}

We thank participants at seminars in CREST, CEPR (Paris), CIAR, Harvard-MIT, and Toronto for helpful comments. Van Reenen would like to thank the ESRC for help with financing this research at the Centre for Economic Performance. The views expressed herein are those of the author(s) and do not necessarily reflect the views of the National Bureau of Economic Research.

(C2006 by Daron Acemoglu, Philippe Aghion, Claire Lelarge, John Van Reenen and Fabrizio Zilibotti. All rights reserved. Short sections of text, not to exceed two paragraphs, may be quoted without explicit permission provided that full credit, including $(\odot$ notice, is given to the source. 
Technology, Information and the Decentralization of the Firm

Daron Acemoglu, Philippe Aghion, Claire Lelarge, John Van Reenen and Fabrizio Zilibotti

NBER Working Paper No. 12206

April 2006

JEL No. O31, O32, O33, F23

\begin{abstract}
This paper develops a framework to analyze the relationship between the diffusion of new technologies and the decentralization decisions of firms. Centralized control relies on the information of the principal, which we equate with publicly available information. However, the manager can use her informational advantage to make choices that are not in the best interest of the principal. As the available public information about the specific technology increases, the trade-off shifts in favor of centralization. We show that firms closer to the technological frontier, firms in more heterogeneous environments and younger firms are more likely to choose decentralization. Using three datasets of French and British firms in the 1990s we report robust correlations consistent with these predictions.

Daron Acemoglu

MIT Department of Economics

E52-380B

50 Memorial Drive

Cambridge MA 02142-1347

and NBER

daron@mit.edu

Philippe Aghion

Department of Economics

Harvard University

Cambridge, MA 02138

and NBER

paghion@fas.harvard.edu

Claire Lelarge

National Institute of Statistics and Economic

Studies

Direction des Études et Synthèses

Économiques

15 Boulevard Gabriel Peri

92244 Malakoff Cedex,

FRANCE

John Van Reenen

Department of Economics

London School of Economics

Houghton Street

London WC2A 2AE

UNITED KINGDOM

Fabrizio Zilibotti

Institute for International Economic Studies

Stockholm University

SE 10691Stockholm

SWEDEN
\end{abstract}




\section{Introduction}

Recent years have witnessed increasing interest in the determinants of firms' organizational choices. This interest is partly motivated by the belief that recent technological developments are favoring more decentralized firms. Summarizing the conventional wisdom, Business Week wrote: "Globalization and the arrival of the information economy have rapidly demolished all the old precepts. The management of global companies, which must innovate simultaneously and speed information through horizontal globe-spanning networks, has become a daunting challenge. Old, rigid hierarchies are out ....". ${ }^{1}$ Despite this interest, there is limited work on the determinants of the decentralization decisions of firms.

This paper undertakes a theoretical and empirical investigation of how the allocation of authority within firms changes as the information structure in an industry evolves. We develop a simple model where firms make choices under incomplete information regarding the (correct, most productive) implementation of new technologies. Different organizational forms are distinguished by the amount of information they use in these decisions. As in Aghion and Tirole (1997), centralized control relies more on the information of the principal, which we equate with publicly available information, especially concerning past implementations of the same or similar technologies. Decentralized control delegates authority to a specialized agent (manager), who potentially possesses more information than available in the public history. However, because the interests of the principal and the manager are not perfectly aligned, the agent can also use her informational advantage to make choices that are not in the best interest of the principal. This trade-off determines the optimal degree of decentralization. The main focus of our analysis is how learning from the experiences of other firms changes this tradeoff. In particular, as the available public information about the specific technology increases, the trade-off shifts in favor of centralization. In contrast, when dealing with new technologies decentralization may be preferable.

Using this basic framework we derive three sets of empirical predictions:

1. Firms closer to the technological frontier are more likely to choose decentralization, because they are dealing with new technologies about which there is only limited information in the public history.

\footnotetext{
${ }^{1}$ Business Week The 21st Century Corporation, cover story August 21-28, 2000.
} 
2. Firms in more heterogeneous environments are more likely to be decentralized, because learning from the experience of others is more difficult.

3. Young firms, that have had a limited history to learn about their own specific needs, are also more likely to be decentralized than older firms.

The bulk of the paper investigates these predictions using two large datasets of French firms and establishments and one smaller set of British establishments in the 1990s. We document a number of conditional correlations that are consistent with the predictions of the theory. Specifically, we find that firms closer to the technology frontier of their industry and younger firms are more likely to choose decentralize.

We also document that there is a significant relationship between heterogeneity and decentralization, which is a distinctive prediction of our approach. Our main measure of heterogeneity is the variation in firm-level productivity growth within a four-digit sector. We also consider alternative measures such as the IT weighted "distance" between the product mix of a firm and those by other firms in the sample. The results suggest that firms in more heterogeneous environments are more likely to choose decentralization.

In addition, since our theoretical approach emphasizes the importance of learning about the implementation of new technologies, we also look at high-tech industries separately. Consistent with our theoretical approach, we find that the relationship between heterogeneity or distance to frontier and decentralization is stronger in high-tech than in low-tech industries.

While most of the empirical results in the paper should be interpreted as correlations, the predictions of our theoretical approach concern the causal effect of heterogeneity and distance to frontier on decentralization. To remove some of the most obvious sources of omitted variable biases and reverse causality, we present instrumental variable estimates on the French data using matched industry information from the UK over the same time period. These instrumental variable estimates largely support the baseline results that treat heterogeneity and distance to the frontier as exogenous.

Our main measure of decentralization is whether different units of the firm are organized into "profit centers" (see below for further discussion). We show that our results on heterogeneity and distance to frontier are robust to using alternative measures of decentralization, including measures of delayering and managerial autonomy in investment decisions (the age results are somewhat weaker with some of these alternative measures).

Finally, we further substantiate the results using a smaller dataset of British firms, with similar questions on decentralization. The estimates from the British dataset also show similar 
patterns.

On the theoretical side, our paper is most closely related to the literature on the costs and benefits of delegation or decentralization in firms. A first strand in that literature, for example Baron and Besanko (1992) and Melumad, Mookherjee and Reichelstein (1995), investigated the conditions for delegated contracting to replicate the constrained efficient contracting. As emphasized by Mookherjee (2005), however, the presence of complete contracts in these models implies that delegation can at best replicate the constrained efficient allocation, which is also achievable by centralized contracting. A second strand emphasizes information processing and communication costs as determinants of centralization or decentralization in firms. Key papers in this strand include Sah and Stiglitz (1986), Geanakoplos and Milgrom (1991), Radner (1992, 1993), Radner and Van Zandt (1992), Bolton and Dewatripont (1994), and Garicano (2000). Although we also emphasize the importance of information and learning, our approach is different, since it focuses on the effect of information on the relationship between the principal and the agent, and how much autonomy the principal would like to grant to the agent. Closer to the model in our paper are the recent papers emphasizing the trade-off between loss of control and better information under decentralization - in particular, Aghion and Tirole (1997), Baker, Gibbons and Murphy (1999), Rajan and Zingales (2001), Dessein (2002), and Hart and Moore $(2005){ }^{2}$ The main differences between these papers and ours are twofold: first, because there are no incentive effects of the form of the organization, our framework is significantly simpler and allows us to focus on the basic trade-off between information and loss of control; second; we allow the principal to learn from other firms' or from their own past experience, which is the source of all the comparative static results we investigate in the empirical work. ${ }^{3}$

The main contribution of our paper is the empirical evidence we provide on the determinants of decentralization. The existing empirical literature on the subject focuses on the general move towards "flatter" organizations. ${ }^{4}$ Rajan and Wulf (2005) provide the most systematic statistical

\footnotetext{
${ }^{2}$ Aghion and Tirole (1997) emphasize the trade-off between loss of control and the agent's ex ante incentives to acquire information under decentralization. Hart and Moore (2005) show how the trade-off between loss of control and information can explain why in many hierarchies generalists command specialists. Dessein (2002) develops a model in which decentralization to the agent entails a loss of control for the principal, but at the same time reduces the agent's incentive to miscommunicate her information to the principal.

${ }^{3}$ Acemoglu and Zilibotti (1999) present a different model where endogenous accumulation of information affects the internal organization of firms. In their model, a larger number of firms in the economy enables better relative performance of evaluation and creates a shift from direct to indirect monitoring. The number of firms in the economy is, in turn, determined endogenously as a function of the stage of development and the level of the capital stock.

${ }^{4}$ This phenomenon is described by different terms in different contexts, including decentralization, delayering and delegation. In the theory, consistent with the principal-agent literature, we use the term "delegation", while in the empirical analysis, we adopt the terms used in the datasets, namely "decentralization" in the first dataset and "delayering" in the second.
} 
description of recent organizational trends, showing a strong movement towards flatter corporations in the United States between 1986 and 1999. Bresnahan, Brynjolfsson and Hitt (2002) and Caroli and Van Reenen (2001) report a positive association between various measures of decentralization and organizational change on the one hand and information technology (and human capital) on the other. Baker and Hubbard (2003, 2004) document the effect of new technologies (on-board computers) on ownership patterns in the US trucking industry. In addition, Colombo and Delmastro (2004) present empirical models of decentralization in Italian manufacturing plants, Lerner and Merges (1998) examine the allocation of control rights in biotechnology alliances, and Black and Lynch (2001), Ichinowski et al (1997) and Janod and Saint-Martin (2004) examine the impact of human resource practices and firm reorganization on productivity. None of these papers investigate the relationship between decentralization (or more generally organizational change) and distance to frontier or heterogeneity.

The remaining part of the paper is organized as follows. Section 2 presents some preliminary data description to motivate the basic theoretical framework, which is presented in Section 3. Section 4 describes our main econometric specifications and data. Section 5 presents the empirical results. Section 6 concludes. Appendix A contains the proofs from Section 3, while Appendices $\mathrm{B}$ and $\mathrm{C}$ contain additional data description and robustness checks.

\section{Basic Patterns}

To motivate our focus in the paper and the theory, we first present some salient patterns from a database of several thousand French manufacturing firms, the "Changements Organisationnels et Informatisation" (COI). This dataset, as well as another French dataset (Enquête Reponse) covering manufacturing and non-manufacturing establishments and a similar British dataset

(the Workplace Employee Relations Survey), will be described below. For now, it suffices to note that our key indicator for decentralization from the COI is whether a firm is organized primarily into profit centers or whether it is more centrally controlled with divisions organized as a cost or production centers. A manager of a profit center is concerned with all aspects of the business that contribute to profitability. Managers in charge of production centers focus on output targets and managers of costs centers target costs. When a firm organizes its divisions into profit centers, it has delegated substantially more authority to its managers (see the discussion in Section 4).

Figures 1-3 show the proportion of over 3,570 firms that are decentralized into profit centers broken down by various firm characteristics. Figure 1 divides firms into deciles depending on the "heterogeneity" of the firm's environment. Heterogeneity is measured as the dispersion in 
firm productivity growth rates in each four-digit industry. Productivity growth is measured as the growth in value added per hour and the dispersion measure is the inter-decile range (i.e., the difference between log productivity growth at the 90th and that at the 10th percentiles, see equation (11) below). This variable and its construction are discussed in greater detail in Section 4.

Figure 1 shows a general increase in the probability of decentralization as we move from the firms in the least heterogeneous industries (in the second decile $22 \%$ of the firms are decentralized) to the most heterogeneous industries (in the tenth decile $41 \%$ of the firms are decentralized). The first decile is somewhat anomalous, but closer investigation shows a disproportionately large number of less productive and older firms in these sectors, aspects which we now turn to.

Figure 2 plots the fraction of firms decentralized into profit centers against the "proximity to the frontier" (measured as the ratio of the firm's value added per hour to the value added per hour of the firm at the 99th percentile of the distribution in the same four-digit industry). $27 \%$ of the firms in the bottom quintile of the proximity distribution (i.e., those who are most distant from the frontier) are decentralized, while $38 \%$ of the firms in the top quintile are decentralized (i.e., those who are closest to the frontier).

Finally, Figure 3 depicts the relationship between decentralization and firm age and shows that younger firms are, on average, more decentralized than older firms: about $45 \%$ of the firms under the age of five years are decentralized compared to a rate of $30 \%$ for the older firms.

These correlations therefore suggest that firms that operate in more heterogeneous environments, that are closer to the technological frontier, and that are younger are more likely to be decentralized. While these patterns may be consistent with a variety of different approaches, they are also indicative of a relationship between information and decentralization. We expect firms in more heterogeneous environments, those closer to the technology frontier and younger firms to face greater uncertainty regarding the optimal implementation of new technologies than firms that are in more homogeneous environments, farther from the frontier and more experienced. This motivates our simple theoretical approach emphasizing the relationship between learning and decentralization, which is presented in the next section.

\section{Theory}

In this section, we describe the theory and derive some testable implications. 


\subsection{Environment}

The economy is populated by a set $\mathcal{F}$ of firms. Time is discrete. New technologies $k=1,2, \ldots$ become available sequentially and randomly to firms. As a new opportunity of technology adoption materializes, firms must choose the form of its implementation. In each period, one (and only one) new technology becomes available to the firm $i \in \mathcal{F}$ with positive probability $p_{i} \in(0,1]$. The speed at which new opportunities become available can differ across firms, and $p_{i}$ measures the speed at which firm $i$ climbs the technology ladder. The realizations of technological opportunities are independent across firms and over time.

Each technology can be implemented successfully or unsuccessfully. The successful implementation of a technology increases the firm's productivity by a factor $\gamma>1$, while unsuccessful implementation leaves the productivity of the firm unchanged. So the law of motion of firm $i$ 's productivity is given by

$$
y_{i, t}=\gamma^{S_{i}(t)} y_{i, t-1}
$$

where $y_{i, t}$ is the productivity (and revenue) of the firm at time $t$ and $S_{i}(t)$ is an indicator function taking the value 1 if a technological opportunity arises for firm $i$ at time $t$ and is successfully implemented, and zero otherwise. Whether the technology is successful or not depends on an action taken by the firm, which we denote by $x_{i, k, t} \in\{L, R, \varnothing\}$, with $x_{i, k, t}=\varnothing$ standing for not attempting the technology, and $L$ and $R$ denoting two alternative ways of implementing the new technology, or two "actions". We will see below that the firm will never choose $x_{i, k, t}=\varnothing$, so the relevant choice is between $L$ and $R$. One of these two actions, denoted by $x_{i, k}^{*} \in\{L, R\}$, leads to successful implementation, while the other leads to an unsuccessful outcome. We will refer to the action leading to successful implementation as the correct action.

We model the correct action as follows: for each technology $k$ there exists a reference action $x_{k}^{*} \in\{L, R\}$, and the right action for firm $i$ is given by

$$
x_{i, k}^{*}=\left\{\begin{array}{cc}
x_{k}^{*} & \text { with probability } 1-\varepsilon \\
\sim x_{k}^{*} & \text { with probability } \varepsilon
\end{array},\right.
$$

where $x_{i, k}^{*}$ denotes the correct action for firm $i$ in implementing technology $k$ and $\sim x_{k}^{*}$ denotes "not $x_{k}^{*}$ " (i.e., if $x_{k}^{*}=L$, then $\sim x_{k}^{*}=R$ ) and $\varepsilon<1 / 2$. We further assume that conditional on $x_{k}^{*}, x_{i, k}^{*}$ and $x_{i^{\prime}, k}^{*}$ for any $i \neq i^{\prime}$ are independent, or stated alternatively, the sequence $\left\{x_{i, k}^{*}\right\}_{i \in \mathcal{F}}$ is exchangeable in the sense that any permutation of this sequence is equally likely (see Billingsley, 1995). This implies that $\left\{x_{i, k}^{*}\right\}_{i \in \mathcal{F}}$ is a Bernoulli sequence with a parameter of $1-\varepsilon$ or $\varepsilon$ (depending on whether $x_{k}^{*}=L$ or $R$ ). We also assume that

$$
\operatorname{Pr}\left(x_{k}^{*}=L\right)=q_{0}=\frac{1}{2} .
$$


This specification implies that there is a generally correct way of implementing each technology, given by the reference action, but idiosyncratic differences between firms's needs and competencies may imply that some firms need to take a different action in order to be successful with this technology. Equation (2) makes it clear that $\varepsilon$ is a measure of the heterogeneity among firms. When $\varepsilon$ is close to zero, the reference action is the correct action for almost all firms, while when $\varepsilon$ is close to $1 / 2$, the correct action differs substantially across firms.

Finally, each firm is owned by a principal, who maximizes the present discounted value (PDV) of profits, with discount factor $\beta \in(0,1)$, conditional on information, $h^{t}$, and their initial productivity, $y_{i, t-1}<\infty$. For now, we ignore any costs on the side of firms, so profits are equal to revenue (productivity), and therefore the objective function of firm $i$ is given by

$$
V\left(y_{i, t-1}, h^{t}\right)=\mathbb{E}\left[\sum_{j=0}^{\infty} \beta^{j} y_{i, t+j} \mid h^{t}\right] .
$$

We assume that $\beta<\gamma^{-1}$ so that the firm's value $V\left(y_{i, t-1}, h^{t}\right)$ always remains finite.

The above specification makes it clear that it is always advantageous for the firm to implement a technology whenever it becomes available, so we can restrict attention to $x_{i, k, t} \in$ $\{L, R\} .{ }^{5}$ Consequently, a firm's productivity and value will depend on how many technologies have become available in the past to this firm and how successful the firm has been in implementing them.

Success in the implementation of technologies depends on the organization of the firm. The two alternative organizational forms available to each firm are: centralization and delegation. In the first, the principal (owner) manages the firm and chooses the action $x_{i, k}$, while in the second, the action choice is delegated to a manager.

The principal has no special skills in identifying the right action, so she bases her decision on the publicly available information $h^{t}$. Without loss of any generality, for the decision regarding technology $k$, we can restrict attention to the history that is payoff relevant to technology $k$. Moreover, throughout we will focus on a (representative) firm $i$ that has access to technology $k$ at time $t$. In this case, with a slight abuse of terminology, we will refer to the payoff-relevant history for the implementation of technology $k$ as a history $h_{k}^{i}$. As shown more formally in subsection 3.3 below, under centralization the principal will choose $x_{i, t, k}=L$ when the posterior that $x_{k}^{*}=L$ given history $h_{k}^{i}$,

$$
q\left(h_{k}^{i}\right)=\operatorname{Pr}\left(x_{k}^{*}=L \mid h_{k}^{i}\right)
$$

\footnotetext{
${ }^{5}$ By delaying the implementation of technology $k$ available at date $t$, the firm may obtain more information about this technology, but by assumption, it will never have an opportunity to adopt this technology again. Instead, at $t+1$, technology $k+1$ would become available to firm $i$ with probability $p_{i}$.
} 
is greater than $1 / 2$. We discuss the derivation of this posterior further below.

In contrast to the principal, we assume that the manager observes $x_{i, k}^{*}$, so that he knows exactly which action will lead to successful implementation. However, the manager of firm $i$ may have interests that are not aligned with those of the owner. Following Aghion and Tirole (1997), we model this in a reduced form way, and assume that the most preferred action for technology $k$ of the manager is given by

$$
z_{i, k}^{*}=\left\{\begin{array}{cc}
x_{i, k}^{*} & \text { with probability } \delta \\
\sim x_{i, k}^{*} & \text { with probability } 1-\delta
\end{array}\right.
$$

where $\delta$ measures the congruence between the firm's and the manager's objectives. If $x_{i, k}=z_{i, k}^{*}$, the manager obtains a private benefit $B y_{i, t-1}$. Notice that equation (4) implies that the manager is informed about the right action for this particular firm, not (or not simply) the right reference action.

We introduce a number of simplifying assumptions, which enable us to focus on the main effects we would like to highlight. First, we assume that the relationship between the firm and each manager is short-term (for example, because the manager has special skills which are useful with a specific vintage of technology). Second, managers have zero outside option, are credit-constrained and cannot compensate principals for the private benefit they receive from choosing their preferred action. This assumption also implies that whether the firm delegates control when there is no new technology to be implemented is of no consequence. Finally, we assume that $B$ is sufficiently large that it is not profitable for the principal to use an incentive contract to induce the manager to take the right action, and given this large private benefit, the principal also need not make any additional payments to the manager (this assumption is relaxed in Appendix A). Consequently, delegation implies that the action most preferred by the manager will be chosen, i.e., if there is delegation, then $x_{i, k}=z_{i, k}^{*}{ }^{6}$

Finally, we impose:

\section{Assumption 1}

$$
\delta \in(1 / 2,1-\varepsilon)
$$

The first part of the assumption, $\delta>1 / 2$, means that the manager's interests are more likely to be aligned with that of the principal than otherwise, so that delegation improves the

\footnotetext{
${ }^{6}$ Put differently, in this model the choice between centralization and delegation simply corresponds to whether the "advice" or information of the manager is followed or not. In particular, all the results would be identical if we imagined a different game form in which the manager reports his recommendation and then the principal decides which action to take. In this different game form, the equilibrium would be identical to the one we consider here, and "delegation" would correspond to the principal following the recommendation of the manager.
} 
firm's decision-making relative to the principal deciding without any information. The second part, $\delta<1-\varepsilon$, implies that the conflict of interest between the principal and the manager is sufficiently severe that a principal who knows the reference action is more likely to make the correct choice herself than the manager. This assumption generates an interesting trade-off between the two organizational forms.

\subsection{Organizational Choice}

We denote by $d_{i, k} \in\{0,1\}$ the organization of firm $i$ facing an opportunity to implement technology $k$. Throughout, we suppress time dependence whenever this causes no confusion. Here $d_{i, k}=0$ stands for centralization and $d_{i, k}=1$ for delegation. Both choices (organization and action) depend on the available stock of public information that is relevant for the firm to infer the reference action for technology $k$.

We assume that all actions by other firms in the past are publicly observable. This implies that history $h_{k}^{i}$ includes all previous attempts with technology $k$, which actions were chosen and whether they led to successful implementation. Since conditional on $x_{k}^{*}$ the success or failure of different firms in the past are independent, all payoff relevant information is summarized by two integers: the number of firms that have attempted to implement this technology before firm $i$ denoted by $n_{k}^{i}$, and the number of firms for whom $L$ turned out the profitable action, denoted by $\tilde{n}_{k}^{i} \leq n_{k}^{i}{ }^{7}$

The first important point to note is that $n_{k}^{i}$ is a direct measure of distance to the technology frontier. ${ }^{8}$ If $n_{k}^{i}$ is high, it means that by the time firm $i$ is considering the implementation of technology $k$ that many other firms have already implemented it. ${ }^{9}$ Therefore, comparative statics with respect to $n_{k}^{i}$ will give us predictions regarding the effect of the distance to the technology frontier.

The second important point is that since $\tilde{n}_{k}^{i}$ is the number of successes out of $n_{k}^{i}$ in a Bernoulli trial, the payoff-relevant public information for firm $i$ implementing technology $k$ is simply $h_{k}^{i}=\left\{n_{k}^{i}, \tilde{n}_{k}^{i}\right\}$. Since the choice of organization depends on the public information, we denote the optimal organization choice as $d_{i, k}=d\left(h_{k}^{i}\right)$.

\footnotetext{
${ }^{7}$ Note that $\tilde{n}_{k}^{i}$ is the sum of the number of firms that have adopted technology $k$ before $i$ and chose $x_{i^{\prime}, k}=L$ and were successful plus the number of firms that chose $x_{i^{\prime}, k}=R$ and were unsuccessful. The public information set also includes the organizational form chosen by firms that have previously adopted technology $k$, but equation (4) implies that $\tilde{n}_{k}^{i}$ is a sufficient statistic for this information.

${ }^{8}$ In the theory section, we state the results in terms of "distance to the technology frontier," while in the empirical work it will be more convenient to use an inverse measure, "proximity to the frontier".

${ }^{9}$ This, in turn, is more likely when the probability $p_{i}$ that firm $i$ will have access to the next previouslyunavailable technology is relatively small. It is thus straightforward to see that $E\left(n_{k, t}^{i} \mid p_{i}\right)$ is a decreasing function of $p_{i}$ for given $t$.
} 
With this specification, an optimal strategy for each firm is straightforward to specify. Given an opportunity to implement technology $k$, the firm will decide an organization $d_{i, k} \in$ $\{0,1\}$ and an action $x_{i, k} \in\{L, R\}$ as functions of history $h_{k}^{i}$ so as to maximize (3), with the understanding that if $d_{i, k}=1$, the action will be chosen by the manager. More formally, let $\mathcal{H}_{k}^{t}$ be the set of all possible histories at time $t$ regarding technology $k$. Then a strategy for the firm is $s=\left\{s_{k}^{t}\right\}_{t, k}$ where $s_{k}^{t}: \mathcal{H}_{k}^{t} \rightarrow\{0,1\} \times\{L, R\}$, i.e., for every possible history at time $t$ for any technology $k$ that could be available to the firm, an optimal strategy specifies whether the principal will delegate control to a manager, and if she does not do so, what action she will take. Let the set of all such strategies be denoted by $\mathcal{S}$. An optimal strategy is $s^{*} \in \mathcal{S}$ that maximizes (3).

\subsection{Analysis}

Let $\pi\left(d_{i, k} ; h_{k}^{i}\right)$ denote the posterior probability that the firm chooses the correct action conditional on the history $h_{k}^{i}$ and the organizational form $d_{i, k}$. We start our analysis by comparing $\pi\left(d_{i, k} ; h_{k}^{i}\right)$ under the two organizational forms, delegation and centralization (Lemmas 1 and 2 ). Next we show that profit-maxizing firms always choose the organization form that maximizes $\pi\left(d_{i, k} ; h_{k}^{i}\right)$ (Lemma 3). Finally, we turn to the main testable implications of the theory, linking distance to frontier $\left(n_{k}^{i}\right)$ and heterogeneity $(\varepsilon)$ to the probability that firms choose either delegation or centralization (Propositions 1 and 2).

When the principal delegates the implementation of a new technology to an informed manager, the probability of success is constant and equal to $\delta$, i.e.,

$$
\pi\left(1 ; h_{k}^{i}\right)=\delta
$$

If, on the other hand, the principal retains authority, the probability of success is a stochastic variable that depends on $h_{k}^{i}$, thus both on the firm's distance to the frontier, $n_{k}^{i}$, and on the experiences of firms further ahead, captured by the number of firms $\tilde{n}_{k}^{i}$ out of $n_{k}^{i}$ for whom $L$ was the right action. The following lemma provides the expression for $\pi\left(0 ; h_{k}^{i}\right)$.

Lemma 1 Given a history $h_{k}^{i}$, the probability of success for a principal who retains authority is

$$
\pi\left(0 ; h_{k}^{i}\right)=\left\{\begin{array}{cc}
\varepsilon+q\left(h_{k}^{i}\right)(1-2 \varepsilon) & \text { if } q\left(h_{k}^{i}\right) \geq 1 / 2 \\
\varepsilon+\left(1-q\left(h_{k}^{i}\right)\right)(1-2 \varepsilon) & \text { if } q\left(h_{k}^{i}\right)<1 / 2 .
\end{array}\right.
$$

where

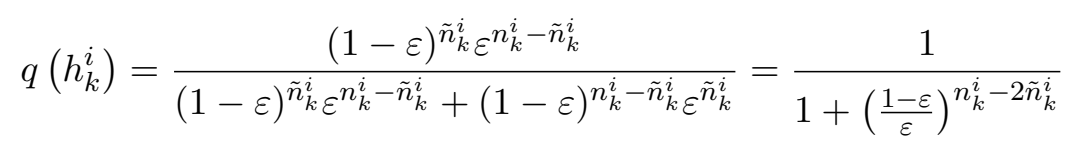


is the posterior probability that the right choice is $L$.

The proofs of this and the following lemmas are provided in Appendix A. To understand the expression of $\pi\left(0 ; h_{k}^{i}\right)$, note that the principal chooses $L$ if $q\left(h_{k}^{i}\right) \geq 1 / 2$ and $R$ if $q\left(h_{k}^{i}\right) \leq 1 / 2$. The first row of (6) gives then the probability that, when $q\left(h_{k}^{i}\right) \geq 1 / 2$, the firm correctly infers that the reference action is $L$ and the reference action coincides with the correct action. The second row gives the probability that, when $q\left(h_{k}^{i}\right)<1 / 2$, the firm incorrectly infers that the reference action is $R$ and the reference action does not coincide with the correct action (hence, due to a double mistake, the firms makes the successful adoption).

The expression of $q\left(h_{k}^{i}\right)$ in (7) follows from the Bayes' rule, given the Bernoulli assumption and $q_{0}=1 / 2 .{ }^{10} q\left(h_{k}^{i}\right)$ is a random variable that depends on the realization of the stochastic vector $h_{k}^{i}$. Since $h_{k}^{i}$ consists of a deterministic component, $n_{k}^{i}$, and a stochastic one, $\tilde{n}_{k}^{i}$, we can determine the first moment of $q\left(h_{k}^{i}\right)$ conditional on the sample size $n_{k}^{i}, E\left(q_{k}^{i} \mid n_{k}^{i}\right)$, where expectation is taken over possible realizations of $\tilde{n}_{k}^{i}$.

The following lemma establishes how this conditional expectation changes with $n_{k}^{i}$ and the limiting behavior of $q\left(h_{k}^{i}\right)$. In the rest of the analysis, without loss of any generality, we assume that $x_{k}^{*}=L$.

Lemma 2 Let $E\left(q_{k}^{i} \mid n_{k}^{i}\right)$ denote the expectation of $q\left(h_{k}^{i}\right)$ conditional on sample size $n_{k}^{i}$ and suppose that $x_{k}^{*}=L$. Then $E\left(q_{k}^{i} \mid n_{k}^{i}\right)$ is an increasing function of $n_{k}^{i}$. Moreover, $p \lim _{n_{k}^{i} \longrightarrow \infty} q\left(h_{k}^{i}=\left\{n_{k}^{i}, \tilde{n}_{k}^{i}\right\}\right)=1$.

Lemma 2 establishes the intuitive result that, as the history relevant to technology $k$ expands, the principal learns the reference action $x_{k}^{*}$ with increasing precision.

Next, we establish that profit-maximizing firms always choose the organization form which maximizes $\pi\left(d_{i, k} ; h_{k}^{i}\right)$. Although firms have a dynamic objective function, given by (3), the maximization program is equivalent to a sequence of static problems. Intuitively, the current organization choice only affects the PDV of the firm via its effect on current productivity, $y_{i, t}$, so the optimal strategy simply maximizes the probability of successful implementation of new technologies in each period.

Lemma 3 A firm $i$ maximizing (3) chooses, for all technologies $\mathrm{k}$,

$$
d_{i, k}^{*}\left(h_{k}^{i}\right) \in\{0,1\}=\arg \max _{d_{i, k}} \pi\left(d_{i, k} ; h_{k}^{i}\right) .
$$

\footnotetext{
${ }^{10}$ Note that, since $\varepsilon \in(0,1 / 2), q\left(h_{k}^{i}\right)>1 / 2$ whenever $\tilde{n}_{k}^{i}>n_{k}^{i} / 2$, and $q\left(h_{k}^{i}\right)<1 / 2$ whenever $\tilde{n}_{k}^{i}<n_{k}^{i} / 2$.
} 
In particular, given history $h_{k}^{i}$, firm $i$ will choose $d_{i, k}^{*}\left(h_{k}^{i}\right)=1$ (delegation) if $\pi\left(0 ; h_{k}^{i}\right)<\delta$, and $d_{i, k}^{*}\left(h_{k}^{i}\right)=0$ (centralization) if $\pi\left(0 ; h_{k}^{i}\right)>\delta$, where $\pi\left(0 ; h_{k}^{i}\right)$ is given by $(6)$.

Lemmas 1, 2 and 3 enable us to characterize how the organizational form changes with distance to frontier, $n_{k}^{i}$, and heterogeneity, $\varepsilon$. Consider, first, distance to frontier. Suppose, in particular, that a firm is at the technology frontier, so that it is the first firm implementing technology $k$. In this case, $n_{k}^{i}=0$, and so $q\left(h_{k}^{i}\right)=1 / 2$ and $\pi\left(0 ; h_{k}^{i}\right)=q_{0}=1 / 2<\delta$. Thus, when no public information is available, the firm will choose delegation, $d_{i, k}^{*}\left(h_{k}^{i}\right)=1$. Next, consider the other extreme where the firm is far behind the technology frontier, so that many other firms have implemented the same technology before. In this case, we have $n_{k}^{i} \rightarrow \infty$ and $p \lim _{n_{k}^{i} \longrightarrow \infty} q\left(h_{k}^{i}\right)=1$ from Lemma 2. Equation (6) then implies $p \lim _{n_{k}^{i} \longrightarrow \infty} \pi\left(0, h_{k}^{i}\right)=$ $1-\varepsilon>\delta$, where the inequality follows from Assumption 1. Hence, the firm will (almost surely) choose centralization, $d_{i, k}^{*}\left(h_{k}^{i}\right)=0$. This discussion establishes the following proposition:

Proposition 1 (Distance to Frontier) Consider the adoption decision of technology $k$ by firm $i$, and suppose that Assumption 1 holds and $x_{k}^{*}=L$. Then:

(i) For a firm at the frontier, i.e., $n_{k}^{i}=0$, the principal chooses delegation, $d_{i, k}^{*}\left(h_{k}^{i}\right)=1$.

(ii) For a firm sufficiently far from the frontier, i.e., $n_{k}^{i} \rightarrow \infty$, the principal chooses almost surely centralization, i.e., $p \lim _{n_{k}^{i} \longrightarrow \infty} d_{i, k}^{*}\left(h_{k}^{i}=\left\{n_{k}^{i}, \tilde{n}_{k}^{i}\right\}\right)=0$.

From this proposition and the fact that, $E\left(q_{k}^{i} \mid n_{k}^{i}\right)$ is increasing in $n_{k}^{i}$ (Lemma 2), one might expect a more general result, such that as distance to frontier $n_{k}^{i}$ increases, decentralization becomes more likely. Unfortunately, though intuitive, this result is not correct because of integer issues. To illustrate the problem, consider Figure 4, which plots the probability of centralization as a function of $n_{k}^{i}$ from an example with $\delta=0.65$ and $\varepsilon=0.3$. As implied by Proposition 1, delegation is always chosen for $n_{k}^{i} \leq 2$ and never chosen as $n_{k}^{i}$ exceeds 30 . In between, however, due to integer problems the relationship is non-monotonic. ${ }^{11}$ Clearly, if one smooths out the plot taking a moving average, the probability of centralization is indeed increasing with $n_{k}^{i}$. Therefore, in the empirical analysis, we disregard the integer problem and focus on the prediction that centralization increases with the distance to the frontier. We will proxy distance to the frontier with the gap between the productivity of a firm and the highest productivity (or more precisely the highest percentile productivity) in the same industry. It is clear that firms further from the frontier in terms of having high $n_{k}^{i}$,s are less productive,

\footnotetext{
${ }^{11}$ In particular, when $n_{k}^{t}=3$, delegation is chosen when $\tilde{n}_{k}^{t}=1$ or when $\tilde{n}_{k}^{t}=2$, so that the probability of centralization overall is approximately 0.37. On the other hand, when $n_{k}^{t}=4$, delegation is chosen for $\tilde{n}_{k}^{t} \in\{1,2,3\}$, and the probability of centralization is approximately 0.25 . Thus, the probability of centralization is smaller for $n_{k}^{t}=4$ than for $n_{k}^{t}=3$.
} 
since these are the firms that have been unlucky and have had fewer opportunities to adopt technologies, and they are also likely to be the ones with relatively low $p_{i}$ 's, that is, those that are slower in climbing their technology ladder.

We next turn to heterogeneity. Let us define $\operatorname{Pr}\left(d_{i, k}^{*}\left(h_{t}^{i}\right)=1\right)$ as the ex ante probability that firm $i$ facing technology $k$ at time $t$ will choose decentralization. This probability is clearly a function of the parameters of the model, in particular $\varepsilon$, which measures the extent of heterogeneity, and the firm's distance to frontier. In particular, recall that greater $\varepsilon$ translates into a greater heterogeneity in the firm's environment. The following proposition establishes that greater heterogeneity—-higher $\varepsilon$ - encourages decentralization (proof in Appendix A):

Proposition 2 (Heterogeneity) Consider the adoption decision of technology $k$ by firm $i$. Given the distance to frontier, we have

$$
\frac{\partial \operatorname{Pr}\left(d_{i, k}^{*}\left(h_{t}^{i}\right)=1\right)}{\partial \varepsilon} \geq 0,
$$

so that an increase in $\varepsilon$ makes delegation more likely.

Intuitively, when $\varepsilon$ is small, the performance of firms that have implemented the same technology in the past reveals more information about the reference action. Thus, firms' posterior beliefs are more responsive to public information. Note that this applies to both "correct" and "incorrect" beliefs. For instance, suppose that $x_{k}^{*}=L$, but in the sample available to the firm $R$ has been successful more than half of the time; then, when $\varepsilon$ is small, the firm will assign higher probability to $R$ being the correct action (i.e., $\pi\left(0 ; h_{k}^{i} \mid x_{i, k}=R\right)$ will take on a larger value). The complication in establishing Proposition 2 comes from the fact that a change in $\varepsilon$ affects the likelihood of different histories. Nevertheless, Appendix A establishes that a greater $\varepsilon$ changes the ex ante distribution of different histories so as to also increase $\operatorname{Pr}\left(d_{i, k}^{*}\left(h_{t}^{i}\right)=1\right)$.

Proposition 2 provides the most interesting testable implication of our approach; it suggests that there should be more decentralization in industries with greater dispersion of performance across firms and also for firms that are more dissimilar to others.

\subsection{Delegation and Age}

Finally, we briefly extend our basic model to derive a relationship between firm age and organizational structure. In the model analyzed so far the deviation between the reference action and the correct action for each firm was independently and identically distributed across technologies, firms and time. Consequently, a firm's information on how to implement technology 
$k$ was independent from that firm's actions and performance on previous technologies $k^{\prime}<k$. More generally, one could assume that there is a positive correlation between the correct actions that a firm should take across successive technologies, for example, because the specific skills of the employees or the culture of the organization differ across firms. In this case, the firm could learn from its own past experience as well as from the experiences of other firms. ${ }^{12}$

Since solving the signal extraction problem with multiple sources of uncertainty is complicated and not our main focus here, we assume in this subsection that firms cannot learn from other firms. This enables us to focus instead on firms' learning from their own performance. The analogue equation to $(8)$ is as follows. For any $I_{i}(k ; t)=1$, we have:

$$
x_{i, k}^{*}=\left\{\begin{array}{cc}
x_{i}^{*} & \text { with probability } 1-\varepsilon_{i} \\
\sim x_{i}^{*} & \text { with probability } \varepsilon_{i}
\end{array}\right.
$$

so that the reference action for firm $i$ is $x_{i}^{*} \in\{L, R\}$, the correct action for technology $k$ may differ from this with some probability $\varepsilon_{i}<1 / 2$.

This equation implies that the updating problem is now identical to that discussed previously, up to a reinterpretation of the information set. In particular, what used to be history $h_{k}^{i}=\left\{n_{k}^{i}, \tilde{n}_{k}^{i}\right\}$ is now replaced by $h_{k}^{i}=\left\{n_{i}^{k}, \tilde{n}_{i}^{k}\right\}$, where, given $I_{i}(k ; t)=1, n_{i}^{k}$ denotes the number of technologies that firm $i$ has implemented before technology $k$, and $\tilde{n}_{i}^{k}$ denotes the number of times in which action $L$ turned out to be the correct choice in this firm's own experience in the past. Given this reinterpretation, our previous analysis implies (proof omitted):

Proposition 3 (Age) Consider the adoption decision of technology $k$ by firm $i$, and suppose that Assumption 1 holds and $x_{i}^{*}=L$. Then:

(i) For the youngest firm with $n_{i}^{k}=0$, we have $q\left(h_{t}^{i}=\{0,0\}\right)=\pi\left(0, h_{t}^{i}=\{0,0\}\right)=1 / 2<\delta$, and the principal chooses delegation, $d_{i, k}^{*}\left(h_{t}^{i}\right)=1$;

(ii) For a sufficiently old firm, i.e., $n_{i}^{k} \rightarrow \infty$, we have $p \lim _{n_{i}^{k} \longrightarrow \infty} q\left(h_{t}^{i}=\left\{n_{i}^{k}, \tilde{n}_{i}^{k}\right\}\right)=1$, $p \lim _{n_{k}^{i} \longrightarrow \infty} \pi\left(0, h_{t}^{i}=\left\{n_{i}^{k}, \tilde{n}_{i}^{k}\right\}\right)=1-\varepsilon>\delta$, and the principal almost surely chooses centralization, i.e., $p \lim _{n_{k}^{i} \longrightarrow \infty} d_{i, k}^{*}\left(h_{t}^{i}=\left\{n_{i}^{k}, \tilde{n}_{i}^{k}\right\}\right)=0$.

\footnotetext{
${ }^{12}$ For example, one can modify equation $(2)$ as follows. Given $I_{i}(k ; t)=1$,

$$
x_{i, t, k}^{*}=\left\{\begin{array}{cc}
x_{k}^{*} & \text { with probability } \xi_{k} \\
x_{i}^{*} & \text { with probability } 1-\xi_{k}-\xi_{i} \\
\eta_{i, k, t} & \text { with probability } \xi_{i}
\end{array}\right.
$$

where $\eta_{i, k, t}$ is equal to $L$ with probability $1 / 2$ and equal to $R$ with probability $1 / 2$, and also i.i.d across technologies, firms and time. As before, firms do not observe $x_{k}^{*}$ or $x_{i}^{*}$, whereas informed managers know $x_{i, k, t}^{*}$. The case analyzed in the text corresponds to the one where $\xi_{k}=0$ and $\varepsilon_{i}=\xi_{i} / 2$.
} 


\section{Econometric Specification and Data}

\subsection{Empirical Strategy}

In our empirical work, we will document a number of correlations motivated by the theory presented in the previous section. Recall that the main predictions of our approach, as summarized in Propositions 1-3, are:

1. Delegation should be more common for firms closer to the technological frontier.

2. Delegation should be more prevalent in environments with greater heterogeneity.

3. Young firms should be more likely to choose delegation.

We investigate these predictions by studying the correlation between various explanatory factors and decentralization decisions of several thousand French and British firms. Consider the following equation:

$$
d_{i l t}^{*}=\alpha H_{i l t-1}+\beta P F_{i l t-1}+\gamma P M C_{i l t-1}+\delta a g e_{i l t-1}+\mathbf{w}_{i l t-1}^{\prime} \boldsymbol{\zeta}+u_{i l t},
$$

where $i$ denotes firm, $l$ denotes industry and $t$ denotes time. $d_{i l t}^{*}$ is a latent variable indicating the propensity to delegate authority to managers. $H_{i l t-1}$ is a measure of heterogeneity (or in some experiments inverse heterogeneity, or "homogeneity"), $P F_{i l t-1}$ is a measure of "proximity to the frontier" (inverse measure of "distance to the frontier"), age $e_{i l t-1}$ denotes the age of the firm, $\mathbf{w}_{i l t-1}$ is a vector of other controls, and $P M C_{i l t-1}$ is a measure of product market competition, which we find to be a robust predictor of delegation and thus include it as part of our main specification (we return to an interpretation of this term below in subsection 5.9). All right-hand side variables refer to $t-1$, while the dependent variable is for $t$, which is an attempt to prevent the most obvious form of reverse causality. Nevertheless, we do not view estimates from equation (9) as corresponding to causal effects, since there may be other omitted factors, simultaneously affecting both the (lagged) right-hand side variables and the delegation decisions. Below, we deal with part of this endogeneity issue by using values from the UK manufacturing sector to instrument for $H$ and $P F$. For now, all omitted factors are captured by the error term $u_{i l t}$, which we assume to be normally distributed.

In all of our specifications, we observe an indicator of decentralization, $d_{i l t} \in\{0,1\}$, and in our baseline specifications, we assume that

$$
d_{i l t}=\left\{\begin{array}{ll}
1 & \text { if } d_{i l t}^{*}>0 \\
0 & \text { if } d_{i l t}^{*} \leq 0
\end{array},\right.
$$


where $d_{i l t}^{*}$ is given by (9). Equation (10) leads to the standard probit model (see Wooldridge, 2002, Chapter 15). We therefore estimate (9) by maximum likelihood probit. We check the robustness of our results by using logit and linear probability specifications. In all cases, the standard errors are robust and allow for arbitrary variance-covariance structure at the fourdigit industry level (White, 1980).

\subsection{Data and Measurement}

We use two datasets of French firms and one of British firms. The use of multiple datasets is an important cross-validation of the robustness of our results. Our first and main dataset, "Changements Organisationnels et Informatisation" (COI) ${ }^{13}$ covers just over 4,000 manufacturing firms. Using unique firm identifiers, firms in this dataset are matched to the dataset FUTE (see Appendix B), which contains the entire population of French firms with more than 20 employees. ${ }^{14}$ Many of our right-hand side variables are constructed from the FUTE and thus refer to this entire population. Since the COI contains some firms with less than 20 employees, the match leaves us with a total of 3,570 firms for our basic analysis.

Using the COI, we build a measure of decentralization based on the organization of a firm's business units into profit centers (see Appendix B for a more detailed description). In practice, once a firm grows beyond a certain size it faces the choice of retaining centralized control or allowing some decentralization. Firms are generally organized into business units, with different degrees of responsibility delegated to the managers of these units. While some firms retain complete command and control at the center, most create some form of "responsibility centers" for business unit managers. ${ }^{15}$ These responsibility centers (from the most to the least decentralized) are profit centers, cost centers and revenue centers. Our key indicator for decentralization is whether the firm is organized primarily into profit centers. As the name suggests, when a firm organizes into profit centers, a manager is responsible for the profits of the unit that she manages. She is given considerable autonomy to make decisions on the purchase of assets, hiring of personnel, the management of inventories and determination of bonuses and

\footnotetext{
${ }^{13}$ For previous uses of this dataset see, Aubert, Caroli and Roger (2004), Janod (2002), Janod and Saint-Martin (2004), Crépon, Heckel and Riedinger (2004), and Greenan and Mairesse (1999).

${ }^{14}$ FUTE also contains population of non-manufacturing firms with more than ten employees. These data are not published in the French National Accounts, so we worked directly with the underlying micro data located in the French statistical agencies in order to construct the appropriate variables. Similarly the information on the demographic structure of each firm (skills, worker age, hours, gender, etc.) had to be built up from the employee level datasources aggregated to the firm level (see Appendix B).

${ }^{15}$ For the meaning of the terms responsibility centers and profit centers in the business literature and in management, see, for example: http://smccd.net/accounts/nurre/online/chtr12a.htm. In addition, http://www.aloa.co.uk/members/downloads/PDF\%20Output/costcentres.pdf, provides a standard discussion of autonomy of profit centers. Janod (2002) and Janod and Saint-Martin (2004) have previously used these data on profit centers as a measure of decentralization.
} 
promotions. She keeps track of both revenues and costs with the aim of maximizing profit. ${ }^{16}$ In contrast, a cost (revenue) center manager is responsible only for costs (revenue). Milgrom and Roberts (1992, pp. 229-230), for example, contrast cost and profit centers managers as follows: "Managers who are given responsibility for profits, for example, are commonly given broader decision authority than those responsible just for costs or sales." Overall about 30\% of French firms in our sample are organized into profit centers.

Our second dataset, the "Enquête Reponse" (ER), is a survey of just under 3,000 French establishments covering all sectors of the economy conducted in 1998. This dataset is also matched with the FUTE to construct the right-hand side variables, which leaves us with a dataset of around 2,200 establishments. In this data set, delegation can be measured in two ways. First, there is a direct question asked to plant managers over the degree of autonomy they have in investment decisions relative to Head Quarters. Since this question only makes sense for firms that are part of a larger group, the analysis is restricted to this sub-sample (of 1,258 establishments). Second, there is a question related to delayering, which indicates whether there was any reduction in the number of hierarchical layers between 1996 and 1998. Although, a priori, delayering may increase or reduce delegation (it may, for example, reduce delegation by making the chief executive more informed about lower layers), existing evidence shows that delayering is associated with delegating power down the managerial hierarchy (Rajan and Wulf, 2005, Caroli and Van Reenen, 2001). Since delayering provides information on organizational "changes" (i.e., whether a firm became more or less hierarchical) rather than "levels", we use a variation of equation (9).

Finally, we draw on a UK dataset, the 1998 Workplace Employee Relations Survey (WERS), which is similar in structure to Enquête Reponse (in fact, ER was modeled on earlier waves of WERS). WERS does not have a question on plant managers' autonomy in investment decisions, but contains a question on their autonomy from headquarters in making employment decisions. We use this question to denote the degree of decentralization (a binary variable equal to unity if a manager could make recruiting decisions without having to consult headquarters). Unlike the French data for confidentiality reasons, we are not allowed to legally match WERS with productivity at the firm level, though we can match in productivity information at the fourdigit industry level. ${ }^{17}$

\footnotetext{
${ }^{16}$ Merchant's (1989, p.10) textbook on profit centers explains: "The profit center managers frequently know their business better than top management does because they can devote much more of their time to following up developments in their specialized areas. Hence, top level managers usually do not have detailed knowledge of the actions they want particular profit center managers to take, and even direct monitoring of the actions taken, if it were feasible would not ensure profit center managers were acting appropriately."

${ }^{17}$ Full details from COI, ER and WERS are in the Appendix B and Appendix Tables B1 and B2 contain
} 
For $H_{i l}$ we use two measures; $H_{l}^{+}$and $H_{i}^{-}$. Both of these measures are constructed from the FUTE dataset (in the UK we can construct $H_{l}^{+}$using the ABI Census data). The main measure we use of heterogeneity, $H_{l}^{+}$, is the dispersion of firm productivity growth within a four-digit sector. In terms of the model in Section 3, high values of $H_{l}^{+}$therefore correspond to high values of $\varepsilon$. This variable is constructed using the entire FUTE dataset (regardless of whether a firm was surveyed by in COI or ER). We measure productivity growth by the average annual growth in value added per hour over the 1994 to 1997 period. ${ }^{18}$ Our main measure of dispersion is the the difference in productivity growth rates between the 90th percentile and the 10th percentile in the four-digit industry

$$
H_{l}^{+}=\left(\Delta \ln y_{i l}\right)^{90}-\left(\Delta \ln y_{i l}\right)^{10}
$$

where $\left(\Delta \ln y_{i l}\right)^{P}$ is the $P$ th percentile of the distribution of productivity growth across all firms in industry $l$. Productivity growth is defined as the three-year average change in (the log of) value added per hour. We also consider several alternatives such as the difference between the 95th and the 5th percentiles (instead of the 90-10), the standard deviation of firm productivity growth rates and the standard deviation of the trimmed productivity growth distribution.

Since the measure of $H_{l}^{+}$is the same across all firms in a four-digit industry, we also constructed a second firm-specific measure. This second index, $H_{i}^{-}$, is an inverse measure of heterogeneity, i.e., a measure of homogeneity, hence the "-" superscript. In terms of the model in Section 3, high values of $H_{i}^{-}$therefore correspond to low values of $\varepsilon$. This measure attempts to quantify how many other firms are close "neighbors" in the product space. When there are more similar firms (neighbors), the firm will have greater opportunity to learn from the experiences of other firms. This measure of closeness is inspired by Jaffe's (1986) approach, but uses the proportion of production in a four-digit industry. ${ }^{19}$

First, for each firm $i$ we compute the distribution of production across 400 four-digit sectors. Let the set of firms in this dataset be denoted by $\mathcal{N}$, and denote the set of firms in COI by $\mathcal{C}$. Let $S_{i l}$ denote the production of firm $i \in \mathcal{N}$ in industry $l$ for all industries $l \in \mathcal{L} \equiv\{1, . ., L\}$, and define $S_{i}=\left(S_{i 1}, \ldots, S_{i l}, \ldots, S_{i L}\right)$ as the vector of production for firm $i$. We then define the share of a firm's total production in industry $l$ as $s_{i l}=S_{i l} / \sum_{j \in \mathcal{L}} S_{i j}$. The denominator

detailed descriptive statistics.

${ }^{18}$ As discussed in detail in the Appendix B, data before 1994 are not reliable. Note that we only average over two years if the firm enters the sample in 1995 and one year if it enters in 1996.

We also report TFP-based measures as a robustness check. TFP is closer to the theory, but more likley to be affected by measurement error.

${ }^{19}$ Jaffe originally used patents technology class, which has the potential disadvantage that many firms do not patent, especially in service sectors. 
of $s_{i l}$ is the total production of the firm, so that $s_{i l}$ will be unity for a firm that only operates in industry $l$ (and zero for other industries). More generally, for firms operating in multiple industries it will lie between zero and one. The firm-specific vector of production shares across all $L$ industries for firm $i \in \mathcal{N}$ is then

$$
s_{i}=(\underbrace{\frac{S_{i 1}}{\sum_{h \in \mathcal{L}} S_{i h}}}_{s_{i 1}}, \ldots, \underbrace{\frac{S_{i l}}{\sum_{h \in \mathcal{L}} S_{i h}}}_{s_{i l}}, \ldots, \underbrace{\frac{S_{i L}}{\sum_{h \in \mathcal{L}} S_{i h}}}_{s_{i L}}) .
$$

We then calculate the "closeness" of any two firms, $i$ and $i^{\prime}$ as the uncentered correlation

$$
c_{i i^{\prime}}=\frac{\sum_{l \in \mathcal{L}} s_{i l} . s_{i^{\prime} l}}{\sqrt{\left(\sum_{l \in \mathcal{L}} s_{i l}^{2}\right) \cdot\left(\sum_{l \in \mathcal{L}} s_{i^{\prime} l}^{2}\right)}},
$$

which takes greater values when the production profiles of two firms are more similar, and is equal to unity when the two profiles are identical.

Since our theoretical approach emphasizes the importance of similarity in the context of experimenting with new technologies, our preferred measure of homogeneity for firm $i \in \mathcal{C}$ at time $t, H_{i}^{-}$, is

$$
H_{i}^{-}=\frac{\sum_{i^{\prime} \in \mathcal{N}, i^{\prime} \neq i} c_{i i^{\prime}} \cdot I T_{i^{\prime}}}{\sum_{i^{\prime} \in \mathcal{N}, i^{\prime} \neq i} I T_{i^{\prime}}}
$$

where $I T_{i^{\prime}}$ is calculated as the level of investment in IT by firm $i^{\prime}$, so that (12) weights firms according to their investment in new technology. Equation (12) also emphasizes that $H_{i}^{-}$is calculated from the similarity of each firm in our dataset to any firm in the FUTE, i.e., the entire French population of firms.

A possible shortcoming of the index $H_{i}^{-}$is that many new technologies may fall outside the IT category, so we also check the robustness of our results by looking at an alternative unweighted measure, calculated as

$$
H_{i}^{A-}=\frac{1}{N-1} \sum_{i^{\prime} \in \mathcal{N}, i^{\prime} \neq i} c_{i i^{\prime}}
$$

where $N=\sum_{i^{\prime} \in \mathcal{N}} i^{\prime}$ denotes the number of firms in the FUTE sample. We also construct another alternative measure, $H_{i}^{R-}$, which weights firms differentially depending on their geographic proximity, and this measure is described in greater detail in Appendix B.

An important concern with these homogeneity measures is that they may be related to the level of product market competition. If there are many other firms "close" to a company in the product market space, then this company may be facing tougher competition. ${ }^{20}$ To alleviate

\footnotetext{
${ }^{20}$ See Bloom, Schankerman and Van Reenen (2004) for a discussion.
} 
this concern, we control for a number of measures of the extent of product market competition in our main specifications. Nonetheless, it is important to note that to the extent that our homogeneity measure is correlated with product market competition (beyond our controls), this will likely bias the results towards finding a positive effect of our homogeneity variables (i.e., the opposite of the prediction in Section 3). This is because, as we document below, there is a fairly robust positive relationship between product market competition and delegation. ${ }^{21}$

Our key indicator of proximity to the frontier is the gap between the log labor productivity of a firm (measured as value-added per hour) and the frontier (log) labor productivity in the primary four-digit industry of the firm, $\ln y_{i l t}-\ln y_{F l t}$, where $F$ denotes the frontier, measured in a number of alternative ways. In addition to average labor productivity, we also report robustness checks using Total Factor Productivity (TFP). ${ }^{22}$ We also construct several indicators of "frontier" productivity. Our main measure is the highest productivity in the firm's primary four-digit industry (defined as the 99th percentile to mitigate any measurement error from outliers that might arise had we used the maximum) again calculated from the FUTE dataset. We repeat the same exercise using other percentiles (90th and 95th), and we consider alternative measures based on the firm's productivity rank in the four-digit industryan ordinal measure which relies less on our cardinal measurement of productivity.

As a robustness check on our main specification, we also allow $\ln y_{i l t-1}$ and $\ln y_{F l t-1}$ to have different coefficients in the regression equation, by estimating

$$
d_{i l t}^{*}=\alpha H_{i l t-1}+\beta_{1} \ln y_{i l t-1}+\beta_{2} \ln y_{F l t-1}+\gamma P M C_{i l t-1}+\delta a g e_{i l t-1}+\mathbf{w}_{i l t-1}^{\prime} \boldsymbol{\zeta}+u_{i l t} .
$$

This specification allows us to test whether $\beta_{2}<0$ (i.e., whether as predicted by our theory, delegation is negatively correlated with lagged frontier productivity) and also whether $\beta_{1}=$ $-\beta_{2}$. This robustness check is particularly important, since a positive correlation between distance to frontier and decentralization may reflect a positive effect of decentralization on productivity. Equation (14) enables us to check for this directly by seeing whether $\beta_{2}=0$.

In addition, since our motivating theory relates to the implementation of new technologies, we also estimate (9) and (14) separately in high-tech and low-tech firms. We expect the patterns suggested by our model to be more pronounced for high-tech firms.

To measure age, $a g e_{i l t-1}$, we use four dummies for age ranges less than 5 years, between 5 and 10 years, between 10 and 20 years, and the reference category, greater than 20 years. ${ }^{23}$

\footnotetext{
${ }^{21}$ This is also consistent with the results in Nickell, Nicolitsas and Patterson (2001) and McKinsey Global Institute (2002).

${ }^{22}$ In specifications that also include firm-level and industry-level capital intensity variables, the labor productivity terms also approximate TFP.

${ }^{23}$ Since our main models are cross-sectional, we cannot distinguish age and cohort effects. Nevertheless, the
} 
Finally, our main measure of product market competition is the Lerner index, calculated as profits (value added minus labor costs) divided by sales from the FUTE dataset.

As an attempt to control for the potential endogeneity of heterogeneity/homogeneity and proximity to frontier measures, and also to examine the direction of potential biases, we also experiment with an instrumental-variable strategy treating these terms as endogenous, and using values of the same variables in the corresponding four-digit UK industry as instruments (see Hausman and Taylor, 1981). The idea is that, as discussed above, firm-specific or French industry-specific shocks to $d_{i l t}^{*}$ could feedback to the heterogeneity or distance to frontier terms, biasing the coefficient estimates. ${ }^{24}$ The UK values of heterogeneity should be correlated with the French values insofar as they represent "fundamentals" about the industry, but should not be affected by shocks specific to French firms. Similarly, fundamental technological changes should simultaneously raise the UK and French frontier (for example, because the US makes a breakthrough that benefits frontier firms in UK and France). It is important to note, however, that this instrumental variables strategy will not necessarily estimate causal effect either, since there may still exist omitted factors that are common to both French and UK industries that affect both the right-hand side variables and delegation.

\section{Results}

\section{$5.1 \quad$ Decentralization}

Table 1 presents the basic findings using the decentralization measure from COI. In this table, all regressions are estimated by maximum likelihood (ML) probit following equations (9) and (10) above. We report marginal effects evaluated at the sample means. As in all other tables, standard errors are computed using the Huber formula allowing for heteroskedasticity and an arbitrary variance-covariance matrix at the four-digit industry level. Moreover, all of our regressions include a full set of three-digit industry dummies. ${ }^{25}$

The first column is the most parsimonious specification to look at the effect of the heterogeneity measure, $H_{l}^{+}$. The regression only includes this variable and a full set of three-digit industry dummies. Consistent with the predictions in Section 3, there is a positive correlation between heterogeneity and decentralization, so that firms in more heterogeneous environments

results in Table 6 below suggest that the patterns we document are not purely due to cohort effects.

${ }^{24}$ The fact that we are using lagged values on the right-hand side ameliorates but does not solve this problem because of potential serial correlation in these variables.

${ }^{25}$ The frontier productivity term and the heterogeneity measure $H_{l}^{+}$are defined at the four-digit level, so we can only include three-digit industry dummies if we want to identify their coefficients. We present some specifications including four-digit dummies to show the robustness of the marginal effects of the other variables. 
are more likely to be decentralized. The marginal effect of heterogeneity is -0.212 and is significant at the $5 \%$ level.

The second column estimates an equation similar to (14) in order to look at the effect of the frontier productivity term (measured as the 99th percentile of the productivity distribution in the primary four-digit industry of the firm) and the firm's own productivity. This specification still includes a full set of three-digit industry dummies. Both productivity terms are significant, and consistent with the predictions above, there is a negative coefficient on the frontier productivity term (i.e., $\beta_{2}<0$ ) and a positive coefficient on the own productivity term (i.e., $\beta_{1}>0$ ). The Wald test at the bottom of the table rejects the restriction that $\beta_{1}=-\beta_{2}$, though when additional covariates are included in columns (7) and (8) this restriction will no longer be rejected. The third column imposes that the coefficients are equal and have opposite signs, and includes a single "proximity to frontier" variable as in equation (9). The marginal effect is now estimated to be 0.159 (standard error $=0.024$ ). Overall, these patterns suggest that firms closer to the technology frontier of their industry are more likely to be decentralized.

The fourth column looks at the effect of age and includes only the dummy variables for the age of the firm (this regression includes a full set of four-digit industry dummies). The youngest firms (under 5 years old) are 13\% more likely to be decentralized than the oldest firms (those over 20 years old) and this difference is significant at the $5 \%$ level.

The remaining columns include all these variables simultaneously and look at the effect of including additional covariates. Without the additional covariates, in columns (5) and (6), heterogeneity, age, and the proximity terms remain jointly and individually significant. The magnitudes are also quite similar to those in columns (1)-(4).

The final two columns include a large number of additional controls to check whether the partial correlations are due to some other omitted variables. These additional covariates include the following variables: the Lerner Index, a foreign ownership dummy, the log number of plants of the firm, the (log of) capital stock divided by value added, log firm size, the fraction of employees working with computers, ${ }^{26}$ the fraction of high skilled workers, the average age of workers, the firm's market share, a diversification index (see Appendix B), as well as a number of industry-level variables, in particular, (in logs) capital stock divided by employment, IT expenditures divided by employment and the Herfindahl index. The capital stock and computer use variables are included both as potential controls and also to bring the measure of labor productivity closer to TFP by controlling for the contribution of various components

\footnotetext{
${ }^{26}$ We also experimented with the firm-level IT investment intensity, but this variable was never significant given the industry-level IT measure and the fraction of employees using computers (which is consistent with the results in Askenazy et al, 2005).
} 
of the capital stock. Firm-level worker characteristics are included since these may affect organizational choices; for example, firms with more skilled workers and/or younger workers might be more likely to decentralize control. Finally, centralized management may be more difficult for more diversified and larger firms (Colombo and Delmastro, 2004). The full results from these regressions are presented in Table C1 in Appendix C. Columns (7) and (8) in Table 1 report the estimates for our main variables of interest. The additional controls improve the fit of the model. Nevertheless, the heterogeneity, age and productivity terms all remain individually significant at the $5 \%$ level or less. Also interestingly, in this specification we can no longer reject the hypothesis that $\beta_{1}=-\beta_{2}$, i.e., the hypothesis that frontier and own labor productivity terms have equal and opposite-signed coefficients.

The full results in Appendix Table $\mathrm{C} 1$ show that consistent with the results in the previous literature, firms that are more skill-intensive (Caroli and Van Reenen, 2001), that employ younger workers (Aubert et al, 2004) and/or that are more in more IT-intensive industries (Bresnahan et al, 2002) appear significantly more likely to be decentralized. Furthermore, firms that are large, multi-plant, foreign owned and/or more diversified are also more likely to decentralize. Firm-level capital stock or industry-level capital stock do not appear to have a major effect on decentralization. The Lerner index (a proxy for the price cost margin) is strongly negatively associated with the probability of decentralizing. We show that this a very robust empirical result suggesting that firms with market power are less likely to delegate. In subsection 5.9, we discuss a potential explanation for the relationship between competition and decentralization based on our model in Section 3.

Overall, the results in Table 1 suggest that, consistent with our model and the relationships shown in Figures 1-3, firms that operate in more heterogeneous environments, that are closer to the technology frontier, and that are younger are significantly more likely to be decentralized.

\subsection{Magnitudes}

It is also useful to look at the magnitudes of the effects estimated in Table 1. To gauge the quantitative magnitudes of these estimates, we look at the impact of doubling each variable starting from its sample mean.

Using the estimate in Table 1 column (8), 0.251, we find that doubling the mean value of heterogeneity (the inter-decile range of firm productivity growth in the industry) from 0.275 to 0.550 increases the predicted probability of a firm being decentralized into profit centers by approximately 7 percentage points $(0.251 \times 0.275 \approx 0.069)$ starting from a base of 30 percent, which is a sizeable effect. Thus, in "elasticity" terms, a doubling of heterogeneity is associated 
with a $23 \%$ increase in the probability of decentralization (a 6.9 percentage point increase on a base of 30 percent). ${ }^{27}$ Again using the estimate from column (8) of Table 1, doubling the proximity measure leads to a substantial increase in the probability of decentralization of about 11 percentage points which represents a $37 \%$ increase on the base of about 30 percent $(0.164 \times \ln 2 / 0.3)$. Also using the estimates from column (8) of Table 1, increasing the age of a firm from four years to eight years reduces the probability of decentralization by a third (11 percentage points on a 30 percent base), while doubling the Lerner index at the mean (0.075) reduces decentralization probabilities by about 5.5 percentage points ( $18 \%$ on the 30 percent base). These calculations suggest that the statistical associations documented in Table 1 appear to be economically as well as statistically significant.

\subsection{Alternative Measures of Heterogeneity}

Table 2 contrasts our basic measure of heterogeneity (the decile ratio of firm productivity growth rates in the industry) with several alternative indicators of heterogeneity. The first column of Table 2 replicates the specification from the last column of Table 1 for comparison. The next three columns (2)-(4) use alternative measures of heterogeneity, $H_{l}^{+}$still based on the dispersion of productivity growth rates across firms within the four-digit industry. Column (2) shows a similar result to column (1) using the difference between the productivity growth rates at the 95 th and 5 th percentiles (instead of the 90 th and 10 th percentiles). The marginal effect is 0.142 with a standard error of 0.069 . In column (3) we use the standard deviation of the growth rate, which also has a positive marginal effect, but is only significant at the $10 \%$ level. This lack of precision is due to a number of outliers in the firm-level productivity growth distribution. When we calculate the standard deviation after trimming the top and bottom $5 \%$ of the firm-level productivity growth distribution, we obtain a much larger and much more significant marginal effect in column (4). Overall, the results in this table show that there is a robust positive association between heterogeneity and decentralization. ${ }^{28}$

As an alternative to $H_{l}^{+}$we use an index of homogeneity, $H_{i}^{-} \cdot{ }^{29}$ Recall that this index measures is the IT-weighted distance of a firm to all other firms, where "distance" is defined

\footnotetext{
${ }^{27} \mathrm{~A}$ one standard deviation increase in heterogeneity (0.148) results in a smaller increase in the likelihood of decentralization: a 3.7 percentage point, or $12 \%$ increase.

${ }^{28}$ One concern with any measure of heterogeneity is that, since it is correlated with uncertainty in firm's environment, it may affect the extent of the moral hazard problem between the firm and the manager (an issue we have abstracted from in the model). Nevertheless, everything else equal, this effect would bias the results against finding a positive association between heterogeneity and decentralization, since greater uncertainty in the environment will increase agency costs and make centralization more attractive.

${ }^{29}$ All of the results in Table 1 are similar if we use these homogeneity index, $H_{i}^{-}$, instead of the heterogeneity index $H_{l}^{+}$. For example, the most parsimonious specification in column (1) of Table 1 gives a marginal effect of $H_{i}^{-}$of 0.112 with a standard error of 0.034 (further results available upon request, and see also Appendix C1).
} 
over the sectors in which the firm is active. This is an entirely different source of variation in heterogeneity, so constitutes a useful cross-validation for whether the relationship between the heterogeneity index and decentralization in Table 1 is indeed related to the effect of heterogeneity of the environment facing the firm on decentralization decisions. In column (5) of Table 2, the homogeneity index takes its expected negative sign with a marginal effect of -0.063 and a standard error of 0.031. In column (6) we look at the simpler unweighted measure of homogeneity $\left(H_{i}^{A-}\right)$. This is also useful as another check to see whether our homogeneity measure is capturing some competition-related factors. If this were the case, we would expect the unweighted measure to be stronger. The unweighted measure also has a negative effect, but with a smaller coefficient that is not statistically significant at the $5 \%$ level. This suggests that the IT weights increase the explanatory power of the homogeneity index. ${ }^{30}$

We also experimented with a third alternative homogeneity index, which exploits the geographical proximity of firms, $H_{i}^{R-}$. This index captures the idea that it may be easier to learn from firms that are physically close as suggested by the economic geography literature (e.g., Keller, 2002). Essentially, $H_{i}^{R-}$ gives a greater weight to firms that are geographically (as well as technologically) close to each other (See Appendix B for the exact definition of this variable). In the final column we see that the marginal effect of homogeneity rises to -0.069 with a standard error of 0.034 , slightly stronger than the simpler version of homogeneity, $H_{i}^{-}$, in column (4).

\subsection{Differences Between High-Tech and Low-Tech Sectors}

Since the theory in Section 3 relates the propensity to decentralize to the adoption of new technologies, we may expect a stronger relationship between decentralization and heterogeneity/homogeneity in the high-tech industries than in the low-tech sectors. This is investigated in Table 3. We define "high-tech" sectors to be those with an average ratio of IT investment per worker greater than the sample median.

The first three columns use the baseline heterogeneity index, $\mathrm{H}_{l}^{+}$, measured as the 90-10 dispersion of productivity growth while the last three columns use the homogeneity index, $H_{i}^{-}$.

The first column of Table 3 repeats column (8) of Table 1 for comparison purposes. The second column presents the results for the high-tech sectors and the third column presents results for the low-tech sectors. Consistent with our expectations, the marginal effects and significance of the distance to frontier and heterogeneity variables are stronger in the high-

\footnotetext{
${ }^{30}$ If we include both the weighted and the unweighted measures together with all covariates, the weighted measure is negative and significant at the $5 \%$ level (coefficient $=-0.184$, standard error $=0.096$ ), while the unweighted measure is positive (coefficient $=0.142$, standard error $=0.109$ ).
} 
tech sectors than in the low-tech sectors (the pattern is similar but less clear for age). For example, column (3) shows that the heterogeneity index, $H_{l}^{+}$, is positive and significant in the high-tech sectors, but negative and insignificant in the low-tech sector. The marginal effects of proximity to frontier and the youngest age bin are twice as large in the high-tech sectors as the low-tech sectors. The Wald tests at the bottom of the table show that these differences are significant at the $1 \%$ level for heterogeneity, the $5 \%$ level for proximity to frontier but insignificantly different for age. The next three columns repeat the same regressions using the homogeneity index, $H_{i}^{-}$. The pattern of differences between high-tech and low-tech sectors is similar to those for heterogeneity. For example, the marginal effects of proximity and youngest firm are twice as large in the high-tech sectors as the low-tech sectors. The marginal effect of homogeneity is almost five times as large in absolute magnitude in the high-tech sector. With the homogeneity measure, however, the marginal effects in the two subsamples are statistically different only at the $10 \%$ level.

These results are encouraging since they suggest that, consistent with our theory in Section 3 , the relationship between heterogeneity or proximity to frontier and decentralization appears to be more pronounced in high-tech sectors.

\subsection{Further Robustness Checks}

Table 4 reports the results of a further series of robustness checks. It is designed to show that the results do not depend on the precise functional form, control variables or sample used in the main regressions. Each column corresponds to a separate regression and reports the marginal effects and standard errors of the key variables (heterogeneity, frontier productivity, own productivity, age and competition).

The first column replicates the baseline results from column (7) of Table 1 for comparison. Column (2) reports the marginal effects from a logit model instead of a probit; these results are very similar to the probit estimates. Column (3) reports estimates from a linear probability model. The results are again very similar to the baseline of the probit model.

Column (4) uses TFP instead of labor productivity as the measure of the proximity to frontier. ${ }^{31}$ TFP is more closely related to the theoretical idea of productivity we wish to capture, though it is also likely to be subject to greater measurement error. Both frontier and own TFP remain statistically significant with the expected signs; the estimate is smaller in absolute magnitude on frontier TFP and larger in absolute magnitude on the firm's own TFP.

\footnotetext{
${ }^{31} \mathrm{TFP}$ is constructed using the four-digit industry specific wage bill shares to weight the factor inputs and assumes constant returns (see Appendix B for details).
} 
In column (5), we construct the rank of the firm's labor productivity in the four-digit industry. This measure relies less on the exact distance in productivity space between two firms, and only exploits the ordinal ranking of firms. We find the same pattern of results: companies further down the productivity ranking are significantly less likely to decentralize.

In columns (6) and (7), we use the 95th and 90th percentiles of the productivity distribution to represent the frontier instead of the 99th percentile as in our baseline specifications. Although the coefficient on frontier productivity remains negative, it becomes smaller and less precise as we move down the percentiles of productivity. This is not entirely surprising, since the 99th should be a better measure of the "frontier" than the 95th or the 90th percentiles.

Column (8) weights the regression by firm size as the variables may be measured with greater error for smaller firms. We obtain somewhat more significant results in this weighted regression, but the standard error is similar to that in the baseline specification.

Although a single firm can be organized into divisions with each division decentralized as a profit center, the measure of profit centers may be more natural for firms that are part of larger groups. To investigate this issue further, in column (9) we re-estimated the equation on the sub-sample of 1,793 "under control" firms, which are those that are part of a larger corporate group. ${ }^{32}$ The marginal effects of heterogeneity and frontier are considerably larger and more significant for this subsample, suggesting that the baseline results, if anything, underestimate the importance of heterogeneity and proximity to frontier. An alternative to this sub-sample is to consider only joint stock firms (dropping the smaller limited liability firms). We do this in column (10) and again find that the results are robust.

Another concern is that we have allocated a single "frontier" to each firm, whereas firms that operate across multiple industries will have multiple "frontiers". To address this concern, we limit the sample to firms that have at least $80 \%$ of their sales in their primary four-digit industry, since the multiple industry issue should not be a serious concern for these firms. This restriction reduces our sample to 2,555 firms. Column (11) shows that the frontier term remains negative and significant in this smaller sample, though its marginal effect is also somewhat smaller -0.179 as compared to -0.225 in the baseline specification.

Recall that the specification in column (7) of Table 1 includes a dummy for foreign ownership. Column (12) goes one step further and drops all the foreign-owned firms from the sample. The results remain robust.

We also performed a number of additional robustness checks, including the same set of

\footnotetext{
${ }^{32} \mathrm{An}$ additional reason for focusing on the "under control" sub-sample is that this sample likely excludes owner-managed firms.
} 
regressions in Table 4 using the homogeneity measure. Overall both the robustness checks reported here and others indicate that there are robust associations between distance to frontier, heterogeneity and age, on the one hand, and decentralization.

\subsection{Endogeneity}

In Table 5 we make an attempt to address the issue of endogeneity of our main right-hand side variables. As discussed above, our strategy is to instrument for these variables using their UK counterparts. ${ }^{33}$ We use industry-level variables constructed from British establishment micro-data (the $A B I$ ) and matched to our French four-digit industries for identical time periods. More specifically, we constructed heterogeneity variables identical to $H_{l}^{+}$based on the dispersion of productivity growth between British firms to instrument French heterogeneity. We also constructed the 99th percentile of the productivity distribution in each British fourdigit industry as an instrument for the French proximity to frontier. Appendix B contains more details on the construction of these variables.

Our first strategy uses an instrumental variable probit model (Lee, 1981), but we also compare these results with alternative "two-step" methods (Rivers and Vuong, 1988) and twostage least squares estimates of the linear probability model.

The first column of Table 5 repeats the baseline specification for the sub-sample where we have French and UK data (which is slightly smaller - 3,518 firms - than our baseline sample of 3,570 firms). The results are practically identical to those in the larger sample. The second column shows the first-stage for the French heterogeneity variable in a specification where only the heterogeneity term is treated as endogenous. UK heterogeneity is positively and significantly associated with French heterogeneity in the same industry, even after conditioning on all the other exogenous variables (the t-statistic of the excluded instrument is over 3 and the partial $R^{2}$ is 0.091 , so weak instruments are unlikely to be an issue). The third column shows results from IV probit; all of our key variables are again correctly signed and significant at the $5 \%$ level. Interestingly, the marginal effect of heterogeneity is now much larger, 1.185 as compared to 0.230 in the baseline specification. This suggests that the probit estimates in Tables 1-4 may have been biased downwards due to attenuation, which may be corrected by the instrumentation strategy. ${ }^{34}$ The presence of downward attenuation bias is not entirely surprising since the heterogeneity index (and the proximity to frontier measure below) correspond

\footnotetext{
${ }^{33}$ We chose the UK over the US, since the UK is both geographically closer to France and likely to be more coordinated with the French economy because of the European Union.

${ }^{34}$ If, instead of the IV probit model, we estimate the linear probability model using two stage least squares, the estimated marginal effect is very similar: 1.105 with a standard error of 0.526 .
} 
only approximately to the theoretical concepts we would like to measure in the data.

Column (4) shows the first stage for proximity to frontier, which is now the only variable treated as endogenous and instrumented with the UK frontier variable. The UK frontier variable has the expected negative sign (recall that French frontier productivity is the denominator of the level of the proximity to frontier term that is being instrumented). The first-stage relationship is again quite strong and the t-statistic on the excluded instrument is now over 4 . The fifth column shows the IV probit results treating the proximity to the frontier as endogenous. The estimate of the marginal effect of proximity to the frontier in this IV specification is also larger than the baseline probit estimate reported in column (1); 0.341 versus 0.167 . The other variables retain the same signs as in column (1). ${ }^{35}$ This specification, therefore, also suggests that the main effect of endogeneity might be a downward bias due to attenuation. ${ }^{36}$

In the last columns of Table 5, we simultaneously treat heterogeneity and proximity to frontier as endogenous. Columns (6) and (7) show the two first stages. Encouragingly, the UK heterogeneity measure predicts French heterogeneity and not the French proximity to frontier, while UK frontier productivity predicts French proximity to frontier and not the French heterogeneity term. The decentralization equation is given in the final column. The heterogeneity and proximity to frontier terms are both individually significant at the $5 \%$ level in this IV probit regression and as in the previous columns, the marginal effects are larger than in the probit regressions that treat them as exogenous. ${ }^{37}$ The IV results of Table 5 , therefore, suggest that treating heterogeneity and proximity as exogenous likely makes us underestimate their importance for decentralization.

Overall, the results in Table 1-5 suggest that, consistent with the broad implications of our model, firms that operate in more homogeneous environments, that are further from the technology frontier, and that are older are significantly more likely to be centralized. Furthermore, these effects appear to be stronger for firms in the high-tech industries.

\footnotetext{
${ }^{35}$ Two stage least squares estimate of the effect of proximity to frontier in the linear probability model is 0.293 (standard error $=0.118$ ).

${ }^{36}$ If we split the proximity to frontier into its two components (as in Table 1 column (7)) and use the UK frontier to instrument only the French frontier, the marginal effect of the frontier increases from -0.244 in the probit specification to -0.967 in the IV probit specification.

${ }^{37}$ Using two stage least squares in the linear probability model again generates very similar results. The effect of heterogeneity is estimated to be 1.452 with a standard error of 0.663 (compared with a coefficient of 0.204 with a standard error of 0.111 in the OLS). The coefficient on proximity to frontier is estimated to be 0.410 with a standard error of 0.189 (compared with 0.147 with a standard error of 0.026 in the OLS regressions).
} 


\subsection{Alternative Measures of Decentralization}

We next consider two alternative measures of decentralization; control over investment decisions and delayering. Whether an establishment's senior managers can make investment decisions without consulting headquarters is clearly directly related to delegation of authority. Case study and econometric evidence suggests that reducing the layers of the managerial hierarchy tends to be associated with decentralized decision making. ${ }^{38}$ In the COI dataset there is an indicator of the number of hierarchical levels, but as discussed in the Appendix B, a better datasource to measure delayering is the Enquête Reponse (ER). ${ }^{39}$ The question of autonomy over investment decisions is only available in the Enquête Reponse.

Table 6 shows the results of estimating equation (14) for these alternative measures. Throughout, we show results separately for the full sample and also for the high-tech and the low-tech sub-samples (created using industry IT intensity as in Table 3). We limit the sample to firms that are "under control" (i.e., part of a larger group as defined above) because the question on delegation of investment decisions from headquarters is only relevant for these firms. In columns (1) through (3) the dependent variable is the binary indicator of whether the firm allows autonomy to its plant managers in making investment decisions. In columns (4) through (9), the dependent variable is defined as an indicator for whether there was a reduction in the number of layers in the managerial hierarchy between 1996 and 1998.

In column (1) of Table 6 frontier productivity is negatively and significantly related to the probability of allowing managers to make investment decisions without consulting headquarters (decentralization). Heterogeneity is positively related to decentralization but (like age) is insignificant. When we split the sample into high-tech and low-tech sectors, the results are stronger. In the high-tech sectors heterogeneity is positively related to the probability of delayering at the $5 \%$ significance level, whereas in the low-tech sectors heterogeneity is insignificant. Similarly, the frontier productivity term is negatively and significantly related to decentralization in the high-tech sectors, but is insignificant in the low-tech sectors. Own productivity and age are insignificant in both subsamples.

The next six columns use the measure of delayering as the dependent variable. In column (4) the productivity terms are both correctly signed and significant at the $5 \%$ level, suggesting that the more proximate the firm is to the frontier the more likely it is to delayer. Younger

\footnotetext{
${ }^{38}$ See, for example, Rajan and Wulf (2005) or Caroli and Van Reenen (2001).

${ }^{39}$ Briefly, this is because the Enquête Reponse question on delayering refers explicitly to changes in management, which is the concern of the theory. The COI question, by contrast, refers to the number of "hierarchical levels" that likely includes the levels of hierarchy including those for production workers as well as those for the management.
} 
firms are significantly more likely to delayer than older firms. ${ }^{40}$ The heterogeneity term is positive and significant at the $10 \%$ level. When the samples are split into high-tech (column (5)) and low-tech (column (6)) sectors, the marginal effects of heterogeneity and proximity are larger in the high-tech sectors than in the low-tech sectors, but the standard errors are also much larger in both samples. In contrast, the age effects are larger in the low-tech sample, which is the opposite of the prediction of our theory.

Since the delayering variable measures "organizational change" (rather than the "level" of the centralization as our previous dependent variable), we also consider regressions where the productivity terms are in differences rather than in levels. Since we do not have reliable timeseries information on the heterogeneity term and some of the other covariates, they are still included as lagged levels. The results are presented in columns (7) through (9). The results are similar to those before, but somewhat weaker. The frontier growth term is correctly signed, but no longer significant and the own productivity terms is also insignificant. ${ }^{41}$ The heterogeneity measure remains positive and significant in the full sample. With the sample split, it is no longer significant in either sample (presumably because of the smaller number of observations), though, as expected, the marginal effect is substantially larger in the high-tech sample than in the low-tech sample.

In summary, the results from using delayering and autonomy on investment decisions as alternative indicators of decentralization broadly support our earlier conclusions. Decentralization is more likely when the environment is more heterogeneous and firms are closer to the technology frontier, particularly in high-tech sectors, though the age results appear less robust.

\subsection{Decentralization in Britain}

We complement our evidence from the French micro datasets with an analysis of the British Workplace Employee Relations Survey (WERS98). The French Enquête Reponse was modeled on WERS and we use the 1998 wave to match the year used in ER. The WERS cross-section does not have a question on autonomy over investment decisions, but there is a similar question on the establishment manager's autonomy on employment decisions. Senior managers were

\footnotetext{
${ }^{40}$ Although the ER data is that the establishment level, the regressions in Table 6 use firm age to make the results comparable to those in Tables 1-5. The young firm dummy remains positive and significant if we also condition on establishment age.

${ }^{41}$ The weakness of the frontier growth term is related to the higher correlation between the productivity growth terms and our heterogeneity variable (recall that heterogeneity is defined here as the decile ratio of productivity growth rates in the firm's four-digit industry). In column (7) if we drop the heterogeneity and firm productivity terms, the marginal effect of frontier productivity growth increases to -0.064 with a standard error of 0.031. If we use the full specification of column (7), but just include two-digit (instead of the usual three-digit) industry dummies, the marginal effect of frontier growth becomes -0.074 with a standard error of 0.038 .
} 
asked whether they were able to take decisions on staff recruiting without consulting company headquarters. Our WERS sample is further restricted because we are only able to match manufacturing establishments to industry-level information (unfortunately Census information on non-manufacturing is not available over the necessary time period).$^{42}$ Finally, we are unable to condition on the rich-set of firm level covariates as in the French data, because confidentiality restrictions limit the data that can matched in at the firm level (such as firm-level output, capital or age).

The results are presented in Table 7. Column (1) includes the first measure of heterogeneity (the ratio of the 95 th percentile to the 5th percentile of the productivity growth rates in the four-digit industry) with only a full set of three-digit industry dummies. Heterogeneity is positively and significantly associated with decentralization at the $5 \%$ level. The next column performs the same exercise for the 90-10, the relationship is still positive and significant at the $10 \%$ level. Column (3) includes the frontier growth term which is negatively signed as we would expect from the theory, but insignificant. The fourth column includes the establishment age dummies. These are insignificant and show no clear pattern (possibly because in this dataset we only have establishment age rather than firm age).

The fifth and sixth columns include all the covariates. There appears to be some evidence that firms facing less competition are significantly less likely to decentralize. More importantly, the heterogeneity terms remain positively and significantly associated with the probability of decentralization using either the 90-10 (column (5)) or the 95-5 (column (6)). The frontier term enters negatively in the regressions in both columns and is significant at the $5 \%$ level. Both of these findings are consistent with the theory and the results we presented from the French datasets, even though they are taken from a different dataset from a different country.

\subsection{Interpreting the Competition Effects}

In addition to the main predictions of our theory in Section 3, the empirical results presented so far also show a robust and negative association of competition and decentralization. Although competition was not a variable we originally considered in our model, these results made us reconsider whether there are natural reasons for competition to affect decentralization.

One of the effects of competition would be similar to the heterogeneity/homogeneity variables. Firms with more competitors would learn from the experience of their competitors. However, this effect is the opposite of that found in Tables 1-7, which indicate that firms in more competitive environments are more, not less, decentralized.

\footnotetext{
${ }^{42}$ Because of the smaller sample size in the UK, the sample split into high-tech versus low-tech industries and the IV specifications yield highly imprecise estimates.
} 
A more interesting extension is to allow the value of information to vary across firms and sectors. In particular, greater competition may increase the return to the correct implementation of new technologies, so that firms avoid falling behind their competitors. If so, greater competition will induce the principal to delegate authority to the manager with superior information. Yet another effect of a more competitive environment may be through disciplining the manager; faced with greater competition, managers may be forced to take profit-maximizing decisions more often, thus reducing the conflict of interest between the principal and the manager. This would naturally increase delegation, since delegation becomes more attractive to the principal. We do not present these generalizations here because of space constraints.

\section{Conclusions}

Despite considerable academic and popular interest in the changes in the internal organization of the firm, we are far from a theoretical or an empirical consensus on the determinants of the organizational decisions of firms and on the reasons why there has recently been a significant move towards greater decentralization. In this paper we presented a simple model of the relationship between technology, information and decentralization, and empirically investigated the main predictions of this model using three micro-level datasets. In our model, firms delegate authority to managers, i.e., "decentralize", in order to use the manager's superior information about implementation of new technologies. Because the interests of the manager and the principal are not perfectly aligned, such delegation entails a costly loss of control for the principal. The model predicts that as available public information about the implementation of new technologies increases, firms should become less likely to decentralize, whereas firms dealing with new (frontier) technologies should be more likely to decentralize. We also showed that firms in more heterogeneous environments and young firms are more likely to choose decentralization. These are intuitive, but quite novel, predictions, and have, to the best of our knowledge, never been investigated empirically.

We documented that in all three datasets the correlations are consistent with the predictions of our model. Firms in more heterogeneous environments and those that are closer to the frontier of their industry are more likely to choose decentralization. Moreover, consistent with the predictions of the theory, these results are stronger for firms in high-tech sectors. The results are robust to using UK values to instrument for French heterogeneity and proximity to frontier, alleviating some of the endogeneity concerns. They are also robust to using alternative measures of decentralization and heterogeneity. We also found that younger firms tended to be more likely to decentralize, although this result was less robust when we looked at alternative 
measures of decentralization.

The theory and empirical results taken together suggest that learning and information accumulation may have important effects on the internal organization of firms, and may be especially important for decentralization decisions. It would be interesting to document the same issue using data from other countries, and also investigate whether the relationship between proximity to frontier or heterogeneity and decentralization correspond to the causal effects of the these variables on the internal organization of the firm. Specifying and estimating a more structural model would be a fruitful approach for this purpose. Finally, our approach suggests a natural reason for cross-country differences in the internal organization of firms; we may expect less decentralization in developing countries where most firms use well-established (rather than frontier) technologies. Theoretical and empirical analysis of cross-country patterns of organizational forms and their implications for economic performance is another promising area for future research. 


\section{Appendix A}

\section{A.1 Proofs}

\section{Proof of Lemma 1}

The probability of success for a firm choosing centralization, conditional on action $x_{i, k}$ is:

$$
\begin{aligned}
& \pi\left(0 ; h_{k}^{i} \mid x_{i, k}=L\right)=q\left(h_{k}^{i}\right)(1-\varepsilon)+\left(1-q\left(h_{k}^{i}\right)\right) \varepsilon \\
& \pi\left(0 ; h_{k}^{i} \mid x_{i, k}=R\right)=\left(1-q\left(h_{k}^{i}\right)\right)(1-\varepsilon)+q\left(h_{k}^{i}\right) \varepsilon
\end{aligned}
$$

where $q\left(h_{k}^{i}\right)$ is given by (7). In equation $(15), q\left(h_{k}^{i}\right)(1-\varepsilon)$ is the posterior probability that the reference action is $L$ and that the correct action for the firm coincides with the reference action, whereas $\left(1-q\left(h_{k}^{i}\right)\right) \varepsilon$ is the posterior probability that the reference action is $R$ and that the correct action for the firm differs from the reference action. Equation (16) has a similar form, with $\left(1-q\left(h_{k}^{i}\right)\right)(1-\varepsilon)$ as the posterior probability that the reference action is $R$ and that the correct action for the firm coincides with the reference action and $q\left(h_{k}^{i}\right) \varepsilon$ as the posterior probability that the reference action is $R$ and that the correct action for the firm differs from the reference action.

Thus

$$
\begin{aligned}
\pi\left(0 ; h_{k}^{i}\right) & =\max \left\langle\pi\left(0, h_{k}^{i} \mid x_{i, k}=L\right), \pi\left(0, h_{k}^{i} \mid x_{i, k}=R\right)\right\rangle \\
& =\left\{\begin{array}{cc}
\varepsilon+q\left(h_{k}^{i}\right)(1-2 \varepsilon) & \text { if } q\left(h_{k}^{i}\right) \geq 1 / 2 \\
\varepsilon+\left(1-q\left(h_{k}^{i}\right)\right)(1-2 \varepsilon) & \text { if } q\left(h_{k}^{i}\right)<1 / 2 .
\end{array},\right.
\end{aligned}
$$

establishing the result

\section{Proof of Lemma 2}

(1) To see that $E\left(q_{k}^{i} \mid n_{k}^{i}\right)$ is increasing in $n_{k}^{i}$, let $\left(q_{n}\right)_{k}^{i}$ denote the posterior probability of firm $i$ that $x_{k}^{*}=L$ conditional on a history of length $n$, i.e., $\left(q_{n_{k}^{i}}\right)_{k}^{i} \equiv E\left(q_{k}^{i} \mid n_{k}^{i}\right)$. We need to prove that $\left(q_{n}\right)_{k}^{i}$ is increasing in $n$ when $x_{k}^{*}=L$. First note that $\left(q_{n}\right)_{k}^{i}$ is a sufficient statistic for the history $h_{k}^{i}$. Thus, by the Law of Iterated Expectations, we have

$$
\left(q_{n+1}\right)_{k}^{i}=E\left(\left(q_{n+1}\right)_{k}^{i} \mid\left(q_{n}\right)_{k}^{i}\right)>\left(q_{n}\right)_{k}^{i}
$$

Therefore, it is sufficient to prove that

$$
E\left(\left(q_{n+1}\right)_{k}^{i} \mid\left(q_{n}\right)_{k}^{i}\right)>\left(q_{n}\right)_{k}^{i}
$$

Consider a firm with a posterior $\left(q_{n}\right)_{k}^{i}$ conditional on a sample of $n$ and suppose that it obtains an additional observation, i.e., observes the realization of a $n+1^{\text {st }}$ firm. Since, given $x_{k}^{*}=L, L$ and $R$ will be revealed to be the right choice for the $n+1^{\text {st }}$ firm with respective probabilities $1-\varepsilon$ and $\varepsilon$, Bayes' rule implies that

$$
\left(q_{n+1}\right)_{k}^{i}= \begin{cases}\frac{\left(q_{n}\right)_{k}^{i} \times(1-\varepsilon)}{\left(q_{n}\right)_{k}^{i} \times(1-\varepsilon)+\left(1-\left(q_{n}\right)_{k}^{i}\right) \times \varepsilon} & \text { with prob. } 1-\varepsilon \\ \frac{\left(q_{n}\right)_{k}^{i} \times \varepsilon}{\left(1-\left(q_{n}\right)_{k}^{i}\right) \times(1-\varepsilon)+\left(q_{n}\right)_{k}^{i} \times \varepsilon} & \text { with prob. } \varepsilon\end{cases}
$$


Therefore,

$$
\begin{aligned}
E\left(\left(q_{n+1}\right)_{k}^{i} \mid\left(q_{n}\right)_{k}^{i}\right)= & (1-\varepsilon) \times \frac{\left(q_{n}\right)_{k}^{i} \times(1-\varepsilon)}{\left(q_{n}\right)_{k}^{i} \times(1-\varepsilon)+\left(1-\left(q_{n}\right)_{k}^{i}\right) \times \varepsilon} \\
& +\varepsilon \times \frac{\left(q_{n}\right)_{k}^{i} \times \varepsilon}{\left(1-\left(q_{n}\right)_{k}^{i}\right) \times(1-\varepsilon)+\left(q_{n}\right)_{k}^{i} \times \varepsilon}
\end{aligned}
$$

This implies that

$$
\begin{aligned}
E\left(\left(q_{n+1}\right)_{k}^{i} \mid\left(q_{n}\right)_{k}^{i}\right)- & \left(q_{n}\right)_{k}^{i} \\
& =\frac{\left(1-\left(q_{n}\right)_{k}^{i}\right)^{2}(1-2 \varepsilon)^{2} \times\left(q_{n}\right)_{k}^{i}}{\left(\varepsilon \times\left(q_{n}\right)_{k}^{i}+\left(1-\left(q_{n}\right)_{k}^{i}\right) \times(1-\varepsilon)\right)\left(\left(q_{n}\right)_{k}^{i} \times(1-\varepsilon)+\varepsilon \times\left(1-\left(q_{n}\right)_{k}^{i}\right)\right)} \\
& >0
\end{aligned}
$$

establishing the desired result.

(2) Next, to prove $p \lim _{n_{k}^{i} \longrightarrow \infty} q_{i, k}\left(h_{k}^{i}\right)=1$ note that from the viewpoint of $t=0, q\left(h_{k}^{i}\right)$ is a random variable, since the history $h_{k}^{i}$ is a random vector. We need to show that for almost all histories $q\left(h_{k}^{i}\right)$ will become arbitrarily close to 1 . We will do this by using the Continuous Mapping Theorem (e.g., van der Vaart, 1998, Theorem 2.3). First, when $x_{k}^{*}=L$, by the strong law of large numbers $p \lim _{n_{k} \rightarrow \infty} \tilde{n}_{k}^{i} / n_{k}^{i}=1-\varepsilon$. The Continuous Mapping Theorem then implies that any continuous function, $G\left(\tilde{n}_{k}^{i}, n_{k}^{i}\right)$, converges in probability to $\lim _{n_{k}^{i} \rightarrow \infty} G\left((1-\varepsilon) n_{k}^{i}, n_{k}^{i}\right)$. (7) is such a function, so

$$
p \lim _{n_{k}^{i} \longrightarrow \infty} q_{i, k}\left(h_{k}^{i}\right)=\lim _{n_{k}^{i} \longrightarrow \infty} \frac{1}{1+\left(\frac{\varepsilon}{1-\varepsilon}\right)^{n_{k}^{i}[2(1-\varepsilon)-1]}}=1,
$$

where the last the quality follows from $\varepsilon<1 / 2$.

\section{Proof of Lemma 3}

First, we note that the value of the firm admits a recursive representation, so that for $s^{*} \in \mathcal{S}$ that maximizes (3) with starting productivity $y_{i}$ and corresponding history $h_{k}^{i}$, let this maximum value be $V_{i}\left(y_{i}, h_{k}^{i}\right)$. Then

$$
\begin{gathered}
V_{i}\left(y_{i}, h_{k}^{i}\right)=\max _{d_{i, k} \in\{0,1\}} \mathbb{E}\left[V_{i}\left(y_{i}, h_{k}^{i} \mid d_{i, k}\right) \mid h_{k}^{i}\right], \text { and } \\
V_{i}\left(y_{i}, h_{k}^{i} \mid d_{i, k}\right)= \\
\quad p_{i} \pi\left(d_{i, k} ; h_{k}^{i}\right)\left(\gamma y_{i}+\beta \mathbb{E}\left[V_{i}\left(\gamma y_{i}, h_{k+1}^{i+1}\right) \mid h_{k}^{i}\right]\right) \\
+\left(1-p_{i} \pi\left(d_{i, k} ; h_{k}^{i}\right)\right)\left(y_{i}+\beta \mathbb{E}\left[V_{i}\left(y_{i}, h_{k+1}^{i}\right) \mid h_{k}^{i}\right]\right) .
\end{gathered}
$$

In particular, with probability $p_{i}$, the opportunity to implement the next technology arrives and it is successfully implemented with probability $\pi\left(d_{i, k} ; h_{k}^{i}\right)$. If it is successfully implemented, $y_{i}$ increases to $\gamma y_{i}$, and otherwise it stays at $y_{i}$. Future probabilities of opportunities and success are unaffected by these choices or realizations. The resulting optimal policy $d_{i, k}^{*}$ in this recursive representation is the organizational form induced by $s^{*}$.

To characterize the form of the value function in (17) and the optimal policy $d_{i, k}^{*}$, we guess and verify that $V_{i}\left(y_{i}, h_{k}^{i} \mid d_{i, k}\right)$ takes a linear form, namely

$$
V_{i}\left(y_{i}, h_{k}^{i} \mid d_{i, k}\right)=A_{i}\left(h_{k}^{i} \mid d_{i, k}\right) y_{i}
$$


We then substitute the guess into the value function so as to solve for the unknown coefficient $A_{i}\left(h_{k}^{i} \mid d_{i, k}\right)$. This yields the following recursive equation for $A_{i}$ :

$$
\begin{aligned}
A_{i}\left(h_{k}^{i} \mid d_{i, k}\right)= & p_{i} \pi\left(d_{i, k} ; h_{k}^{i}\right) \gamma+\left(1-p_{i} \pi\left(d_{i, k} ; h_{k}^{i}\right)\right)+ \\
& \beta\left(p_{i} \pi\left(d_{i, k} ; h_{k}^{i}\right) \gamma+\left(1-p_{i} \pi\left(d_{i, k} ; h_{k}^{i}\right)\right)\right) \max _{d_{i, k+1} \in\{0,1\}} \mathbb{E}\left[A_{i}\left(h_{k+1}^{i} \mid d_{i, k+1}\right) \mid h_{k}^{i}\right] .
\end{aligned}
$$

The optimal organizational form is simply that which maximizes $A_{i}\left(h_{k}^{i} \mid d_{i, k}\right)$. This is equivalent, in turn, to choose organization so as to maximize $\pi\left(d_{i, k} ; h_{k}^{i}\right)$ (note that the term $\mathbb{E}\left[A\left(h_{k+1}^{i} \mid d_{i, k+1}\right) \mid h_{k}^{i}\right]$ is outside of the firm's control). Namely, the firm will choose organizational form $d_{i, k}=1$ if $\pi\left(1 ; h_{k}^{i}\right)>$ $\pi\left(0 ; h_{k}^{i}\right)$, and $d_{i, k}=0$ otherwise. Since the program is recursive, we have established that choosing organization period-by-period so as to maximize $\pi\left(d_{i, k} ; h_{k}^{i}\right)$ maximizes the value of the firm.

The second part of the Lemma follows immediately from the previous analysis.

\section{Proof of Proposition 2}

The Proposition will be proved using the following three lemmas (which are themselves proved below).

Lemma 4 For all $n_{k}^{i} \in \mathbb{N}$ and $\tilde{n}_{k}^{i} \in \mathbb{N}$ with $\tilde{n}_{k}^{i} \leq n_{k}^{i}$, we have

$$
\pi\left(0 ;\left(n_{k}^{i}, \tilde{n}_{k}^{i}\right)\right)=\pi\left(0 ;\left(n_{k}^{i}, n_{k}^{i}-\tilde{n}_{k}^{i}\right)\right) .
$$

This lemma states that firms updates their beliefs symmetrically after signals suggesting either L or $\mathrm{R}$ to be the more likely correct action.

Lemma 5 Either $\pi\left(0 ;\left(n_{k}^{i}, \tilde{n}_{k}^{i}\right)\right)<\delta$ for all $\tilde{n}_{k}^{i} \in\left[0, n_{k}^{i}\right]$, or there exists a unique integer, $Q\left(\varepsilon, n_{k}^{i}\right) \in$ $\mathbb{Z}_{+}$, such that

$$
\pi\left(0 ;\left(n_{k}^{i}, \tilde{n}_{k}^{i}\right)\right) \geq \delta \Leftrightarrow\left\{\begin{array}{cc}
\text { either } & \tilde{n}_{k}^{i} \leq Q\left(\varepsilon, n_{k}^{i}\right), \\
\text { or } & \tilde{n}_{k}^{i} \geq n_{k}^{i}-Q\left(\varepsilon, n_{k}^{i}\right) .
\end{array}\right.
$$

In the latter case, $Q\left(\varepsilon, n_{k}^{i}\right) \leq\left(n_{k}^{i}-1\right) / 2$ and $Q\left(\varepsilon, n_{k}^{i}\right)$ is non-increasing in $\varepsilon$.

This lemma states that the posterior that the firm will choose the correct action will be greater than the threshold for decentralization, $\delta$, if the number of successful $L$ actions in the past are either smaller or greater than a specific threshold depending on the integer $Q\left(\varepsilon, n_{k}^{i}\right)$. Finally, we have the following technical result:

\section{Lemma 6 Let}

$$
\chi\left(n_{k}^{i}, \tilde{n}_{k}^{i}, \varepsilon, \bar{Q}\right) \equiv \operatorname{Pr}\left[\tilde{n}_{k}^{i} \leq \bar{Q}\right]+\operatorname{Pr}\left[\tilde{n}_{k}^{i} \geq n_{k}^{i}-\bar{Q}\right]
$$

Then,

$$
\frac{\partial \chi\left(n_{k}^{i}, \tilde{n}_{k}^{i}, \varepsilon, \bar{Q}\right)}{\partial \bar{Q}} \geq 0
$$

and for any $\bar{Q} \leq\left(n_{k}^{i}-1\right) / 2$,

$$
\frac{\partial \chi\left(n_{k}^{i}, \tilde{n}_{k}^{i}, \varepsilon, \bar{Q}\right)}{\partial \varepsilon} \leq 0
$$

Lemmas 4, 5 and 6 prove Proposition 2. In particular, unless $\pi\left(0 ;\left(n_{k}^{i}, \tilde{n}_{k}^{i}\right)\right)<\delta$ for all $\tilde{n}_{k}^{i} \in\left[0, n_{k}^{i}\right]$, we have that

$$
\operatorname{Pr}\left(d_{i, k}^{*}\left(h_{t}^{i}\right)=1\right)=\chi\left(n_{k}^{i}, \tilde{n}_{k}^{i}, \varepsilon, Q\left(\varepsilon, n_{k}^{i}\right)\right) .
$$


By definition,

$$
\frac{d \operatorname{Pr}\left(d_{i, k}^{*}\left(h_{t}^{i}\right)=1\right)}{d \varepsilon}=\left.\frac{\partial \chi\left(n_{k}^{i}, \tilde{n}_{k}^{i}, \varepsilon, Q\left(\varepsilon, n_{k}^{i}\right)\right)}{\partial \varepsilon}\right|_{Q\left(\varepsilon, n_{k}^{i}\right)=\bar{Q}}+\frac{\partial \chi\left(n_{k}^{i}, \tilde{n}_{k}^{i}, \varepsilon, Q\left(\varepsilon, n_{k}^{i}\right)\right)}{\partial Q\left(\varepsilon, n_{k}^{i}\right)} \frac{d Q\left(\varepsilon, n_{k}^{i}\right)}{d \varepsilon} .
$$

Lemma 6 implies that the first term is non-positive and that $\partial \chi\left(n_{k}^{i}, \tilde{n}_{k}^{i}, \varepsilon, \bar{Q}\right) / \partial \bar{Q} \geq 0$, while Lemma 5 establishes that $d Q\left(\varepsilon, n_{k}^{i}\right) / d \varepsilon \leq 0$. Finally, if $\pi\left(0 ;\left(n_{k}^{i}, \tilde{n}_{k}^{i}\right)\right)<\delta$ for all $\tilde{n}_{k}^{i} \in\left[0, n_{k}^{i}\right]$, a change in $\varepsilon$ has no impact on $\operatorname{Pr}\left(d_{i, k}^{*}\left(h_{t}^{i}\right)=1\right)$, which is equal to 0 . This establishes the proposition

Proof of Lemma 4: The equality follows from the assumption that $q_{0}=1 / 2$. More formally, equations (6) and (7) imply that for all $\tilde{n}_{k}^{i} \leq\left(n_{k}^{i}-1\right) / 2$,

$$
\begin{aligned}
\pi\left(0 ;\left(n_{k}^{i}, \tilde{n}_{k}^{i}\right)\right) & =\varepsilon+\left(1-\frac{1}{1+\left(\frac{1-\varepsilon}{\varepsilon}\right)^{n_{k}^{i}-2 \tilde{n}_{k}^{i}}}\right)(1-2 \varepsilon) \\
& =\varepsilon+\frac{1}{1+\left(\frac{1-\varepsilon}{\varepsilon}\right)^{-\left(n_{k}^{i}-2 \tilde{n}_{k}^{i}\right)}}(1-2 \varepsilon)=\pi\left(0 ;\left(n_{k}^{i}, n_{k}^{i}-\tilde{n}_{k}^{i}\right)\right) .
\end{aligned}
$$

The same conclusion follows from applying (6) to the case in which $\tilde{n}_{k}^{i}>\left(n_{k}^{i}-1\right) / 2$.

Proof of Lemma 5: Suppose that there exists $\tilde{n}_{k}^{i} \in\left[0, n_{k}^{i}\right]$ such that $\pi\left(0 ;\left(n_{k}^{i}, \tilde{n}_{k}^{i}\right)\right) \geq \delta$. Let $X\left(\varepsilon, n_{k}^{i}\right) \in \mathbb{R}_{+}$be the unique value of $X$ that solves the following equation:

$$
\tilde{\pi}\left(0 ;\left(n_{k}^{i}, X\right)\right) \equiv \varepsilon+\left(1-\frac{1}{1+\left(\frac{1-\varepsilon}{\varepsilon}\right)^{n_{k}^{i}-2 X}}\right)(1-2 \varepsilon)=\delta .
$$

This equation has a unique solution since, by hypothesis, $\pi\left(0 ;\left(n_{k}^{i}, \tilde{n}_{k}^{i}\right)\right) \geq \delta$ for some $\tilde{n}_{k}^{i} \in\left[0, n_{k}^{i}\right]$; moreover, $\tilde{\pi}\left(0 ;\left(n_{k}^{i}, n_{k}^{i} / 2\right)\right)=1-\varepsilon<\delta$, and the left-hand side is continuous and monotonically decreasing in both $\varepsilon$ and $X$ in the range where $X \in\left(0, n_{k}^{i} / 2\right) .{ }^{43}$ Therefore, there exists a unique $X\left(\varepsilon, n_{k}^{i}\right)$ such that $\tilde{\pi}\left(0 ;\left(n_{k}^{i}, X\left(\varepsilon, n_{k}^{i}\right)\right)\right)=\delta$. Lemma 4 implies that $\tilde{\pi}\left(0 ;\left(n_{k}^{i}, X\left(\varepsilon, n_{k}^{i}\right)\right)\right)=\delta$ if and only if $\tilde{\pi}\left(0 ;\left(n_{k}^{i}, n_{k}^{i}-X\left(\varepsilon, n_{k}^{i}\right)\right)\right)=\delta$. Let $Q\left(\varepsilon, n_{k}^{i}\right) \in \mathbb{Z}_{+}$be the largest integer smaller than $X$, which will be the threshold number of realization of either $\mathrm{L}$ or $\mathrm{R}$ such that $\pi\left(0 ;\left(n_{k}^{i}, \tilde{n}_{k}^{i}\right)\right)>\delta$. More formally, $Q\left(\varepsilon, n_{k}^{i}\right) \equiv \max _{z \in \mathbb{Z}_{+}}\left\{z \leq X\left(\varepsilon, n_{k}^{i}\right)\right\}$. The properties of $X\left(\varepsilon, n_{k}^{i}\right)$ immediately imply that $Q\left(\varepsilon, n_{k}^{i}\right)$ is no larger than $\left(n_{k}^{i}-1\right) / 2$ and is non-increasing in $\varepsilon$

Proof of Lemma 6: Since $\tilde{n}_{k}^{i}$ is the number of successes out of $n_{k}^{i}$ in a Bernoulli trial, then holding $Q$ constant at $\bar{Q}$, we have that

$$
\begin{aligned}
\operatorname{Pr}\left[\tilde{n}_{k}^{i} \leq \bar{Q}\right] & =\sum_{\tilde{n}_{k}^{i}=0}^{\bar{Q}}\left(\begin{array}{c}
n_{k}^{i} \\
\tilde{n}_{k}^{i}
\end{array}\right)(1-\varepsilon)^{\tilde{n}_{k}^{i}} \varepsilon^{n_{k}^{i}-\tilde{n}_{k}^{i}}, \text { and } \\
\operatorname{Pr}\left[\tilde{n}_{k}^{i} \geq 1-\bar{Q}\right] & =\sum_{\tilde{n}_{k}^{i}=n_{k}^{i}-\bar{Q}}^{n_{k}^{i}}\left(\begin{array}{c}
n_{k}^{i} \\
\tilde{n}_{k}^{i}
\end{array}\right)(1-\varepsilon)^{\tilde{n}_{k}^{i}} \varepsilon^{n_{k}^{i}-\tilde{n}_{k}^{i}}, \\
& =\sum_{\tilde{n}_{k}^{i}=0}^{\bar{Q}}\left(\begin{array}{c}
n_{k}^{i} \\
\tilde{n}_{k}^{i}
\end{array}\right) \varepsilon^{\tilde{n}_{k}^{i}}(1-\varepsilon)^{n_{k}^{i}-\tilde{n}_{k}^{i}} .
\end{aligned}
$$

\footnotetext{
${ }^{43}$ To see that $\tilde{\pi}\left(0 ;\left(n_{k}^{i}, X\right)\right)$ is decreasing in $\varepsilon$, let $\zeta\left(n_{k}^{i}, X\right) \equiv\left[1+\left(\frac{1-\varepsilon}{\varepsilon}\right)^{n_{k}^{i}-2 X}\right]^{-1}$. In the range $X \in$ $\left(0, n_{k}^{i} / 2\right)$, we have $\frac{\partial}{\partial \varepsilon} \tilde{\pi}\left(0 ;\left(n_{k}^{i}, X\right)\right)=1-2\left(1-\zeta\left(n_{k}^{i}, X\right)\right)-(1-2 \varepsilon) \frac{\partial \zeta\left(n_{k}^{i}, X\right)}{\partial \varepsilon}$. Since $\zeta\left(n_{k}^{i}, X\right)<1 / 2$ and $\partial \zeta\left(n_{k}^{i}, X\right) / \partial \varepsilon>0, \partial \tilde{\pi}\left(0 ;\left(n_{k}^{i}, X\right)\right) / \partial \varepsilon<0$ follows.
} 
The latter equation implies

$$
\begin{aligned}
\frac{\partial \operatorname{Pr}\left[\tilde{n}_{k}^{i} \geq 1-\bar{Q}\right]}{\partial \varepsilon}= & \sum_{\tilde{n}_{k}^{i}=0}^{\bar{Q}}\left(\begin{array}{c}
n_{k}^{i} \\
\tilde{n}_{k}^{i}
\end{array}\right) \frac{\partial}{\partial \varepsilon}\left(\varepsilon^{\tilde{n}_{k}^{i}}(1-\varepsilon)^{n_{k}^{i}-\tilde{n}_{k}^{i}}\right) \\
= & \left(\begin{array}{c}
n_{k}^{i} \\
0
\end{array}\right)\left(-n_{k}^{i}(1-\varepsilon)^{n_{k}^{i}-1}\right)+ \\
& \left(\begin{array}{c}
n_{k}^{i} \\
1
\end{array}\right)\left((1-\varepsilon)^{n_{k}^{i}-1}-\left(n_{k}^{i}-1\right) \varepsilon(1-\varepsilon)^{n_{k}^{i}-2}\right)+ \\
& \left(\begin{array}{c}
n_{k}^{i} \\
2
\end{array}\right)\left(2 \varepsilon(1-\varepsilon)^{n_{k}^{i}-2}-\left(n_{k}^{i}-2\right) \varepsilon^{2}(1-\varepsilon)^{n_{k}^{i}-3}\right)+ \\
& \left(\begin{array}{c}
. \\
+
\end{array}\right) \\
& \left(\begin{array}{c}
n_{k}^{i} \\
\bar{Q}-1
\end{array}\right)\left((\bar{Q}-1) \varepsilon^{\bar{Q}-2}(1-\varepsilon)^{n_{k}^{i}-\bar{Q}-1}-(n-(\bar{Q}-1)) \varepsilon^{(\bar{Q}-1)}(1-\varepsilon)^{n_{k}^{i}-\bar{Q}}\right)+ \\
& \left(\begin{array}{c}
n_{k}^{i} \\
\bar{Q}
\end{array}\right)\left(\bar{Q} \varepsilon^{\bar{Q}-1}(1-\varepsilon)^{n_{k}^{i}-\bar{Q}}-(n-\bar{Q}) \varepsilon^{\bar{Q}}(1-\varepsilon)^{n_{k}^{i}-\bar{Q}-1}\right)
\end{aligned}
$$

Evaluating these terms and canceling them pairwise, we obtain

$$
\frac{\partial \operatorname{Pr}\left[\tilde{n}_{k}^{i} \geq 1-\bar{Q}\right]}{\partial \varepsilon}=-\left(\begin{array}{c}
n_{k}^{i} \\
\bar{Q}
\end{array}\right)(n-\bar{Q}) \varepsilon^{\bar{Q}}(1-\varepsilon)^{n_{k}^{i}-\bar{Q}-1} .
$$

A similar argument establishes:

$$
\frac{\partial \operatorname{Pr}\left[\tilde{n}_{k}^{i} \leq \bar{Q}\right]}{\partial \varepsilon}=\left(\begin{array}{c}
n_{k}^{i} \\
\bar{Q}
\end{array}\right)(n-\bar{Q})(1-\varepsilon)^{\bar{Q}} \varepsilon^{n_{k}^{i}-\bar{Q}-1} .
$$

Combining these two expressions, we have

$$
\begin{aligned}
\frac{\partial \chi\left(n_{k}^{i}, \tilde{n}_{k}^{i}, \varepsilon, \bar{Q}\right)}{\partial \varepsilon} & =\frac{\partial \operatorname{Pr}\left[\tilde{n}_{k}^{i} \geq 1-\bar{Q}\right]}{\partial \varepsilon}+\frac{\partial \operatorname{Pr}\left[\tilde{n}_{k}^{i} \leq \bar{Q}\right]}{\partial \varepsilon} \\
& =\left(\begin{array}{c}
n_{k}^{i} \\
\bar{Q}
\end{array}\right)(n-\bar{Q})\left((1-\varepsilon)^{\bar{Q}} \varepsilon^{n_{k}^{i}-\bar{Q}-1}-\varepsilon^{\bar{Q}}(1-\varepsilon)^{n_{k}^{i}-\bar{Q}-1}\right) \\
& =\left(\begin{array}{c}
n_{k}^{i} \\
\bar{Q}
\end{array}\right)(n-\bar{Q})(1-\varepsilon)^{n_{k}^{i}-1}\left(\left(\frac{1-\varepsilon}{\varepsilon}\right)^{\bar{Q}}-\left(\frac{1-\varepsilon}{\varepsilon}\right)^{n_{k}^{i}-\bar{Q}-1}\right)<0
\end{aligned}
$$

where the last inequality follows using the facts that $\varepsilon<1 / 2$ and $\bar{Q} \leq\left(n_{k}^{i}-1\right) / 2$

\section{A.2 Analysis with Managerial Contracts}

In this Appendix, we briefly discuss the possibility that firms may use incentive contracts to induce managers to choose the right action. We will show that when $B$ (the benefit accruing to the manager when she chooses her preferred action) is sufficiently large, such incentive contracts will not be optimal. The intuition is that because managers are credit constrained, incentive contracts give the right incentive to managers only by transferring rents to them. If $B$ is large, this is not profitable for the principal.

Let us assume that the principal decides whether to hire the manager before knowing whether that $I_{i}(k, t)=1$. Let us also normalize the outside option of the manager to zero, and recall that the manager is also risk neutral. Given the credit constraints of the manager, the optimal contract takes a simple form: the principal will pay the manager $B y_{i, t-1}$ in case of success. Both when the manager is unsuccessful in the implementation of the new technology and when there is no new technology to be implemented, it is optimal for the principal to pay him zero. This contract will induce the manager 
to choose the right action. It will also meet his participation constraint, since the manager will receive $B y_{i, t-1}$ with probability $p_{i} \delta>0$.

The alternative is to pay the manager zero irrespective of success, and let him choose his preferred action. This contract also meets the manager's participation constraint, since he derives private benefits from the implementation of the project. This option was the one analyzed in the text. Since the issue of whether there is delegation or not is only interesting in the case when there is a technology to be implemented, let us focus on time $t$ such . We then have:

Proposition 4 Suppose that $B>\frac{(\gamma-1)(1-\delta)}{1-\beta p_{i} \gamma}$ and that $I_{i}(k, t)=1$. Then, for any history $h_{k}^{i} \in \mathcal{H}_{k}^{t}$, the optimal strategy for the principal of firm $i$ is not to offer an incentive contract to the manager.

Proof. Let $d_{i, k}=2$ denote firm $i$ 's decision to delegate control with full compensation to the manager for choosing the profit-maximizing action at date $t$ on technology $k$ when $I_{i}(k, t)=1$. The value of the decentralized firm offering the manager an incentive contract is

$$
\begin{aligned}
V_{i}\left(y_{i}, h_{k}^{i} \mid 2\right)= & p_{i}\left[(\gamma-B) y_{i}+\beta \mathbb{E}\left[V_{i}\left(\gamma y_{i}, h_{k+1}^{i}\right) \mid h_{k}^{i}\right]\right] \\
& +\left(1-p_{i}\right)\left\{y_{i}+\beta \mathbb{E}\left[V_{i}\left(y_{i}, h_{k+1}^{i}\right) \mid h_{k}^{i}\right]\right] .
\end{aligned}
$$

Solving this functional equation leads to $V_{i}\left(y_{i}, h_{k}^{i} \mid 2\right)=A_{i}\left(h_{k}^{i} \mid 2\right) y_{i}$, where:

$$
\begin{aligned}
A_{i}\left(h_{k}^{i} \mid 2\right)= & {\left[p_{i}(\gamma-B)+1-p_{i}\right]+} \\
& \beta\left[p_{i} \gamma+1-p_{i}\right] \max _{d_{i, k+1} \in\{0,1,2\}} \mathbb{E}\left[A_{i}\left(h_{k+1}^{i} \mid d_{i, k+1}\right) \mid h_{k}^{i}\right] .
\end{aligned}
$$

Instead, the value of a decentralized firm offering the manager a flat wage is $V_{i}\left(y_{i}, h_{k}^{t} \mid 1\right)=A_{i}\left(h_{k}^{t} \mid 1\right) y_{i}$, where

$$
\begin{aligned}
A_{i}\left(h_{k}^{i} \mid 1\right)= & {\left[p_{i}(\delta \gamma+(1-\delta))+1-p_{i}\right] } \\
& +\beta\left[p_{i}(\delta \gamma+(1-\delta))+1-p_{i}\right] \max _{d_{i, k+1} \in\{0,1,2\}} \mathbb{E}\left[A_{i}\left(h_{k+1}^{i} \mid d_{i, k+1}\right) \mid h_{k}^{i}\right] .
\end{aligned}
$$

Which of the two regimes yields a larger value to the firm depends on whether $A_{i}\left(h_{k}^{i} \mid 1\right)$ is larger or smaller than $A_{i}\left(h_{k}^{i} \mid 2\right)$. To establish when this is the case, note that

$$
\begin{aligned}
A_{i}\left(h_{k}^{i} \mid 1\right) & >A_{i}\left(h_{k}^{i} \mid 2\right) \Leftrightarrow \\
B & >(\gamma-1)(1-\delta)\left(1+\beta \max _{d_{i, k+1} \in\{0,1,2\}} \mathbb{E}\left[A_{i}\left(h_{k+1}^{i} \mid d_{i, k+1}\right) \mid h_{k}^{i}\right]\right) .
\end{aligned}
$$

An upper bound to the future value of the firm can be calculated by assuming that, from period $(t+1)$ onwards, the firm will innovate successfully whenever a new technology opportunity arises, which takes place with probability $p_{i}$, and will pay no managerial wage. This yields

$$
\max _{d_{i, k+1} \in\{0,1,2\}} \mathbb{E}\left[A_{i}\left(h_{k+1}^{i} \mid d_{i, k+1}\right) \mid h_{k}^{i}\right]<\bar{A} \equiv \frac{p_{i} \gamma}{1-\beta p_{i} \gamma} .
$$

Thus, substituting $\max _{d_{i, k+1} \in\{0,1,2\}} \mathbb{E}\left[A_{i}\left(h_{k+1}^{i} \mid d_{i, k+1}\right) \mid h_{k}^{i}\right]$ by $\bar{A}$ we obtain the sufficient condition

$$
B>\frac{(\gamma-1)(1-\delta)}{1-\beta p_{i} \gamma} \Rightarrow A_{i}\left(h_{k}^{i} \mid 1\right)>A_{i}\left(h_{k}^{i} \mid 2\right)
$$

for incentive contracts not to be profitable for the principal. 


\section{References}

[1] Acemoglu, Daron, and Zilibotti, Fabrizio (1999), "Information Accumulation in Development," Journal of Economic Growth, 4, 5-38.

[2] Aghion, Philippe, and Tirole, Jean (1997), "Formal and Real Authority in Organizations," Journal of Political Economy, 105, 1-29.

[3] Aubert, Patrick, Caroli, Eve, and Roger, Muriel (2004), "New Technologies, Workplace Organization and the Structure of the Workforce: Firm-Level Evidence," Economic Journal, forthcoming.

[4] Askenazy, Philippe, Thesmar, David, and Thoenig, Mathias (2005), "On the Relation Between Organizational Practices and New Technologies: The Role of (Time Based) Competition", Economic Journal, forthcoming.

[5] Baker, George, Gibbons, Robert, and Murphy, Kevin (1999), "Informal Authority in Organizations," Journal of Law, Economics, and Organization, 15, 56-73.

[6] Baker, George, and Hubbard, Thomas (2003), "Make Versus Buy In Trucking: Asset Ownership, Job Design and Information", American Economic Review, 93, 551-72.

[7] Baker, George, and Hubbard, Thomas (2004), "Contractibility and Asset Ownership: On Board Computers and Governance in US Trucking," Quarterly Journal of Economics, 119, 1443-79.

[8] Baron, David, and Besanko, David (1992), "Information, Control, and Organizational Structure", Journal of Economics and Management Strategy, 1, 237-275.

[9] Billingsley, Patrick (1995, 1986), Probability and Measure, New York: Wiley and Sons.

[10] Black, Sandra, and Lynch, Lisa (2001), "How to Compete: The Impact of Workplace Practices and Information Technology on Productivity," Review of Economics and Statistics, 83, 434-445.

[11] Bloom, Nicholas, Schankerman, Mark, and Van Reenen, John (2004), "Technological Spillovers and Product Market Rivalry", Centre for Economic Performance Discussion Paper, 675.

[12] Bolton, Patrick, and Dewatripont, Mathias (1994), "The Firm as a Communication Network," Quarterly Journal of Economics, 109, 809-839.

[13] Bouwens, Jan, and Van Lent, Laurence (2004), "Assessing the performance of profit center managers," mimeo, University of Tilburg.

[14] Bresnahan, Timothy, Brynjolfsson, Erik, and Hitt, Lorin (2002), "Information Technology, Workplace Organization and the Demand for Skilled Labor: Firm-level Evidence," Quarterly Journal of Economics, 117, 339-376.

[15] Caroli, Eve, and Van Reenen, John, (2001), "Skill Biased Organizational Change," Quarterly Journal of Economics, 116, 1448-1492.

[16] Colombo, Massimo, and Delmastro, Marco (2004), "Delegation of Authority in business organizations: An empirical test," Journal of Industrial Economics, 52, 53-80.

[17] Crépon, Bruno, Heckel, Thomas, and Riedinger, Nicolas (2004), "Computerization, Organizational Change and Productivity: Microeconometric Evidence for France," mimeo, INSEE. 
[18] Cully, Mark, O’Reilly, Andrew, Woodland, Stephen, Dix, Gill (1999), Britain at Work, London: Routledge.

[19] Dearden, John (1987), "Measuring profit center managers," Harvard Business Review, 65, 84-88.

[20] Dessein, Wouter (2002), "Authority and Communication in Organizations," Review of Economic Studies, 69, 811-838.

[21] Garicano, Luis (2000), "Hierarchies and the Organization of Knowledge in Production," Journal of Political Economy, 108, 874-904.

[22] Geanakoplos, John, and Milgrom, Paul (1991), "A Theory of Hierarchies Based on Limited Managerial Attention," Journal of the Japanese and International Economies, 5, 205-225.

[23] Greenan, Nathalie, and Mairesse, Jacques, (1999), "Organizational Change in French Manufacturing: What Do We Learn From Firm Representatives and From Their Employees," NBER Working Paper, 7285.

[24] Hart, Oliver, and Moore, John (2005), "On the Design of Hierarchies: Coordination versus Specialization," Journal of Political Economy, 113, 675-702.

[25] Hausman, Jerry, and Taylor, William (1981), "Panel data and unobservable individual effects," Econometrica, 49, 1377-1398.

[26] Ichniowski, Casey, Prenushi, Giovanna, and Shaw, Kathryn (1997), "The effects of Human Resource Management: A Study of Steel Finishing Lines," American Economic Review, 87, 291-313.

[27] Jaffe, Adam (1986), "Technological Opportunity and Spillovers from Firms' Patents, Profit, and Market Value," American Economic Review, 76, 984-1001.

[28] Janod, Véronique (2002), "Changements Organisationnel, Qualification et Croissance," PhD Dissertation, Université Paris 1 Panthéon-Sorbonne.

[29] Janod, Véronique, and Saint-Martin, Anne (2004), "Measuring Work Reorganization and its Impact on Firm Performance: an Estimate on French Manufacturing Firms over 19951999," Labour Economics, 11, 785-798.

[30] Keller, Wolfgang (2002), "Geographic localization of international technology diffusion," American Economic Review, 92, 120-142.

[31] Lee, Lung-Fei (1981), "Simultaneous equation models with discrete and censored dependent variables," in Manski, Charles, and McFadden, Daniel (eds), Structural Analysis of Discrete Data and Econometric Applications, Cambridge MA: MIT Press, 346-364.

[32] Lerner, Josh, and Merges, Robert (1998), "The Control of Biotechnological Alliances: An Empirical Examination of the Biotechnology Industry," Journal of Industrial Economics, 46, 125-156.

[33] McKinsey Global Institute (2002), "Reaching Higher Productivity Growth in France and Germany," MGI Reports, http://www.mckinsey.com/knowledge/mgi/europe/index.asp

[34] Melumad, Nahum, Mookherjee, Dilip, and Reichelstein, Stefan (1995), "Hierarchical Decentralization of Incentive Contracts," Rand Journal of Economics, 26, 654-672.

[35] Merchant, Kenneth (1989), Rewarding Results: Motivating Profit Center Managers, Cambridge: Harvard Business School Series in Accounting and Control. 
[36] Milgrom, Paul, and Roberts, John (1992), Economics, Organization and Management, New Jersey: Prentice Hall.

[37] Mookherjee, Dilip (2005), "Decentralization, Hierarchies and Incentives: A Mechanism Design Approach," Journal of Economic Literature, forthcoming.

[38] Nickell, Stephen (1996), "Competition and Corporate Performance," Journal of Political Economy, 104, 724-746.

[39] Nickell, Stephen, Nicolitsas, Daphne, and Patterson, Malcolm (2001), "Does Doing Badly Encourage Managerial Innovation?," Oxford Bulletin of Economics and Statistics, 3, 5-28.

[40] Radner, Roy (1993), "The Organization of Decentralized Information Processing," Econometrica, 61, 1109-1146.

[41] Radner, Roy, and Van Zandt, Timothy (1992), "Information Processing in Firms and Returns to Scale," Annales d'Economie et de Statistique, 25/26, 265-298.

[42] Rajan, Raghuram, and Zingales, Luigi (2001), "The Firm as a Dedicated Hierarchy: A Theory of the Origin and Growth of Firms," Quarterly Journal of Economics, 116, 805-851.

[43] Rajan, Raghuram, and Wulf, Julie (2005), "The Flattening Firm: Evidence from Panel Data on the Changing Nature of Corporate Hierarchies," Review of Economics and Statistics, forthcoming.

[44] Rivers, Douglas, and Vuong, Quang (1988), "Limited Information Estimators and Exogeneity Tests for Simultaneous Probit Models," Journal of Econometrics, 39, 347-366.

[45] Sah, Raaj, and Stiglitz, Joseph (1986), "The Architecture of Economic Systems: Hierarchies and Polyarchies," American Economic Review, 76, 716-727.

[46] van der Vaart, Aad (1998), Asymptotic Statistics, Cambridge: Cambridge University Press.

[47] White, Halbert (1980), "A Heteroskedasticity - Consistent Covariance Matrix Estimator and a Direct Test for Heteroskedasticity," Econometrica, 48, 817-838.

[48] Wooldridge, Jeffrey (2002) Econometric Analysis of Cross Section and Panel Data, Cambridge: MIT Press. 
Figure 1: Heterogeneity and decentralization

Decentralization to Profit Centers (COI)

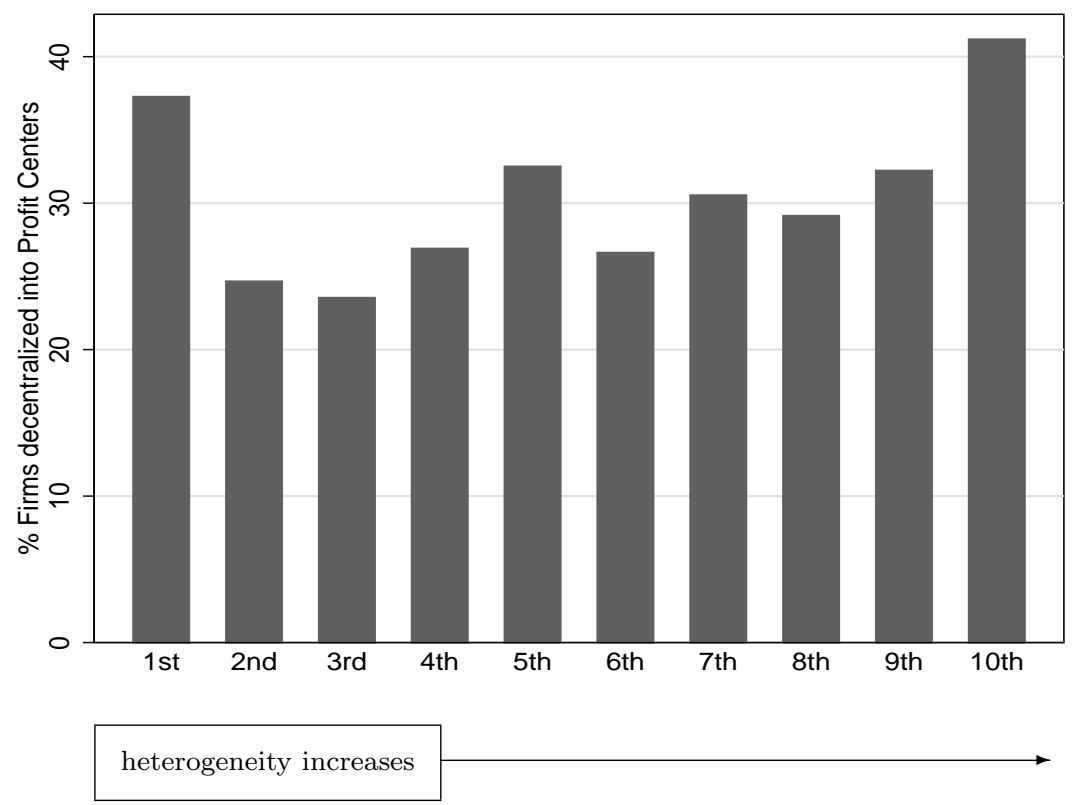

NOTES: The X-axis divides all firms into deciles of heterogeneity from the first decile (low heterogeneity) to the tenth decile (high heterogeneity). Heterogeneity is measured by an index of dispersion (the difference of the $90^{\text {th }}$ minus the $10^{\text {th }}$ percentile) of productivity growth between firms in a four digit industry (see text). The Y-axis indicates the proportion of firms that are decentralized into profit centers in the relevant decile group. The sample is the COI sample $(3,570$ French firms in 1997).

Figure 2: Proximity to frontier and decentralization Decentralization to Profit Centers (COI)

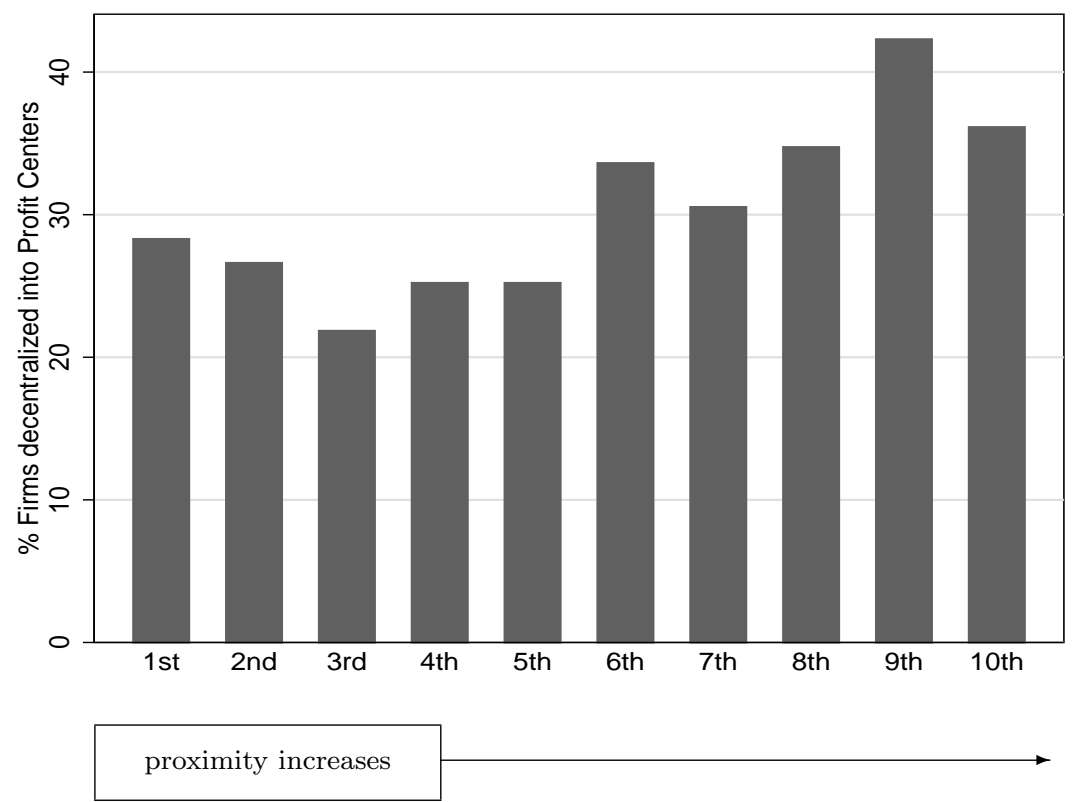

NOTES: The X-axis divides all firms into deciles of proximity to frontier (in terms of value added per hours) from the first decile (low proximity to frontier) to the tenth decile (high proximity to frontier). The Y-axis indicates the proportion of firms that are decentralized into profit centers in the relevant decile group. The sample is the COI sample (3,570 French firms in 1997). 
Figure 3: Age and decentralization

Decentralization to Profit Centres (COI)

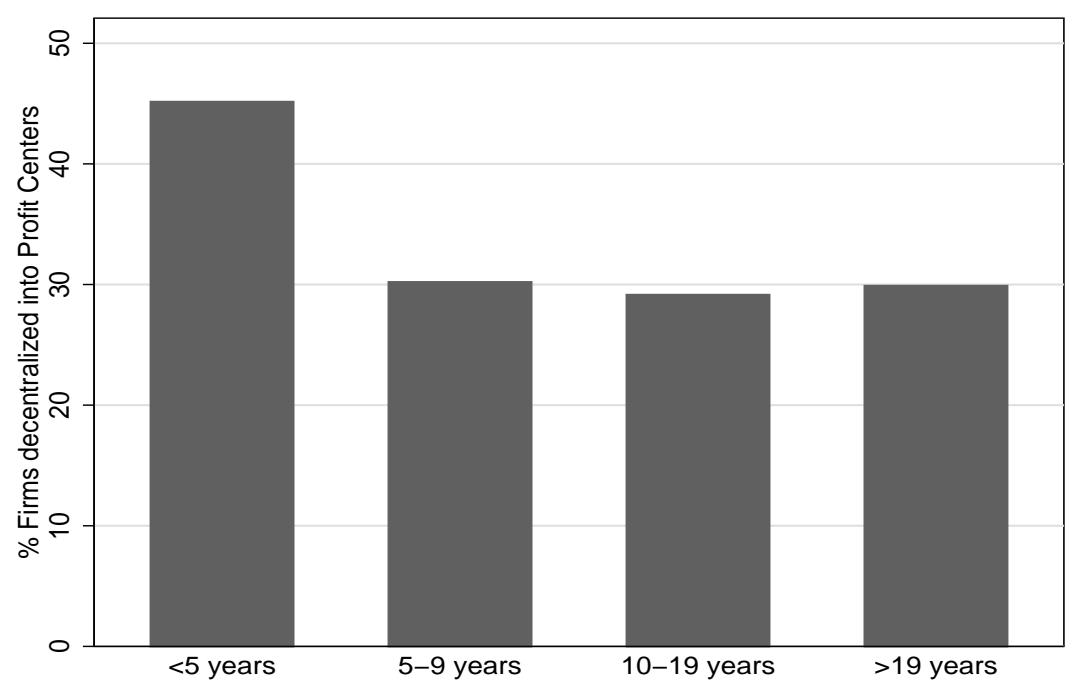

NOTES: Firms are grouped into age bands (dated from the birth of the firm). The Y-axis indicates the proportion of firms that are decentralized into profit centers in the relevant age group. The sample is the COI sample $(3,570$ French firms in 1997).

Figure 4: Probability of centralization as function of sample size

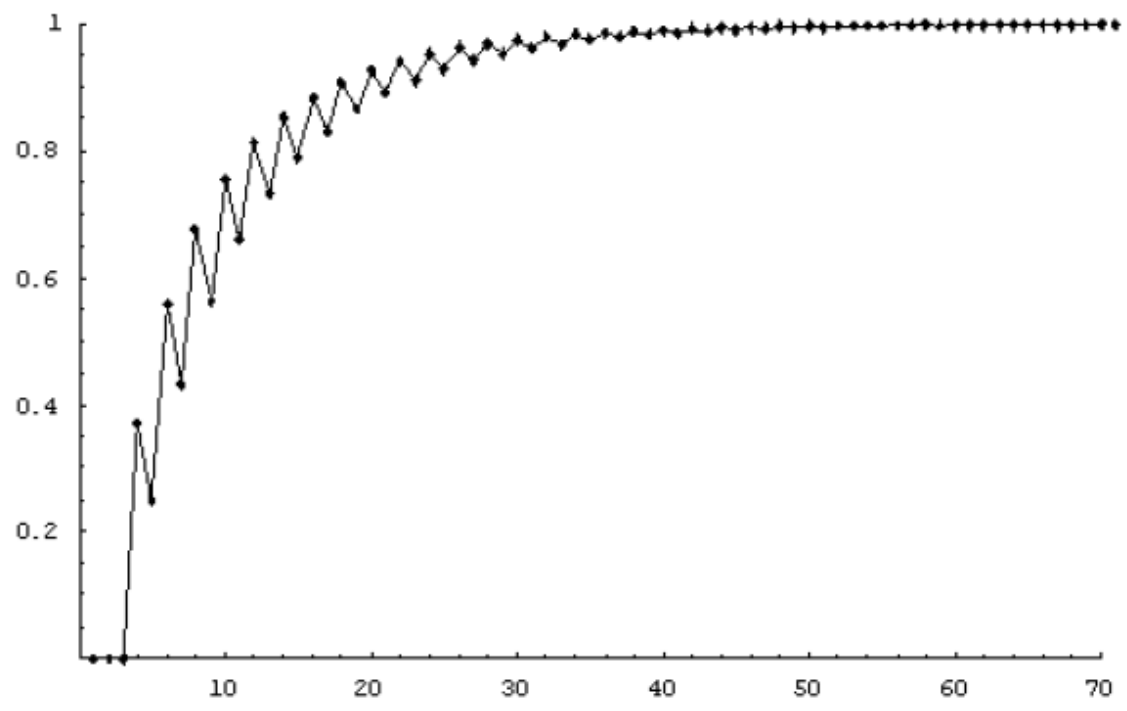

NOTES: The underlying parameters are the following: $\varepsilon=0.3, \delta=0.65$. 


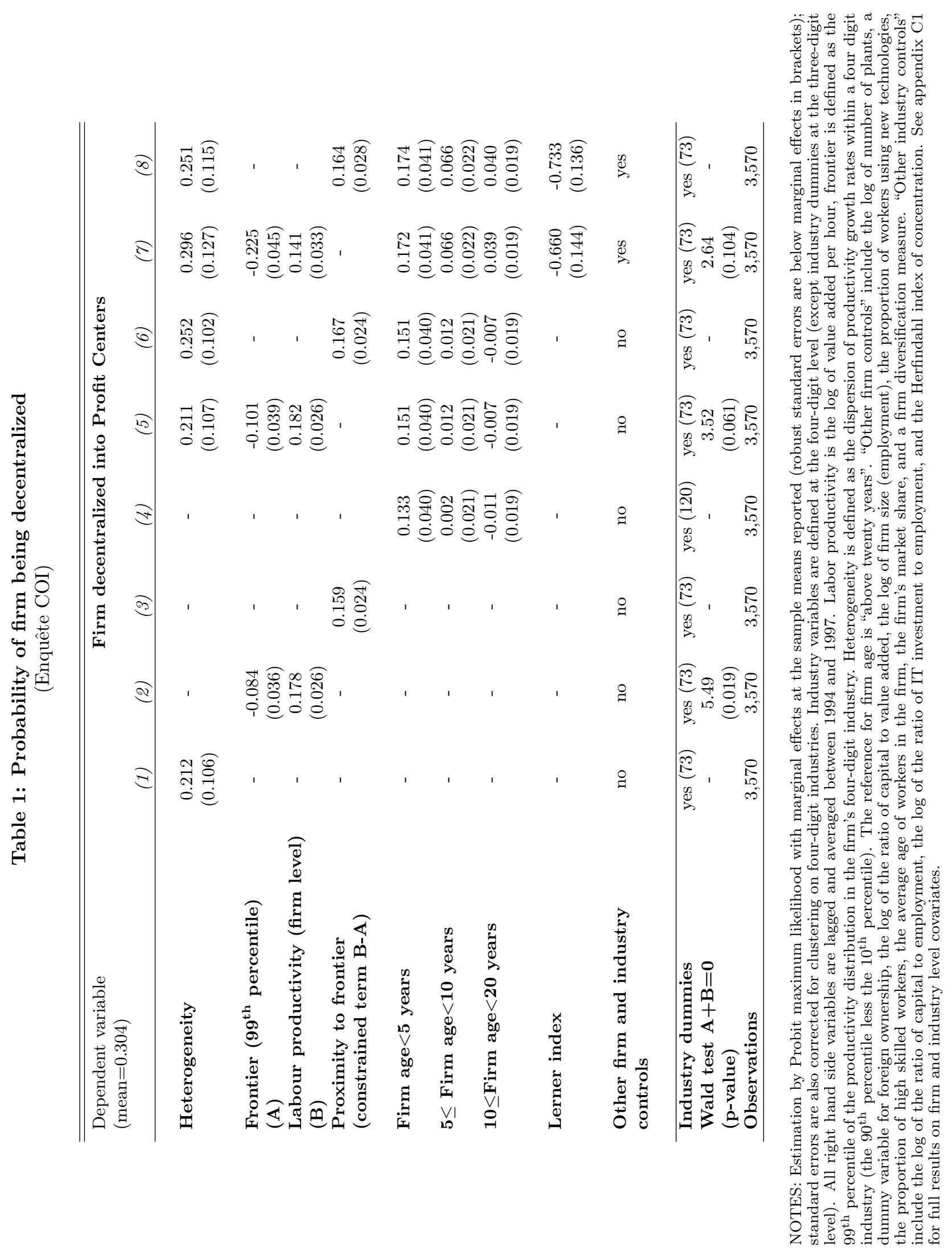




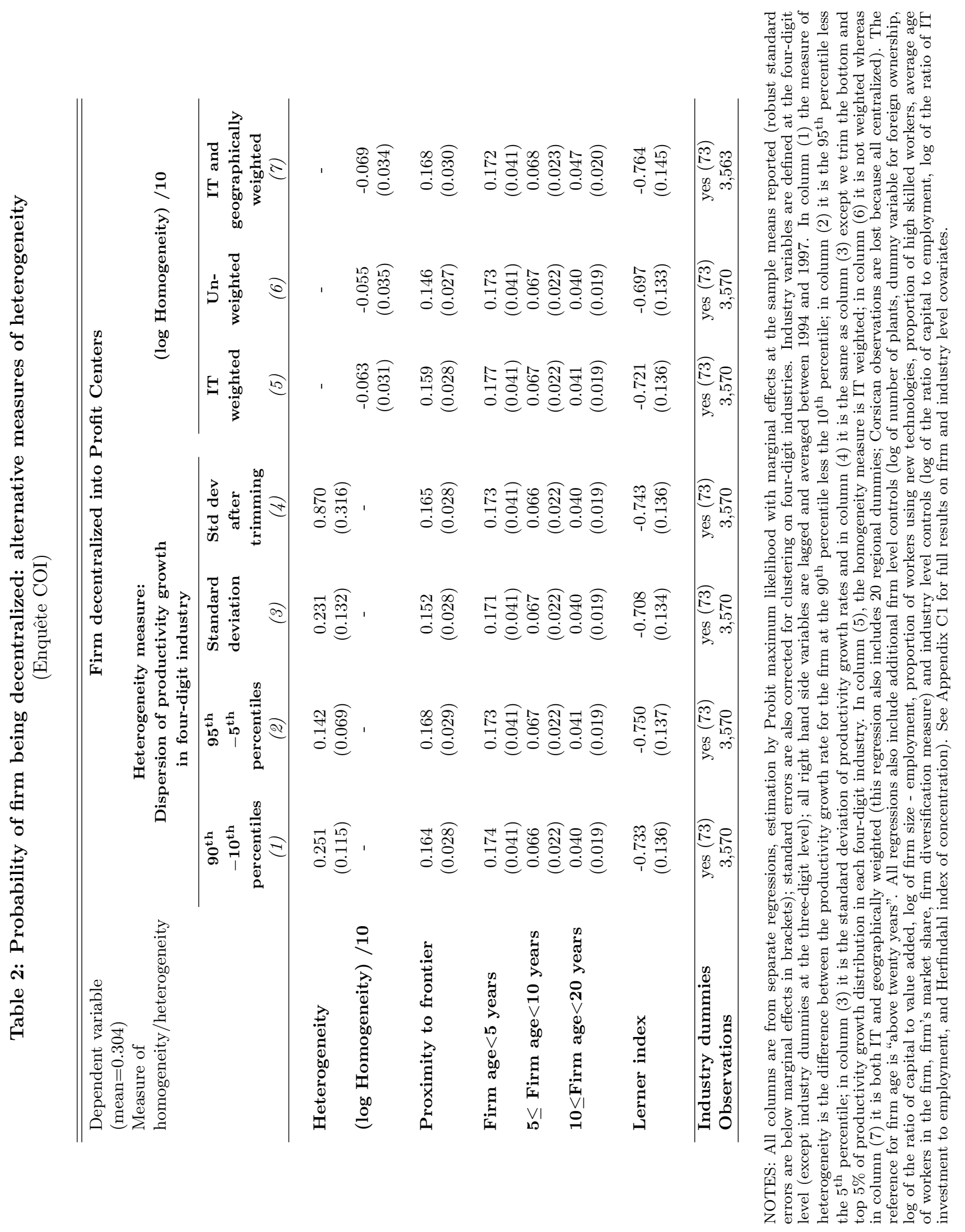


Table 3: Probability of firm being decentralized

broken down into high-tech and low-tech sectors (Enquête COI)

\begin{tabular}{|c|c|c|c|c|c|c|}
\hline \multirow{3}{*}{$\begin{array}{l}\text { Dependent variable } \\
\text { Measure of } \\
\text { heterogeneity/homogeneity }\end{array}$} & \multicolumn{6}{|c|}{ Firm decentralized into Profit Centers } \\
\hline & \multicolumn{3}{|c|}{$\begin{array}{l}\text { Dispersion of productivity } \\
\text { growth in industry }\end{array}$} & \multicolumn{3}{|c|}{$\begin{array}{c}(\log \text { Homogeneity) } / 10 \\
\text { IT weighted }\end{array}$} \\
\hline & $\begin{array}{c}\text { Full } \\
\text { sample } \\
(1)\end{array}$ & $\begin{array}{l}\text { High- } \\
\text { tech } \\
\text { (2) }\end{array}$ & $\begin{array}{c}\text { Low- } \\
\text { tech } \\
(3) \\
\end{array}$ & $\begin{array}{c}\text { Full } \\
\text { sample } \\
(4)\end{array}$ & $\begin{array}{l}\text { High- } \\
\text { tech } \\
(5)\end{array}$ & $\begin{array}{c}\text { Low- } \\
\text { tech } \\
(6)\end{array}$ \\
\hline Heterogeneity & $\begin{array}{c}0.251 \\
(0.115)\end{array}$ & $\begin{array}{c}0.679 \\
(0.189)\end{array}$ & $\begin{array}{l}-0.062 \\
(0.135)\end{array}$ & - & - & - \\
\hline$(\log$ Homogeneity) /10 & - & - & - & $\begin{array}{l}-0.063 \\
(0.031)\end{array}$ & $\begin{array}{l}-0.098 \\
(0.048)\end{array}$ & $\begin{array}{l}-0.019 \\
(0.037)\end{array}$ \\
\hline Proximity to frontier & $\begin{array}{c}0.164 \\
(0.028)\end{array}$ & $\begin{array}{c}0.224 \\
(0.040)\end{array}$ & $\begin{array}{c}0.103 \\
(0.044)\end{array}$ & $\begin{array}{c}0.159 \\
(0.028)\end{array}$ & $\begin{array}{c}0.208 \\
(0.039)\end{array}$ & $\begin{array}{c}0.104 \\
(0.043)\end{array}$ \\
\hline Firm age $<5$ years & $\begin{array}{c}0.174 \\
(0.041)\end{array}$ & $\begin{array}{c}0.215 \\
(0.059)\end{array}$ & $\begin{array}{c}0.122 \\
(0.055)\end{array}$ & $\begin{array}{c}0.177 \\
(0.041)\end{array}$ & $\begin{array}{c}0.214 \\
(0.060)\end{array}$ & $\begin{array}{c}0.123 \\
(0.056)\end{array}$ \\
\hline $5 \leq$ Firm age $<10$ years & $\begin{array}{c}0.066 \\
(0.022)\end{array}$ & $\begin{array}{c}0.069 \\
(0.032)\end{array}$ & $\begin{array}{c}0.049 \\
(0.029)\end{array}$ & $\begin{array}{c}0.067 \\
(0.022)\end{array}$ & $\begin{array}{c}0.068 \\
(0.032)\end{array}$ & $\begin{array}{c}0.049 \\
(0.029)\end{array}$ \\
\hline $10 \leq$ Firm age $<20$ years & $\begin{array}{c}0.040 \\
(0.019)\end{array}$ & $\begin{array}{l}-0.008 \\
(0.027)\end{array}$ & $\begin{array}{c}0.083 \\
(0.028)\end{array}$ & $\begin{array}{c}0.041 \\
(0.019)\end{array}$ & $\begin{array}{l}-0.005 \\
(0.027)\end{array}$ & $\begin{array}{c}0.082 \\
(0.028)\end{array}$ \\
\hline Lerner index & $\begin{array}{l}-0.733 \\
(0.136)\end{array}$ & $\begin{array}{l}-0.947 \\
(0.168)\end{array}$ & $\begin{array}{l}-0.547 \\
(0.218)\end{array}$ & $\begin{array}{l}-0.721 \\
(0.136)\end{array}$ & $\begin{array}{l}-0.895 \\
(0.168)\end{array}$ & $\begin{array}{l}-0.544 \\
(0.218)\end{array}$ \\
\hline Industry dummies & yes $(73)$ & yes $(52)$ & yes $(42)$ & yes $(73)$ & yes $(52)$ & yes $(42)$ \\
\hline Observations & 3,570 & 1,767 & 1,803 & 3,570 & 1,767 & 1,803 \\
\hline $\begin{array}{l}\text { Log-likelihood ratio test (split) } \\
\text { (p-value) }\end{array}$ & \multicolumn{3}{|c|}{$\begin{array}{l}64.40(45) \\
(0.030)\end{array}$} & \multicolumn{3}{|c|}{$\begin{array}{c}62.08(45) \\
(0.046) \\
\end{array}$} \\
\hline Wald test: Heterogeneity (p-val) & \multicolumn{3}{|c|}{$(0.001)$} & \multicolumn{3}{|c|}{-} \\
\hline Wald test: Homogeneity (p-val) & - & \multicolumn{2}{|c|}{-} & - & \multicolumn{2}{|c|}{$(0.197)$} \\
\hline Wald test: Proximity (p-val) & - & \multicolumn{2}{|c|}{$(0.040)$} & - & \multicolumn{2}{|c|}{$(0.075)$} \\
\hline Wald test: Firm age $<\mathbf{5}$ (p-val) & - & \multicolumn{2}{|c|}{$(0.254)$} & - & \multicolumn{2}{|c|}{$(0.264)$} \\
\hline
\end{tabular}

NOTES: Estimation by Probit maximum likelihood with marginal effects at the sample means reported (robust standard errors are below marginal effects in brackets); standard errors are also corrected for clustering on four-digit industries. Industry variables are defined at the four-digit level (except industry dummies at the three-digit level). All right hand side variables are lagged (and averaged between 1994 and 1997). The definition of "high-tech" is if the firm is in an industry which has greater than median IT investment per worker; "low-tech" are all other firms. "Log-likelihood ratio test: Split" tests the equality of all coefficients between high-tech and low-tech sectors. P-values of tests of whether individual marginal effects at the respective (high-tech and low-tech) sample means are significantly different between high-tech and low-tech sectors are given below the log-likelihood ratio test. Heterogeneity is defined as the dispersion of productivity growth rates within a four digit industry (the $90^{\text {th }}$ percentile less the $10^{\text {th }}$ percentile). The reference for firm age is "above twenty years". All regressions also include additional firm level controls (log of number of plants, dummy variable for foreign ownership, log of the ratio of capital to value added, log of firm size - employment, proportion of workers using new technologies, proportion of high skilled workers, average age of workers in the firm, firm's market share, firm diversification measure) and industry level controls (log of the ratio of capital to employment, log of the ratio of IT investment to employment, and Herfindahl index of concentration). 


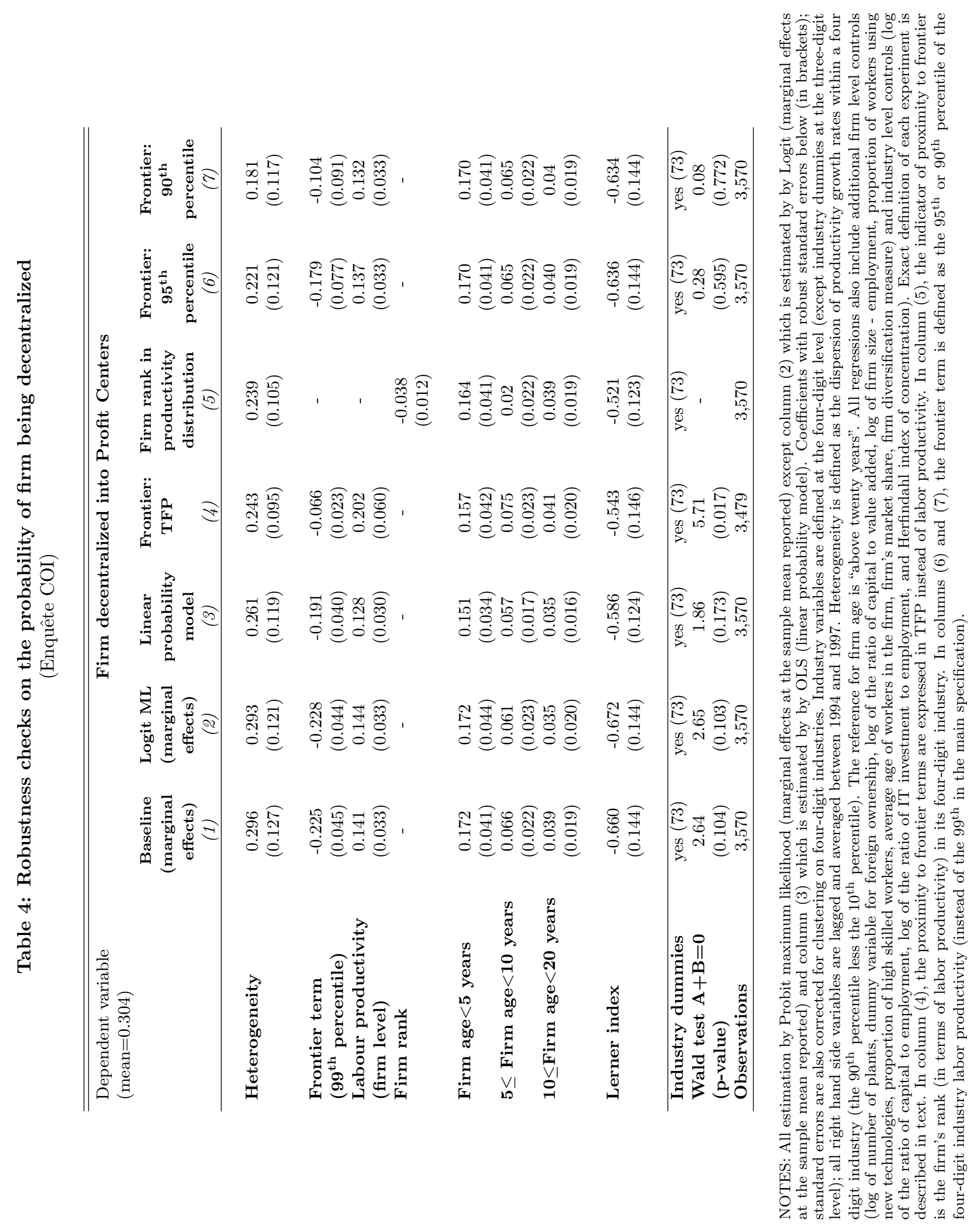




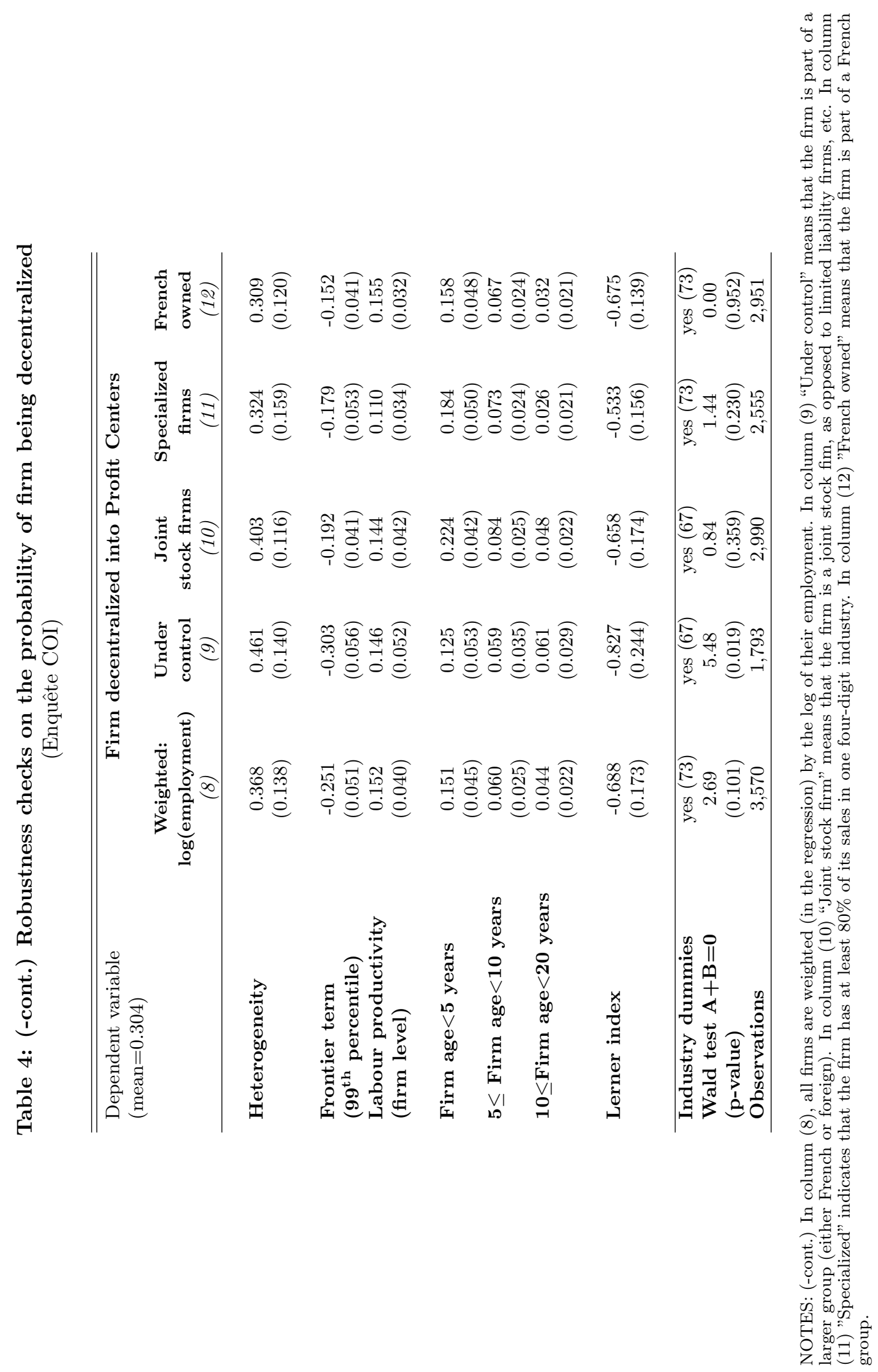




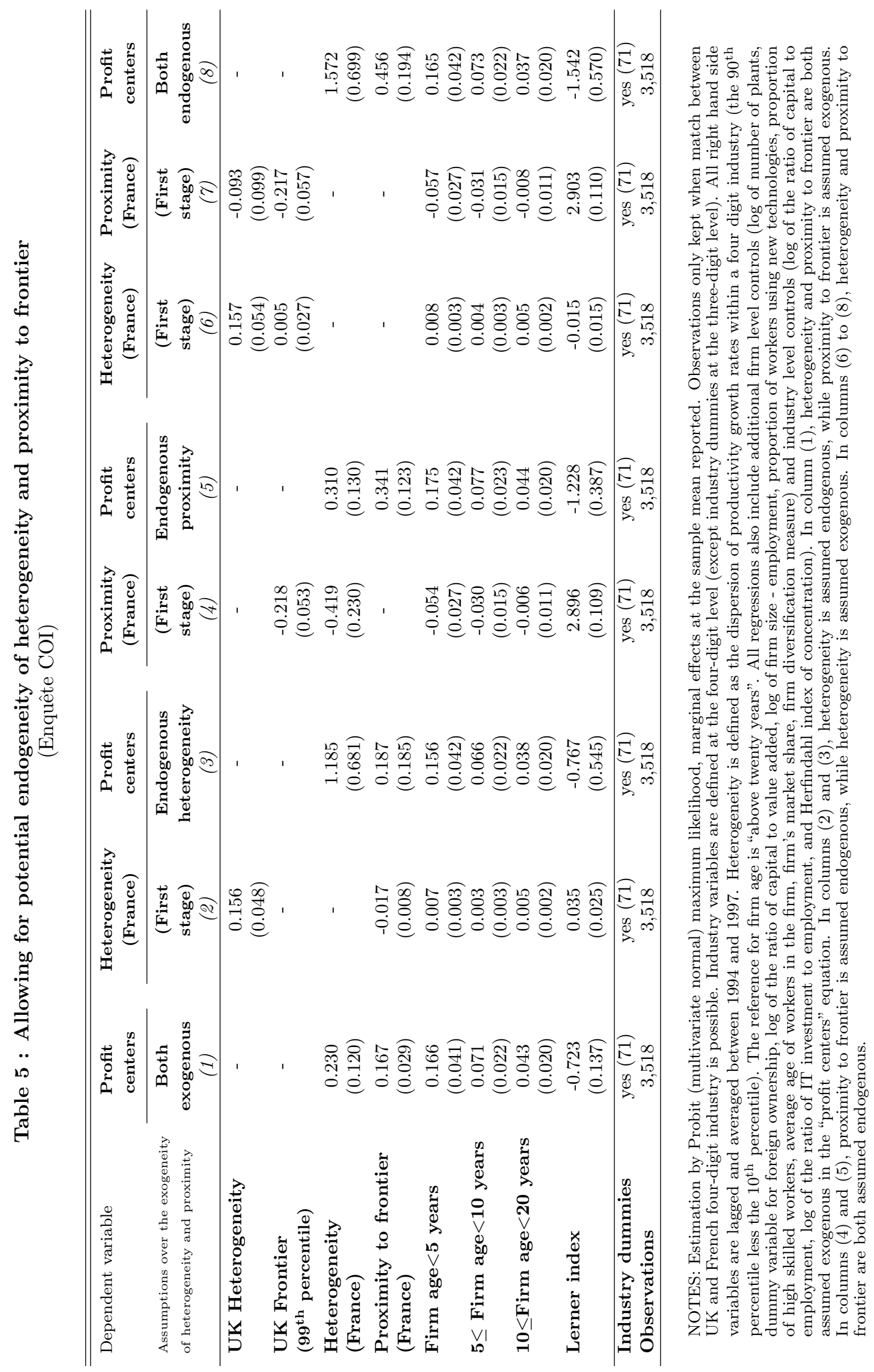




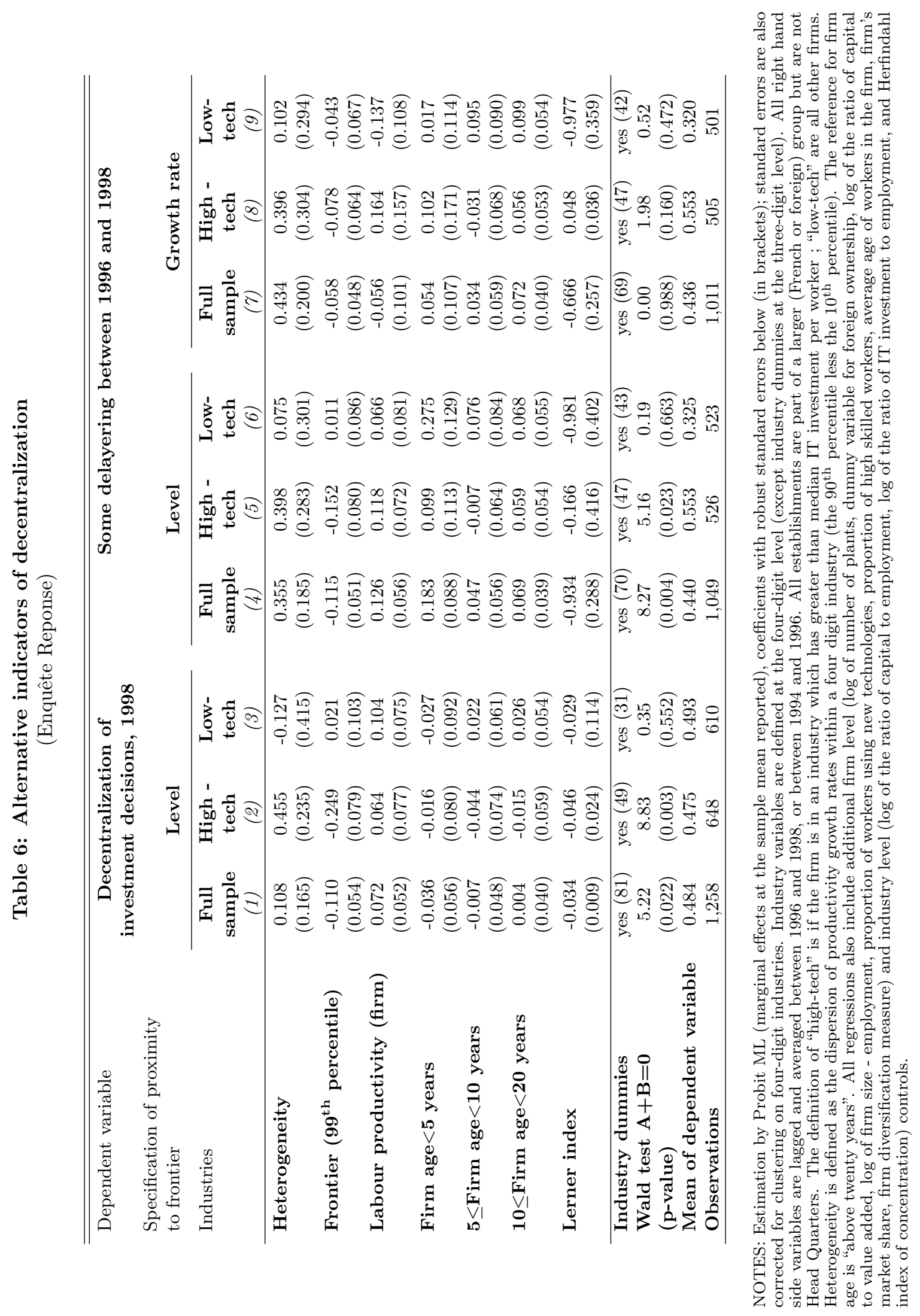


Table 7: Probability of being decentralized (British WERS98)

\begin{tabular}{|c|c|c|c|c|c|c|}
\hline \multirow{2}{*}{$\begin{array}{l}\text { Dependent variable } \\
(\text { mean }=0.805)\end{array}$} & \multicolumn{6}{|c|}{ Decentralization of employment decisions } \\
\hline & (1) & (2) & (3) & (4) & (5) & $(6)$ \\
\hline $\begin{array}{l}\text { Heterogeneity } \\
\left(95^{\text {th }}-5^{\text {th }} \text { percentiles }\right)\end{array}$ & $\begin{array}{c}0.273 \\
(0.130)\end{array}$ & - & - & - & $\begin{array}{c}0.316 \\
(0.129)\end{array}$ & - \\
\hline $\begin{array}{l}\text { Heterogeneity } \\
\left(90^{\text {th }}-10^{\text {th }} \text { percentiles }\right)\end{array}$ & - & $\begin{array}{c}0.540 \\
(0.325)\end{array}$ & - & - & - & $\begin{array}{c}0.659 \\
(0.312)\end{array}$ \\
\hline $\begin{array}{l}\text { Frontier } \\
\left(99^{\text {th }} \text { percentile }\right)\end{array}$ & - & - & $\begin{array}{l}-0.051 \\
(0.073)\end{array}$ & - & $\begin{array}{l}-0.204 \\
(0.073)\end{array}$ & $\begin{array}{l}-0.156 \\
(0.073)\end{array}$ \\
\hline Establishment age $<5$ years & - & - & - & $\begin{array}{l}-0.076 \\
(0.115)\end{array}$ & $\begin{array}{l}-0.099 \\
(0.116)\end{array}$ & $\begin{array}{l}-0.123 \\
(0.114)\end{array}$ \\
\hline $5 \leq$ Est. age $<10$ years & - & - & - & $\begin{array}{l}0.086 \\
(0.081)\end{array}$ & $\begin{array}{c}0.055 \\
(0.089)\end{array}$ & $\begin{array}{c}0.049 \\
(0.089)\end{array}$ \\
\hline $10 \leq$ Est. age $<20$ years & - & - & - & $\begin{array}{l}-0.127 \\
(0.077)\end{array}$ & $\begin{array}{l}-0.164 \\
(0.076)\end{array}$ & $\begin{array}{l}-0.173 \\
(0.075)\end{array}$ \\
\hline Many competitors & - & - & - & - & $\begin{array}{c}0.127 \\
(0.082)\end{array}$ & $\begin{array}{c}0.150 \\
(0.078)\end{array}$ \\
\hline Few competitors & - & - & - & - & $\begin{array}{c}0.210 \\
(0.070)\end{array}$ & $\begin{array}{c}0.228 \\
(0.065)\end{array}$ \\
\hline $\begin{array}{l}\text { Other firm and industry } \\
\text { controls }\end{array}$ & no & no & no & no & yes & yes \\
\hline Industry dummies & yes $(64)$ & yes $(64)$ & yes $(64)$ & yes $(64)$ & yes $(64)$ & yes $(64)$ \\
\hline Observations & 236 & 236 & 236 & 236 & 236 & 236 \\
\hline
\end{tabular}

NOTES: These are data from the 1998 British Workplace Employee Relations Survey (WERS), manufacturing establishments only. Estimation is by OLS, coefficients with robust standard errors below (corrected for clustering by four-digit industry). Dependent variable is a dummy variable indicating whether "Establishment's manager is able to make decisions on which staff to recruit without consulting Head Office". Industry variables defined at the four-digit level (except industry dummies at the three-digit level). Heterogeneity and frontier are averaged between 1994 and 1997. The reference for establishment age is "above twenty years" and the reference for the PMC indicator is "no competitors". All regressions include a control for employment size (current, lagged one year and lagged five years), the proportion of young workers (under 20 years old), the proportion of older workers (aged over 50 years old), the proportion of unskilled manual workers and the proportion of part-time workers. 


\title{
APPENDICES NOT FOR PUBLICATION FOR
}

\author{
Daron Acemoglu, Philippe Aghion, Claire Lelarge, \\ John Van Reenen, and Fabrizio Zilibotti \\ "Technology, Information and the Decentralization of the Firm"
}

\section{Appendix B}

\section{B.1 French Data \\ COI ("Changements Organisationnels et Informatisation," SESSI)}

This is a firm level survey providing information on organization and other firm characteristics conducted in 1997. It covers manufacturing sectors only (4,153 firms). There are several questions on organizational design.

\section{ER (Enquête Reponse 1998; "Relations Professionnelles et Négociations d'Entreprise," DARES)}

The Enquête Reponse is an establishment level survey. This contains information about organizational change between 1996 and 1998. It covers both manufacturing and non-manufacturing sectors and is an updated version of the Reponse 1992 survey used by Caroli and Van Reenen (2001). 2,943 establishments of manufacturing and non-manufacturing sectors were surveyed with senior managers being asked questions about industrial relations, organization and other aspects of performance in 1998.

\section{FUTE files ("Format Unifié Total d'Entreprises," INSEE)}

The FUTE dataset is the key data we use to construct many of the variables used in the paper. FUTE is constructed from the merging of two datasets, the BRN ("Bénéfices Réels Normaux") and the EAE ("Enquêtes Annuelles d'Entreprises"), that are then checked rigorously for consistency at INSEE.

The BRN files consist of firms' balance sheets collected annually by the Direction Générale des Impôts (Fiscal Administration) and provides firm-level accounting information (value added, capital investment, wage bills,employment, etc.). This tax regime is mandatory for the companies that have a level of sales higher than 3.8 million Francs, but can also be also disclosed by smaller firms. These files include around 600,000 firms ${ }^{44}$ in the private non-financial, non-agricultural sectors each year and covers around $80 \%$ of total output in the French economy. The EAE survey is conducted by SESSI (production industries), INSEE (Services and Trade), the Ministry of Agriculture and Ministry of Equipment (Transportation and Construction). The annual survey is mandatory and exhaustive for firms hiring more than 20 workers. It includes a detailed sectoral description of the various activities of each firm surveyed (the amount of each kind of output). ${ }^{45}$

\section{DADS files ("Déclarations Annuelles de Données Sociales")}

The DADS files consists of yearly mandatory employer reports of each worker's gross earnings subject to payroll taxes. Hours are also reported since 1993 (but of good quality only since 1994). These files

\footnotetext{
${ }^{44} 630,593$ firms in 1996 of which 489,783 report a strictly positive number of workers.

45 Question asked :

"Répartir le chiffre d'affaires net hors taxes et les exportations directes de votre entreprise selon les différentes activités conformément aux nomenclatures officielles d'activités et de produits. Le total du chiffre d'affaires net doit correspondre au montant du poste du compte de résultat. Les reventes en l'état de marchandises ou de produits doivent être déclarées dans une ou plusieurs rubriques négoce."
} 
include around 27 million workers each year (27,535,562 in 1996 after some basic cleaning), which we aggregate at the plant $(1,587,157$ plants in 1996) or firm level (1,379,032 firms in 1996) to get information on the workforce structure (age, gender, skill group in terms of hours worked). We also use the total hours series necessary for the measures of productivity underlying the heterogeneity and proximity to the frontier measures (see below).

\section{LIFI Surveys ("Liaisons Financières," INSEE)}

Yearly survey describing the structure of ownership of French firms of the private sector whose financial investments in other firms (participations) are higher than 8,000 KF or having sales above 400,000 KF or a number of workers above 500. Firms cited (under control) are also included in the files. All remaining firms are considered independent.

Even after keeping only firms who are in the COI, BRN, DADS and EAE we are still left with over $90 \%$ of the original COI sample (3,751 observations). The firms who we lose tend to be the smallest firms. We loose a few more observations in our regressions due to missing values on the some of the questions in COI (final sample for regressions is 3,570 observations). For the Reponse sample, we only keep firms that are part of a larger French or foreign group, but that are not the corporate head quarters (final sample for regressions is 1,258 observations).

\section{B.2 Variable Definitions}

The firm and industry level quantitative variables introduced in the regressions are averaged over four years (COI) if available (three years for Reponse, "Delayering"). Unless otherwise indicated all industry variables are at the four-digit NACE level.

\section{B.2.1 Decentralization into Profit Centers}

Our main measure of decentralization is from the COI. Managers were asked:

Is your firm organized into profit centers?

The translation of the French definition used in COI is "Organization in profit centers. A profit center is an enterprise unit that has a margin of budgetary manoeuvre, and therefore some relative autonomy in their choices (usually it has its own accounting system to measure their profit)." 46

We coded the measure of decentralization to be unity if the manager answered "yes" to this question and zero if the answer was "no".

Using the COI we build a measure of decentralization based on the organization of its business units into profit centers. ${ }^{47}$ In practice, once a firm gets beyond a minimal size it faces the choice of retaining central control or allowing some decentralization. Firms are generally organized into business units and different firms make decisions about what degree of responsibility to devolve to the managers of these units. Some firms retain complete command and control at the center, but most create some form of "responsibility centers" for business unit managers. ${ }^{48}$ Business scholars delineate three broad types of responsibility centers (from the most to the least decentralized): profit centers, cost centers and revenue centers. Our key indicator for decentralization is whether the firm is organized primarily into profit centers. As its name suggests, when a firm organizes into profit centers a manager is responsible for the profits of the unit she manages. In general the profit center manager is given considerable autonomy to make decisions on the purchase of assets, hiring of personnel, setting salary and promotion schedules

\footnotetext{
${ }^{46}$ In French: "Votre entreprise utilise-t-elle les dispositifs organisationnels suivants?

- Organisation en centres de profit.

Un centre de profit est une unité de l'entreprise qui a une marge de manœuvre budgétaire, et donc une relative autonomie dans ses choix (souvent, un système de comptabilité en propre, qui lui permet de mesurer son profit)."

${ }^{47}$ This follows Janod (2002) and Janod and Saint-Martin (2004).

${ }^{48}$ For an introduction to responsibility centers in general and profit centers in particular see, for example: http://smccd.net/accounts/nurre/online/chtr12a.htm.
} 
and managing inventories. A manager of a profit center is concerned with all aspects of the business that contribute to profitability. Such a manager keeps track of both revenues and costs with the aim of maximizing profit. As one management specialist puts it:

"The profit center managers frequently know their business better than top management does because they can devote much more of their time to following up developments in their specialized areas. Hence, top level managers usually do not have detailed knowledge of the actions they want particular profit center managers to take, and even direct monitoring of the actions taken, if it were feasible would not ensure profit center managers were acting appropriately." (Motivating Profit Center Managers, Merchant, 1989, p.10)

In contrast to a profit center manager, a cost center manager will have the quantity or quality of output set by someone higher up in the organization. The manager is delegated with some power, however, in order to try and reduce costs. He will be able to decide on some short-run (but not longterm) asset purchases, hire temporary and contract staff (but not permanent employees) and manage inventories. A revenue center manager has the least autonomy of all. ${ }^{49}$ She is told to spend a certain amount of resource and account for revenues but has no (or little) discretion to exceed spending limits. Inventories are managed but staff and investments are not acquired unless he is authorized explicitly to do so.

There are numerous examples from the business literature on the greater autonomy of profit centers. It is well recognized that organizing divisions into profit centers delegates more power to managers, and it is generally agreed that a characteristic of companies that organize divisions into profit centers is that it "allows decision making and power to be delegated effectively". Similarly, the first disadvantage of profit centers is viewed as "loss of overall central control of the company." 50

Although it is possible in principle for a profit center manager to be monitored on profits and yet not be given any powers to affect these profits would seem sub-optimal for the firm (Dearden, 1987, Merchant, 1989, Bouwens and van Lent, 2004). A profit center manager would be held responsible for outcomes that he cannot affect, so this would de-motivate such managers. Some organizations like this probably exist - the only way to know more would be to have subjective questions on the degree to which different profit center managers have greater decision making powers. Even if we had access to such survey information one might doubt its reliability. The advantage of our profit center variable is that it is an objective feature of the firm and does not rely on a manager's subjective statement of his power relative to a senior manager.

In short, we have an indicator equal to unity if the firm is organized into profit centers and a zero otherwise. So the base group contains firms who are organized primarily into responsibility centers with less autonomy (i.e. cost and revenue centers) and those firms who have no responsibility centers at all and maintain command and control. Unfortunately, the data does not allow us to distinguish the latter groups more finely.

\section{B.2.2 Managerial Autonomy to Make Investment Decisions}

In the Enquête Reponse 1998 the establishment's senior manager was asked how much autonomy from headquarters she had to make decisions over investment. ${ }^{51}$ Answers were coded to be one if she answered that she had "full" autonomy or "important" autonomy and coded to zero if she had "limited" or "no" autonomy. This is used as the dependent variable in the last three columns of Table 6. We consider only

\footnotetext{
${ }^{49}$ In fact "revenue center" is rather a misnomer because a notional revenue is assigned by the organization's controller based on activities and transfer prices. "Expense center" is sometimes used as the manager accounts mainly for the expenses incurred.

50 These quotes are taken from the educational web-site:

http://www.aloa.co.uk/members/downloads/PDF\%20Output/costcentres.pdf See also Janod (2002).

${ }^{51}$ In French: "Par rapport au siège ou à la maison mère de l'entreprise ou du groupe, quelle est l'autonomie de votre établissement en matière d'investissement?

Totale / Importante / Limitée / Nulle."
} 
establishments that are part of a wider group (as a single site establishment will not have a separate headquarters).

\section{B.2.3 Delayering}

While COI provides data about the current organization of the firm, the ER dataset provides information on organizational "changes" (i.e., whether a firm became more or less hierarchical) rather than "levels", so we use a variation on equation (9) with these data.

Our preferred measure of delayering is from the Enquête Reponse 1998 where we use the following question: ${ }^{52}$

For any of the following technologies and methods, would you tell us whether it is implemented in your establishment?

- Shortening of the hierarchical line (delayering of an intermediate hierarchical level).

The indicator used is a dummy variable coded to one if the respondent answered "yes" to this question. Case study and econometric evidence suggest that delayering is associated with decentralization (Rajan and Wulf, 2005, Caroli and Van Reenen, 2001).

\section{B.2.4 Proximity to Technological Frontier}

Value-added ( $V A_{i k t}$, FUTE) is defined as sales minus purchases of materials. It is deflated with the value added price index at the two-digit level (NAF36) available from National Accounts (VA at the 1995 prices)

Total hours (HOURS $S_{i k t}$, DADS)

Capital Stock ( $K_{i k t}$, FUTE) is computed from firm level fixed assets. This information is registered at historical cost in the balance sheets. We recover volumes in deflating the initial measure by the investment price index (National Accounts) at the date considered minus an estimated age of capital. This age is calculated as the ratio of depreciated assets over fixed assets multiplied by an average equipment length of life (16 years).

Our Labour Productivity variable is defined as:

$$
y_{i k t}=\ln \left(V A_{i k t}\right)-\ln \left(H O U R S_{i k t}\right)
$$

Our TFP variable is defined as:

$$
T F P_{i k t}=\ln \left(V A_{i k t}\right)-\alpha_{k} \ln \left(H O U R S_{i k t}\right)-\left(1-\alpha_{k}\right) \ln \left(K_{i k t}\right)
$$

Where $\alpha_{k}$ is the wage bill share of value added in the four-digit NACE (we also considered an economy-wide weight of 0.7 ). We drop firms reporting divergent values of total number of employees in the FUTE and in the DADS (values greater than double one way or the other). Industries represented by less than ten firms in the FUTE are also dropped. For each firm (and like other firm level variables introduced in the regressions) the labour productivity and TFP values are averaged over four years if available (three years respectively for Reponse, Delayering).

The industry "frontier" $\left(y_{F_{k} t}\right.$ or $\left.T F P_{F_{k} t}\right)$ is defined as the $99^{\text {th }}$ percentile (or $95^{\text {th }}$, or $90^{\text {th }}$ when specified) of the obtained series at the NACE four-digit level. The constrained term defined as $G A P_{i k t}^{y}=$ $\ln \left(y_{i k t}\right)-\ln \left(y_{F_{k}}\right)$ is a firm level measure of proximity to the technological frontier.

Another alternative measure of distance to frontier is the rank of firms in their industry (the firms are ranked according to their Labour Productivity in the regressions presented, same qualitative results with a ranking based on TFP).

\footnotetext{
52 In French: "Pour les technologies et méthodes suivantes, pouvez-vous nous indiquer si elles sont utilisées dans votre établissement?

- Raccourcissement de ligne hiérarchique (suppression d'un niveau hiérarchique intermédiaire)"

In Reponse, this question about delayering is included in a section entitled "Nous allons maintenant parler de l'organisation du travail". "Delayering'"' is explicitly defined as a "technologie, méthode (de management)".
} 


\section{B.2.5 Heterogeneity Measures}

We use the FUTE to construct $\Delta \ln y_{i k t}$, the firm specific annual productivity growth rate (value added per hour) for all firms. We average this growth rate for up to three years. We then construct the percentiles of the inter-firm productivity growth distribution within each four-digit NACE sector. The 90-10 is $\left(\Delta \ln y_{i k t}\right)^{90}-\left(\Delta \ln y_{i k t}\right)^{10}$ where $\left(\Delta \ln y_{i k t}\right)^{90}$ is the productivity growth at the $90^{\text {th }}$ percentile and $\left(\Delta \ln y_{i k t}\right)^{10}$ is productivity growth at the $10^{\text {th }}$ percentile. Alternative measures of heterogeneity are based on other indicators of dispersion of the same series of firm level labour productivity growth rates: the 95-5 is $\left(\Delta l n y_{i k t}\right)^{95}-\left(\Delta \ln y_{i k t}\right)^{5}$, the standard deviation, the standard deviation after trimming bottom and top $5 \%$ of values in each four-digit industry.

\section{B.2.6 Homogeneity Measures}

We use the FUTE files to construct three types of measures.

A firm $i$ is characterized by its vector of kind of productions (sold, $l$ being one of its markets):

$$
S_{i}=\left(S_{i 1}, \ldots, S_{i l}, \ldots, S_{i L}\right), \quad \text { or in shares : } \quad s_{i}=(\underbrace{\frac{S_{i 1}}{\sum_{h \in \mathcal{L}} S_{i h}}}_{s_{i 1}}, \ldots, \underbrace{\frac{S_{i l}}{\sum_{h \in \mathcal{L}} S_{i h}}}_{s_{i l}}, \ldots, \underbrace{\frac{S_{i L}}{\sum_{h \in \mathcal{L}} S_{i h}}}_{s_{i L}})
$$

where $\mathcal{L}$ refers to the set of industries. Our main index of homogeneity is constructed as

$$
H_{i}^{-}=\frac{\sum_{i^{\prime} \in \mathcal{N}, i^{\prime} \neq i} c_{i i^{\prime}} \cdot I T_{i^{\prime}}}{\sum_{i^{\prime} \in \mathcal{N}, i^{\prime} \neq i} I T_{i^{\prime}}}
$$

for firm $i$ at time $t$, with $\mathcal{N}$ referring to the sample of firms in the FUTE, and $I T_{i}$ refers to the level of IT investment of firm $i,{ }^{53}$ and the closeness measure is

$$
c_{i i^{\prime}}=\frac{\sum_{l \in \mathcal{L}} s_{i l} \cdot s_{i^{\prime} l}}{\sqrt{\left(\sum_{l \in \mathcal{L}} s_{i l}^{2}\right) \cdot\left(\sum_{l \in \mathcal{L}} s_{i^{\prime} l}^{2}\right)}},
$$

Our first alternative measure is an unweighted version of our main measure calculated as:

$$
H_{i}^{A-}=\frac{1}{N-1} \cdot \sum_{i^{\prime} \in \mathcal{N}, i^{\prime} \neq i} c_{i i^{\prime}}
$$

where $N$ is the total number of firms in the set $\mathcal{N}$.

The second alternative measure also takes the geographical dimension into account. A firm $i$ is characterized by its vector of kind of productions in the 21 French administrative regions $g$ :

$$
S_{i}^{R}=(\underbrace{S_{i 11}, \ldots, S_{i l 1}, \ldots, S_{i L 1}}_{\text {region } 1}, \ldots, \underbrace{S_{i 1 g}, \ldots, S_{i l g}, \ldots, S_{i L g}}_{\text {region } g}, \ldots, \underbrace{S_{i 1 G}, \ldots, S_{i l G}, \ldots, S_{i L G}}_{\text {region } G})
$$

This vector is estimated by:

$$
\hat{S}_{i}^{R}=(\underbrace{e_{i 1} \cdot\left(S_{i 1}, \ldots, S_{i l}, \ldots, S_{i L}\right)}_{\text {region } 1}, \ldots, \underbrace{e_{i g} \cdot\left(S_{i 1}, \ldots, S_{i l}, \ldots, S_{i L}\right)}_{\text {region } g}, \ldots, \underbrace{e_{i G} \cdot\left(S_{i 1}, \ldots, S_{i l}, \ldots, S_{i L}\right)}_{\text {region } G})
$$

where $e_{i g}$ is the share of employment of firm $i$ located in region $g$. In shares, we get:

$$
\hat{s}_{i}^{R}=\left(\frac{e_{i 1}}{\sum_{h \in \mathcal{L}} S_{i h}} \cdot\left(S_{i 1}, \ldots, S_{i l}, \ldots, S_{i L}\right), \ldots, \frac{e_{i g}}{\sum_{h \in \mathcal{L}} S_{i h}} \cdot\left(S_{i 1}, \ldots, S_{i l}, \ldots, S_{i L}\right), \ldots, \frac{e_{i G}}{\sum_{h \in \mathcal{L}} S_{i h}} \cdot\left(S_{i 1}, \ldots, S_{i l}, \ldots, S_{i L}\right)\right)
$$

\footnotetext{
${ }^{53}$ Note that the IT investment series (EAE/FUTE) are available in 1996 and 1997.
} 
We then define a new closeness measure between any two firms $i, i^{\prime}$ :

$$
c_{i i^{\prime}}^{R}=\frac{\sum_{l \in \mathcal{L}, g \in \mathcal{R}} s_{i l g} \cdot s_{i^{\prime} l g}}{\sqrt{\left(\sum_{l \in \mathcal{L}, g \in \mathcal{R}} s_{i l g}^{2}\right) \cdot\left(\sum_{l \in \mathcal{L}, g \in \mathcal{R}} s_{i^{\prime} l g}^{2}\right)}} .
$$

where $\mathcal{R}$ refers to the set of regions. $c_{i i^{\prime}}^{R}$ is estimated by (after factoring out the various terms):

$$
\hat{c}_{i i^{\prime}}^{R}=c_{i i^{\prime}} \cdot \frac{\sum_{g \in \mathcal{R}} e_{i g} \cdot e_{i^{\prime} g}}{\sqrt{\left(\sum_{g \in \mathcal{R}} e_{i g}^{2}\right) \cdot\left(\sum_{g \in \mathcal{R}} e_{i^{\prime} g}^{2}\right)}} .
$$

We thus obtain a third IT and geographically weighted measure:

$$
H_{i}^{R-}=\frac{\sum_{i^{\prime} \neq i} \hat{c}_{i i^{\prime}}^{R} \cdot I T_{i^{\prime}}}{\sum_{i^{\prime} \neq i} I T_{i^{\prime}}}
$$

\section{B.2.7 Other Firm Level Variables}

All firm level variables are averaged over four years if available.

Lerner Index: defined as (value added minus labor costs) divided by sales. Sourced from FUTE.

Capital Intensity capital stock divided by value added. Sourced from FUTE.

Firm / Plant age: Information available from the SIRENE dataset (reproduced in the DADS) or from files reporting the yearly creations of firms (Firm Demography Department). Plant age is available in the Reponse survey.

Joint Stock Firms: Indicator of a firm being a Joint Stock Company (as opposed to smaller and less anonymous structures, e.g. limited liability firms). Sourced from FUTE.

Under Control: Indicator of whether a firm is part of a larger (French or foreign) group but is not Head Quarter. Sourced from LIFI.

Foreign Ownership: Indicator of whether a firm is part of a larger foreign group. Sourced from LIFI.

Number of Plants: Number of Plants belonging to each firm (and their region of localization). Sourced from DADS.

Size: The number of workers at the plant level for Reponse and at the firm level for COI. Sourced from DADS.

Skills: Share of hours worked by skilled workers at the firm level. We consider as unskilled: Industrial blue collar workers (CS 67, Ouvriers non qualifiés de type industriel); Craftsmen (CS 68, Ouvriers non qualifiés de type artisanal), Foremen and Supervisors (CS 53, Agents de surveillance), Clerical (CS 55, Employés de commerce), Personnel of the direct services to the private individuals sectors (CS56, Personnels des services directs aux particuliers). Others are considered as "skilled". Sourced from DADS. DADS.

Worker age: Average age of workers at the firm level (weighted by hours worked). Sourced from 
Technology: A pseudo-continuous variable of proportion of workers using micro-computers is constructed from information available in both Reponse 98 (relating to 1998) and COI (1997).

We use the FUTE dataset and the decomposition of the various activities of firms $i$ in terms of amount of each kind of product $l$ produced and sold $\left(S_{i l}\right)$ to construct the following indicators ${ }^{54}$ :

Firm level Market Share:

$$
M S_{i}=\sum_{l} \frac{S_{i l}}{S_{i}} \cdot \frac{S_{i l}}{S_{l}}
$$

Herfindahl Index (Industry level sales concentration):

$$
H_{i}=\sum_{l} \frac{S_{i l}}{S_{i}} . H_{l}, \quad H_{l}=\sum_{i}\left(\frac{S_{i l}}{\sum_{i^{\prime}} S_{i^{\prime} l}}\right)^{2}
$$

This is constructed in the standard way at the industry level $\left(H_{l}\right)$, but note that we weight this measure if a firm operates in more than one market (by a firm's market share in that sector $\left(\frac{S_{i l}}{S_{i}}\right)$, so it has a firm specific component.

Firm level Diversification Indicator:

This simply indicates (the inverse of) the degree to which a firm operates across separate sectors

$$
S P E_{i}=\sum_{l}\left(\frac{S_{i l}}{S_{i}}\right)^{2}
$$

\section{B.2.8 Other Industry Level Information}

All industry level variables are averaged over three years.

Sector Capital Intensity total capital stock in the four-digit industry divided by total number of workers in the industry. Sourced from FUTE.

Sector IT Investment: total IT investment in the four-digit industry divided by total number of workers in industry. Sourced from FUTE.

\section{B.3 UK Data}

\section{B.3.1 Workplace Employee Relations Survey (WERS)}

WERS 1998 is a survey of establishments in Britain conducted in 1998 (there were also surveys in 1980, 1984 and $\left.1990^{55}\right)$. It is described in detail in Cully et al. (1999). In one part of the questionnaire the establishment's senior manager is asked whether she "is able to make decisions without consulting" Head Quarters. Some of these decisions are relatively minor (such as staff appraisal). We focus on whether decisions over staff recruitment can be made by establishment's management without consulting someone higher in the corporate hierarchy as this is a key aspect of decentralized decision making (unfortunately the question on investment decisions used in France was not asked).

\footnotetext{
${ }^{54}$ Notations: $S_{i}=\sum_{l} S_{i l}, \quad S_{l}=\sum_{i} S_{i l}$ where firm $i$ sells an amount $S_{i l}$ of product of type $l$. Note that firms are always $i, i^{\prime}$ and industries $h, l$.

${ }^{55}$ The 1984 and 1990 panels were used by Caroli and Van Reenen (2001). There was also a WERS conducted in 2004 but the four digit industry codes have not yet been released (there are only 12 industry divisions) so we could not use this for the analysis here which required this level of detail.
} 
This question was only asked if the establishment was part of a larger multi-plant firm. Although the question was asked to all establishments we have to focus on manufacturing because the ABI data is only available for services from 1997 onwards so we would not be able to construct a robust measure of heterogeneity. The WERS data cannot be matched at the establishment-level to Census data so we are unable to condition on as rich a set of covariates as we can in France. In particular, we do not have information on value added, profits or capital. Consequently we cannot include measures of the establishment's own productivity or Lerner Index in the regression. WERS does contain basic information on workers demographics (skill, age, female and part-timers) and we condition on these in the regressions (see Table notes). As a proxy for market power we used the question asked to managers whether the establishment faces no competitors, some competitors or many competitors (this is the same as Nickell, 1996).

\section{B.3.2 ABI "Census" Data}

To construct the instrumental variables used in the paper we constructed heterogeneity and GAP terms for each UK four-digit industry to match with its French equivalent. The UK and France share the European Unions' NACE classification system so this was straightforward. The only restriction was that industry averages with cell sizes below 25 are not allowed out of the Office of National Statistics (ONS) so this lead to the loss of a few observations (52 French firms).

Our base dataset is a panel of establishments covering almost all sectors of the UK private sector called the ABI (Annual Business Inquiry). This underlies many of the UK national statistics and is similar in structure to the US Longitudinal Research Database (LRD) being a population sample of large plants and a stratified random sample of smaller plants. The response rates to the ABI are high because it is illegal not to return the forms to the Office of National Statistics (ONS). The ABI contains all the basic information needed to estimate production functions (gross output, labour, materials, investment, etc.). For each firm we constructed value per worker and followed the same rules described for France to calculate heterogeneity (90-10 of productivity growth rates) and the Frontier productivity (99th percentile). The UK data does not contain information on hours so the UK productivity measure is cruder than in France. 
Table B1: "Enquête COI" sample, 1994-1997

\begin{tabular}{|c|c|c|c|c|}
\hline Variable & Source & Mean & Median & St Dev \\
\hline \multicolumn{5}{|c|}{ Heterogeneity measures: Industry level heterogeneity of labour productivity } \\
\hline $90^{\text {th }}-10^{\text {th }}$ percentiles & DADS/FUTE & 0.275 & 0.263 & 0.087 \\
\hline $95^{\text {th }}-5^{\text {th }}$ percentiles & DADS/FUTE & 0.443 & 0.406 & 0.160 \\
\hline Standard deviation & DADS/FUTE & 0.177 & 0.165 & 0.066 \\
\hline Standard deviation after trimming & DADS/FUTE & 0.088 & 0.082 & 0.033 \\
\hline \multicolumn{5}{|c|}{ Homogeneity measure (firm level, IT weighted) } \\
\hline Homogeneity, level & FUTE & $18,821.930$ & $7,564.954$ & $2,699.990$ \\
\hline Homogeneity, normalized & & 0.343 & 0.138 & 0.049 \\
\hline log Homogeneity & & 8.407 & 8.931 & 2.381 \\
\hline \multicolumn{5}{|c|}{ Distance to technological frontier } \\
\hline Firm labour productivity & DADS/FUTE & 0.163 & 0.143 & 0.089 \\
\hline Sectoral $99^{\text {th }}$ perc. labour productivity & DADS/FUTE & 0.508 & 0.397 & 0.315 \\
\hline Proximity to frontier & DADS/FUTE & 0.358 & 0.334 & 0.159 \\
\hline log Proximity to frontier & & -1.125 & -1.096 & 0.457 \\
\hline \multicolumn{5}{|c|}{ Other firm level variables } \\
\hline Profit centers & COI & 0.304 & 0 & 0.216 \\
\hline Foreign ownership & LIFI & 0.173 & 0 & 0.143 \\
\hline Under control & LIFI & 0.502 & 1 & 0.500 \\
\hline Joint-stock companies & FUTE & 0.838 & 1 & 0.369 \\
\hline Number of Plants & DADS & 3.092 & 1 & 8.510 \\
\hline Firm age & SIRENE & 21.658 & 18 & 12.740 \\
\hline Capital Intensity ( / VA) & FUTE & 1.143 & 0.907 & 1.036 \\
\hline Number of Workers (Firm) & FUTE & 323.463 & 88.375 & 677.080 \\
\hline$\%$ workers working with computers & COI & 59.669 & 71.846 & 26.300 \\
\hline Unskilled workers & DADS & 27.004 & 22.623 & 20.202 \\
\hline Age of workers & DADS & 38.870 & 39.010 & 3.403 \\
\hline Lerner index & FUTE & 0.075 & 0.068 & 0.077 \\
\hline Market share & FUTE & 1.732 & 0.404 & 4.171 \\
\hline Herfindahl index & FUTE & 0.049 & 0.031 & 0.057 \\
\hline 1 / Herfindahl Index & FUTE & 53.971 & 31.987 & 69.721 \\
\hline Specialization & FUTE & 0.831 & 0.931 & 0.203 \\
\hline $1 /$ Specialization (diversification) & FUTE & 1.318 & 1.074 & 0.499 \\
\hline \multicolumn{5}{|c|}{ Other industry level variables } \\
\hline Capital intensity ( & FUTE & 404.987 & 289.242 & 369.064 \\
\hline IT investment (per worker) & FUTE & 0.849 & 0.600 & 0.725 \\
\hline
\end{tabular}

NOTES: 3,570 observations. 
Table B2: "Enquête Réponse" sample, 1996-1998

\begin{tabular}{|c|c|c|c|c|}
\hline Variable & Source & Mean & Median & St Dev \\
\hline \multicolumn{5}{|c|}{ Heterogeneity measures: Industry level heterogeneity of labour productivity growth } \\
\hline $90^{\text {th }}-10^{\text {th }}$ percentiles & DADS/FUTE & 0.323 & 0.298 & 0.121 \\
\hline \multicolumn{5}{|c|}{ Distance to technological frontier } \\
\hline Firm labour productivity & DADS/FUTE & 0.190 & 0.154 & 0.228 \\
\hline Sectoral $99^{\text {th }}$ perc. labour productivity & DADS/FUTE & 0.741 & 0.497 & 0.837 \\
\hline Proximity to frontier & DADS/FUTE & 0.323 & 0.297 & 0.171 \\
\hline log Proximity to frontier & & -1.278 & -1.214 & 0.577 \\
\hline \multicolumn{5}{|c|}{ Other plant / firm level variables } \\
\hline Delayering & Reponse & 0.436 & 0 & 0.496 \\
\hline Decentralization of investment decisions & Reponse & 0.484 & 0 & 0.500 \\
\hline Foreign ownership & LIFI & 0.371 & 0 & 0.483 \\
\hline Firm age & SIRENE & 20.586 & 17 & 12.816 \\
\hline Number of plants & DADS & 15.192 & 4 & 27.695 \\
\hline Capital intensity (/ VA) & FUTE & 1.265 & 0.987 & 1.312 \\
\hline Number of workers (firm level) & FUTE & 2067 & 535 & 4554 \\
\hline$\%$ workers working with computers & Reponse & 37.452 & 35.000 & 28.844 \\
\hline Unskilled workers & DADS & 23.704 & 14.862 & 22.420 \\
\hline Age of workers & DADS & 39.195 & 39.659 & 3.713 \\
\hline Lerner index & FUTE & 0.002 & 0.057 & 0.996 \\
\hline Market share & FUTE & 3.802 & 1.180 & 6.258 \\
\hline Herfindahl index & FUTE & 0.044 & 0.026 & 0.055 \\
\hline 1 / Herfindahl index & FUTE & 68.893 & 38.820 & 104.865 \\
\hline Specialization & FUTE & 0.748 & 0.801 & 0.237 \\
\hline $1 /$ Specialization (diversification) & FUTE & 1.603 & 1.248 & 1.044 \\
\hline \multicolumn{5}{|c|}{ Other industry level variables } \\
\hline Capital intensity (per workers) & FUTE & 445.906 & 282.757 & 528.296 \\
\hline IT investment (per worker) & FUTE & 1.164 & 0.677 & 1.460 \\
\hline
\end{tabular}

NOTES: 1,258 observations. All firms are part of a French or foreign group (and are not the corporate head quarters). 


\section{Appendix C: Full sets of Regression Results}

In order to keep the Tables clear we have not included the coefficients on all the controls in the regressions. These are given below for completeness (other results are available from the authors on request). Table C1 corresponds to Table 2. 


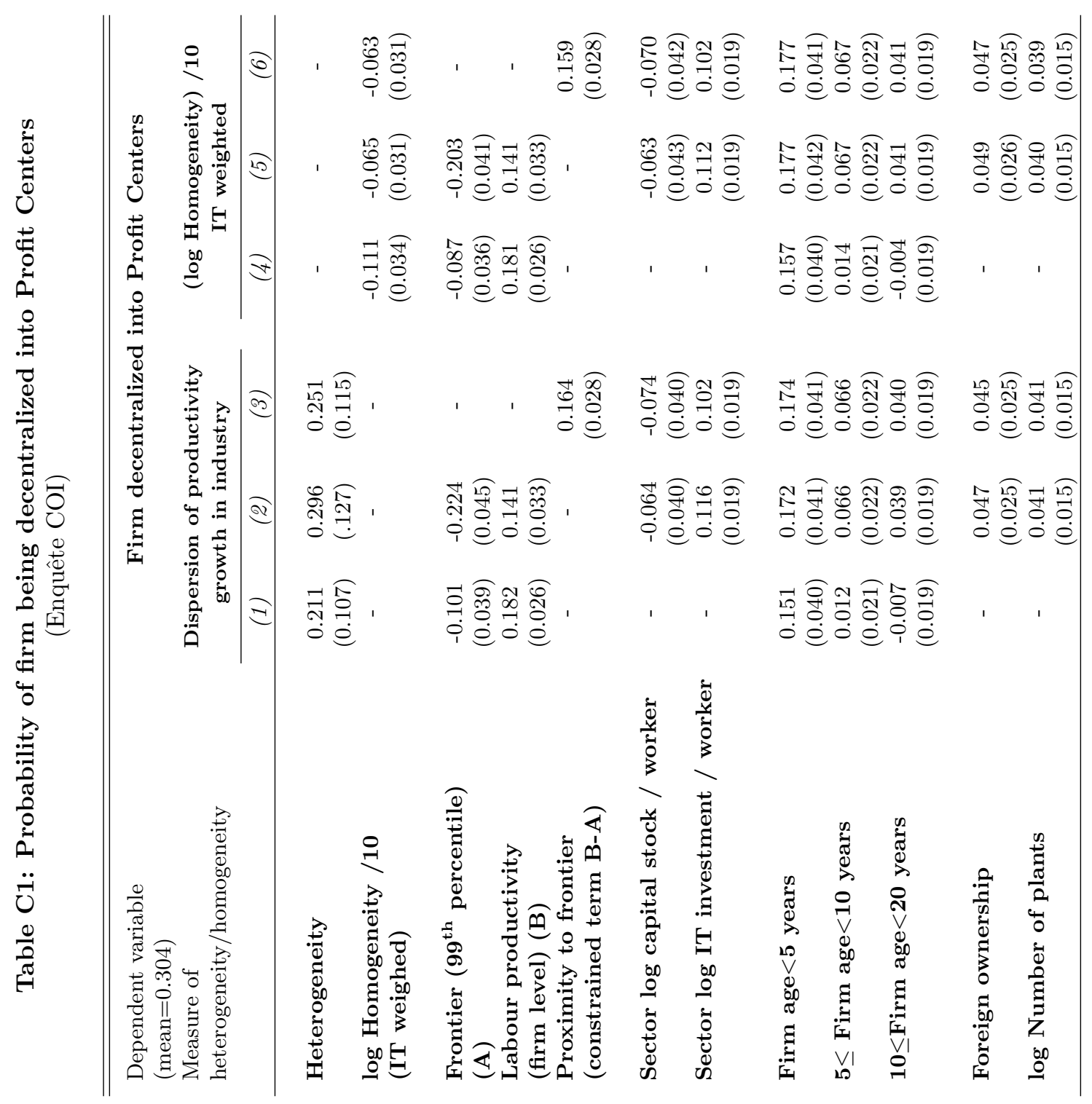




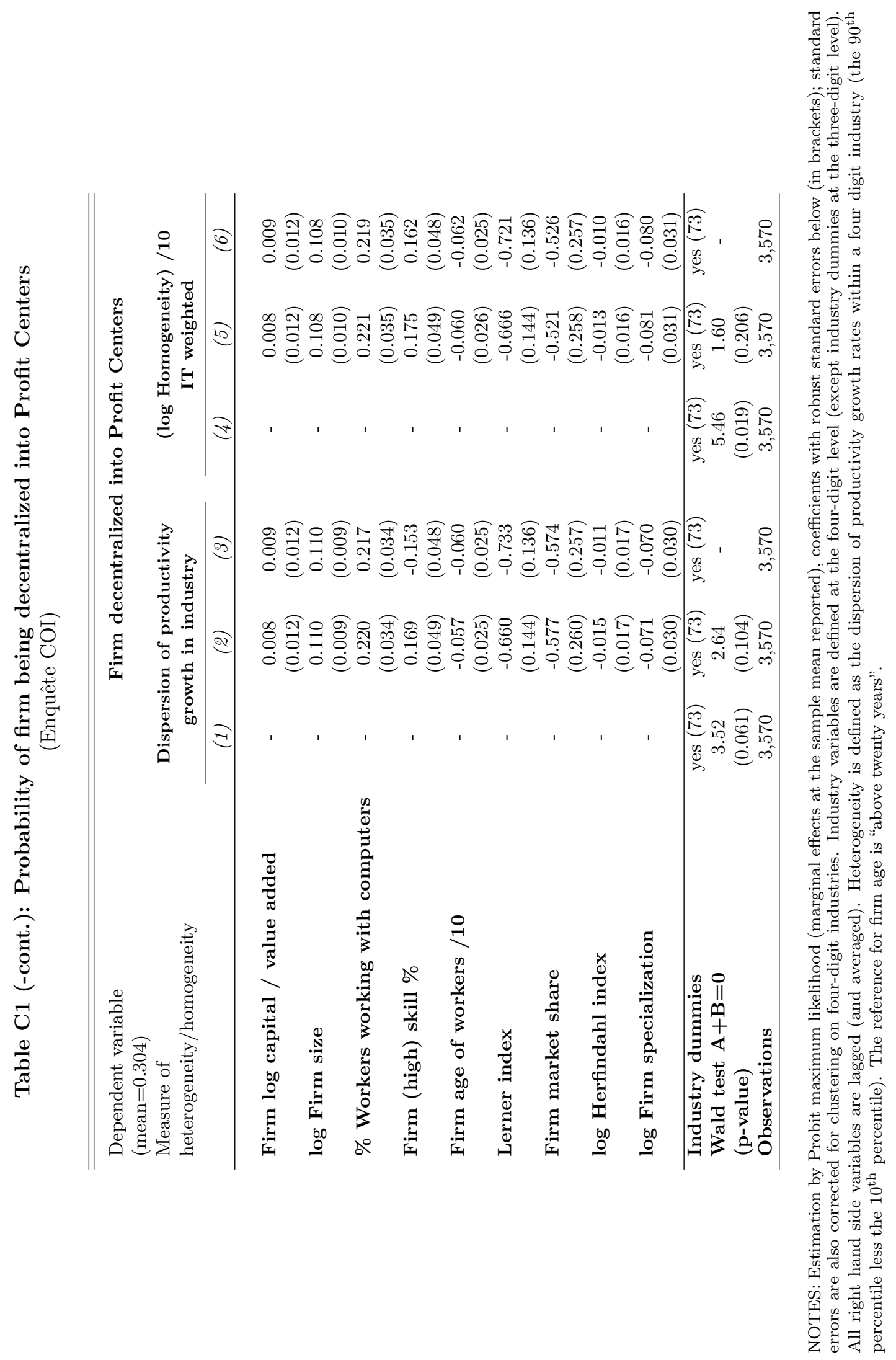

